KAPL-P-000209

(K97163)

\title{
CZOCHRALSKI GROWTH OF GALLIUM INDIUM ANTIMONIDE ALLOY CRYSTALS
}

G. Nichols, S. Tsaur, et. al.

February 1998

DISTRIBUTION OF THIS DOCLANENT IS URHLMITED

MASTER

NOTICE

This report was prepared as an account of work sponsored by the United States Government. Neither the United States, nor the United States Department of Energy, nor any of their employees, nor any of their contractors, subcontractors, or their employees, makes any warranty, express or implied, or assumes any legal liability or responsibility for the accuracy, completeness or usefulness of any information, apparatus, product or process disclosed, or represents that its use would not infringe privately owned rights. 


\section{DISCLAIMER}

Portions of this document may be illegible in electronic image products. Images are produced from the best available original document. 


\title{
CZOCHRALSKI GROWTH OF GALLIUM INDIUM
}

\section{ANTIMONIDE ALLOY CRYSTALS}

\author{
by \\ Shuenn-Ching Tsaur
}

A dissertation submitted in partial fulfillment of the requirements for the degree of

Doctor of Philosophy

(Materials Science)

at the

University of Wisconsin-Madison

1997 


\begin{abstract}
Attempts were made to grow alloy crystals of $\mathrm{Ga}_{1-x} \mathrm{In}_{\mathrm{x}} \mathrm{Sb}$ by the conventional Czochralski process. A transparent furnace was used, with hydrogen purging through the chamber during crystal growth. Single crystal seeds up to about 2 to 5 mole\% InSb were grown from seeds of 1 to 2 mole\% InSb, which were grown from essentially pure GaSb seeds of the [111] direction. Single crystals were grown with InSb rising from about 2 to 6 mole $\%$ at the seed ends to about 14 to $23 \mathrm{~mole} \% \mathrm{InSb}$ at the finish ends.
\end{abstract}

A floating-crucible technique that had been effective in reducing segregation in doped crystals, was used to reduce segregation in Czochralski growth of alloy crystals of $\mathrm{Ga}_{1-\mathrm{x}} \mathrm{In}_{\mathrm{x}} \mathrm{Sb}$. Crystals close to the targeted composition of $1 \mathrm{~mole} \% \mathrm{InSb}$ were grown. However, difficulties were encountered in reaching higher targeted InSb concentrations. Crystals about 2 mole\% were grown when 4 mole $\%$ was targeted. It was observed that mixing occurred between the melts rendering the compositions of the melts; and, hence, the resultant crystal unpredictable. The higher density of the growth melt than that of the replenishing melt could have triggered thermosolutal convection to cause such mixing. It was also observed that the floating crucible stuck to the outer crucible when the liquidus temperature of the replenishing melt was significantly higher than that of the growth melt.

The homogeneous $\mathrm{Ga}_{1-x} \mathrm{In}_{\mathrm{x}} \mathrm{Sb}$ single crystals were grown successfully by a pressure-differential technique. By separating a quartz tube into an upper chamber for 
crystal growth and a lower chamber for replenishing. The melts were connected by a capillary tube to suppress mixing between them. A constant pressure differential was maintained between the chambers to keep the growth melt up in the growth chamber. The method was first tested with a low temperature alloy $\mathrm{Bi}_{1-x} \mathrm{Sb}_{x}$. Single crystals of $\mathrm{Ga}_{1-\mathrm{x}} \mathrm{In}_{\mathrm{x}} \mathrm{Sb}$ were grown with uniform compositions up to nearly $5 \mathrm{~mole} \% \mathrm{InSb}$. 


\section{ACKNOWLEDGMENTS}

The author wishes to express his sincere appreciation to Professor Sindo Kou, his advisor, for his guidance and enthusiasm.

I am glad to have shared this experience with my colleagues. I am also indebted to Norman Elway and Jọn Ames, for their assistance with the quartz apparatus, and to Dr. John Fournelle who provided assistance in EPMA.

Very special thanks go to my parents for their unending encouragement. 


\section{TABle of CONTENTS}

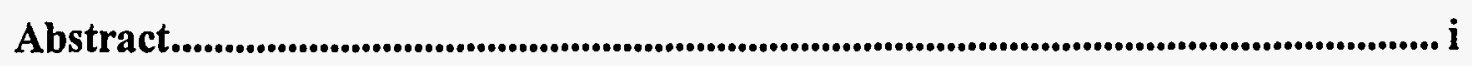

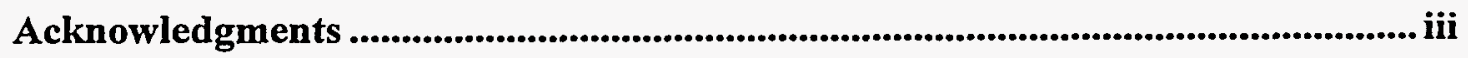

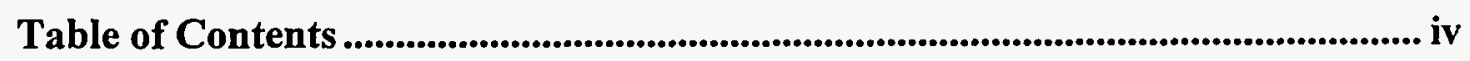

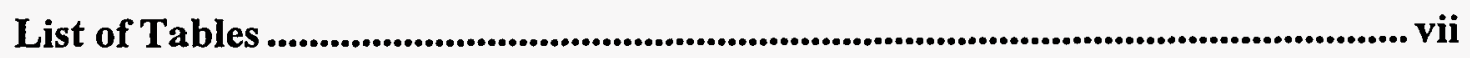

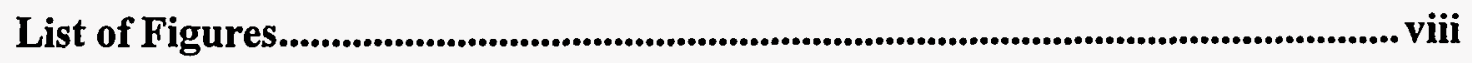

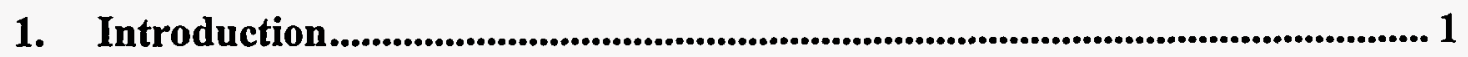

1.1 Fundamental of Czochralski Growth ................................................... 1

1.1 .1 Liquid phase: melt................................................................. 2

1.1.2 Solid phase: grown crystal...................................................... 3

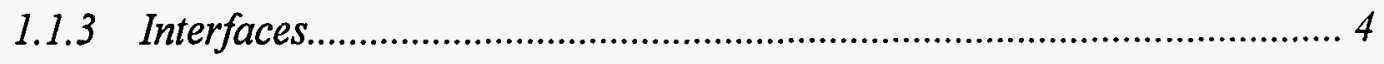

1.2 Difficulties in Czochralski Growth of Alloy Crystal ..................................... 5

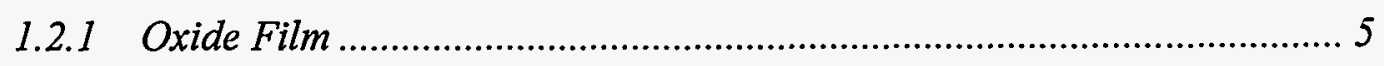

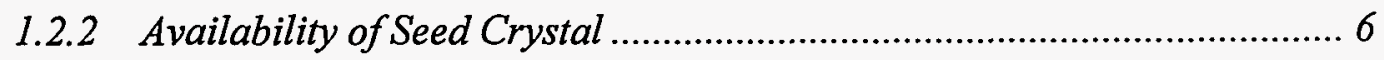

1.2.3 Constitutional Supercooling .......................................................... 7

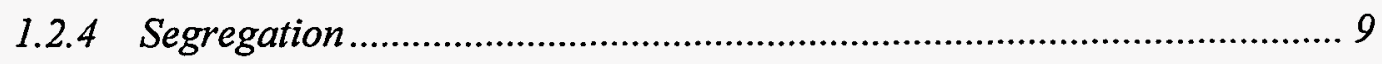

1.3 Techniques for Reducing Segregation in Czochralski Growth.................... 11

1.3.1 Double-Crucible or Floating-Crucible Technique .......................... 12

1.3.2 Push-Pull Technique ............................................................. 13

1.3.3 Drop-Pull Technique .............................................................. 14

1.3.4 Bottom Replenishing Technique ............................................... 14 
1.3.5 Melt Injection Technique ................................................................ 15

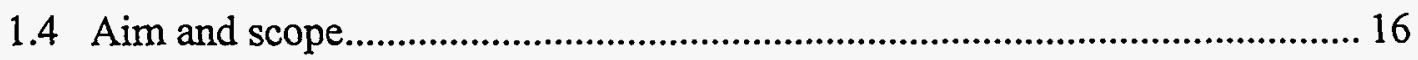

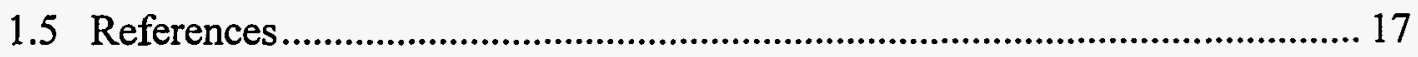

2. Growth of $\mathbf{G a}_{1-x} \mathrm{In}_{\mathrm{x}} \mathrm{Sb}$ Crystals by Conventional Czochralski Pulling .......... 30

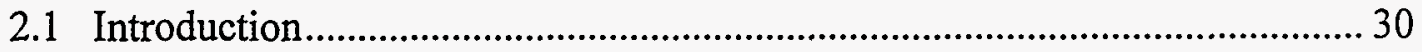

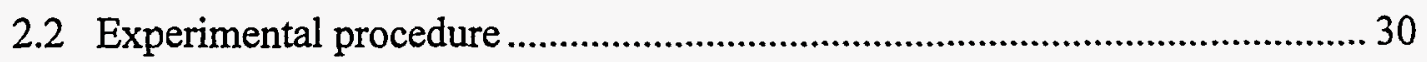

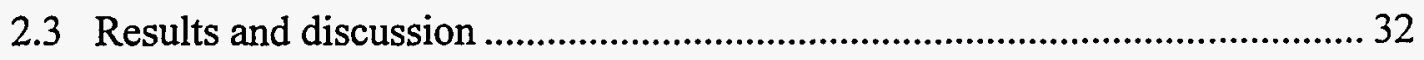

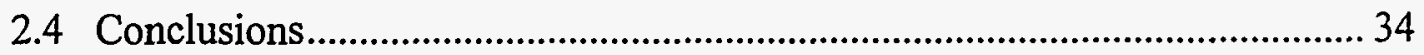

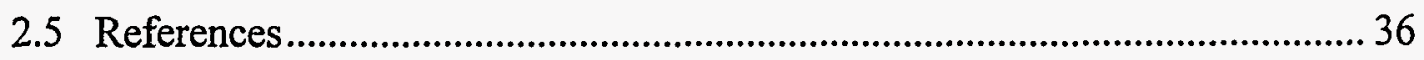

3. Growth of $\mathbf{G a}_{1-x} \mathrm{In}_{\mathbf{x}} \mathrm{Sb}$ by Floating-Crucible Czochralski .............................. 51

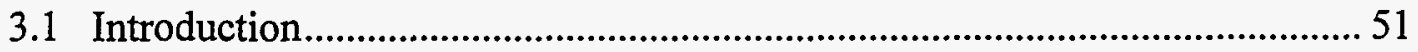

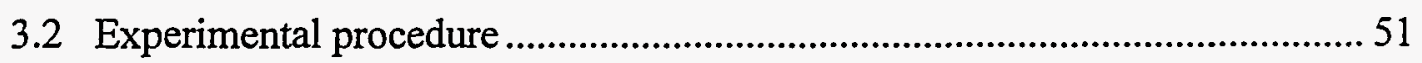

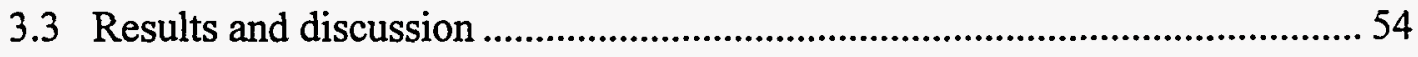

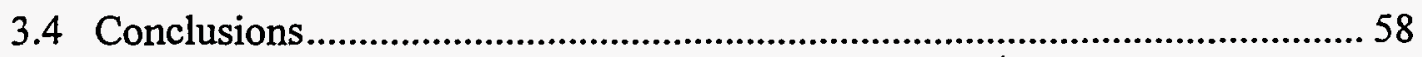

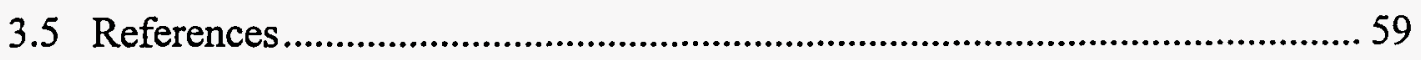

4. Czochralski Growth of $\mathrm{Ga}_{1-x} \mathrm{In}_{x} \mathrm{Sb}$ under a Pressure Differential.................. 68

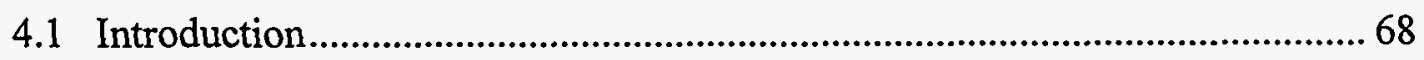

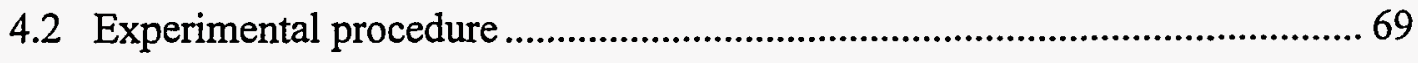

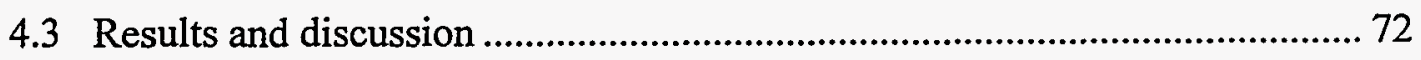

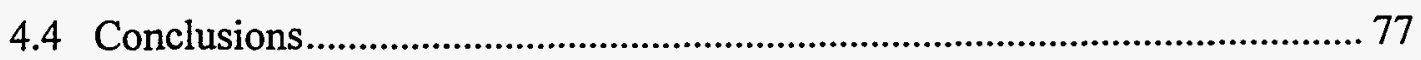

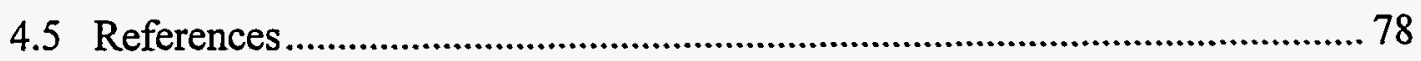




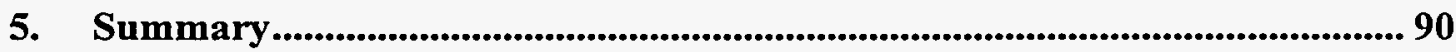

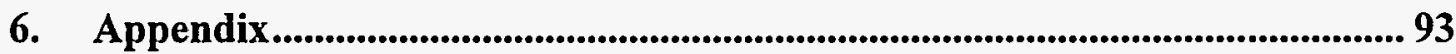

6.1 Transparent Czochralski puller ........................................................... 93

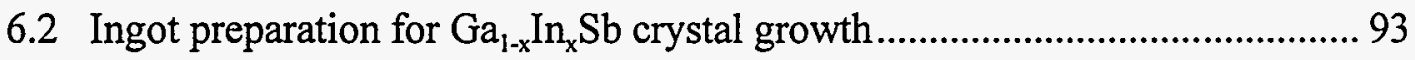

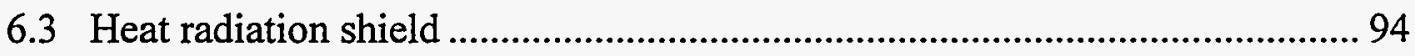

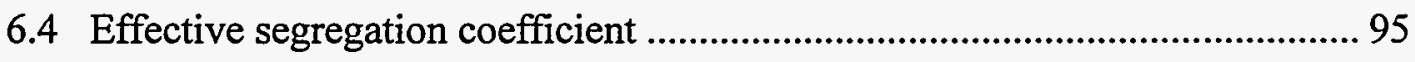

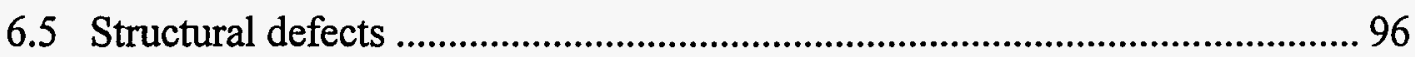

6.6 Back diffusion in Czochralski growth with melt replenishing ..................... 97

6.7 Melt replenishing in Czochralski growth under a pressure differential .......... 98

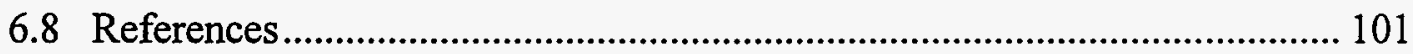




\section{LIST OF TABLES}

Table 1 Review of various techniques for growing alloy crystals............................ 21

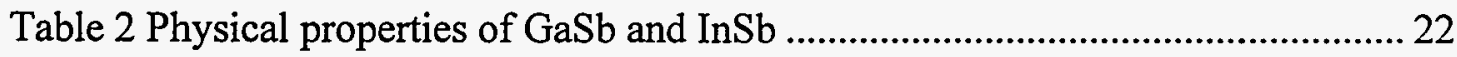

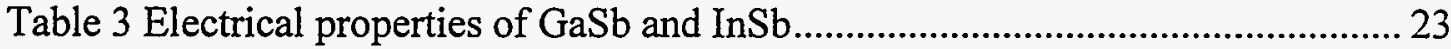

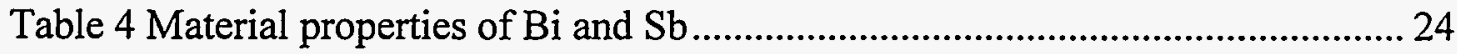

Table 5 Parameters of conventional Czochralski growth and properties of $\mathrm{Ga}_{1-x} \mathrm{In}_{\mathrm{x}} \mathrm{Sb}$

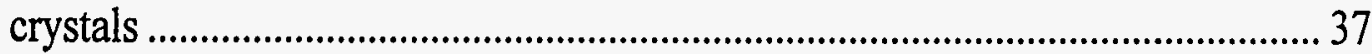




\section{List of Figures}

Figure 1.1 Schematic representation of conventional Czochralski pulling. 25

Figure 1.2 The Bi-Sb phase diagram ${ }^{(23)}$ 26

Figure 1.3 The GaInSb equilibrium phase diagram ${ }^{(14)}$........................................... 26

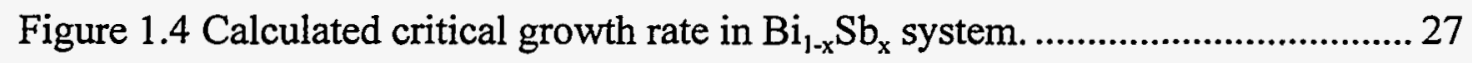

Figure 1.5 Calculated critical growth rate in $\mathrm{Ga}_{1-x} \mathrm{In}_{\mathrm{x}} \mathrm{Sb}$ system..........................2 27

Figure 1.6 Calculated critical pulling rate in the $\mathrm{Bi}_{1-\mathrm{x}} \mathrm{Sb}_{\mathrm{x}}$ system. ............................ 28

Figure 1.7 Calculated critical pulling rate in the $\mathrm{Ga}_{1-\mathrm{x}} \mathrm{In}_{\mathrm{x}} \mathrm{Sb}$ system..........................2 28

Figure 1.8 Relationship between the length of passageway and the concentration ratio of phosphorus concentration in the silicon melt ${ }^{(37)}$. 29

Figure 2.1 Schematic illustration of conventional Czochralski pulling with radiation shield. 38

Figure 2.2 An essentially pure GaSb crystal grown in experiment 1. 39

Figure $2.3 \mathrm{Ga}_{1-\mathrm{x}} \mathrm{In}_{\mathrm{x}} \mathrm{Sb}$ single crystal grown in experiment 2 . 40

Figure 2.4 Results of experiment 2 : (a) axial and (b) lateral composition profiles. .. 41

Figure $2.5 \mathrm{Ga}_{1-x} \mathrm{In}_{\mathrm{x}} \mathrm{Sb}$ single crystal grown in experiment 4. 42

Figure 2.6 Results of experiment 4 : (a) axial and (b) lateral composition profiles. .. 43

Figure $2.7 \mathrm{Ga}_{1-x} \mathrm{In}_{\mathrm{x}} \mathrm{Sb}$ single crystal grown in experiment 5 . 44

Figure 2.8 Results of experiment 5 : (a) axial and (b) lateral composition profiles. .. 45

Figure $2.9 \mathrm{Ga}_{1-\mathrm{x}} \mathrm{In}_{\mathrm{x}} \mathrm{Sb}$ single crystal grown in experiment 6. 46

Figure 2.10 Results of experiment 6 : (a) axial and (b) lateral composition profiles. 47 


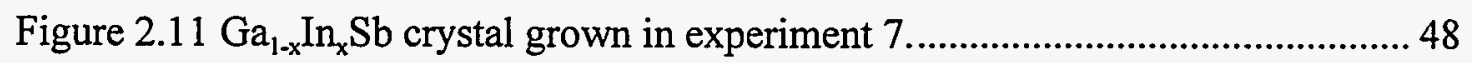

Figure 2.12 Results of experiment 7 : (a) axial and (b) lateral composition profiles. 49

Figure 2.13 Axial temperature profiles above the melt surface.................................50

Figure 3.1 Illustration of CZ Pulling with floating-crucible technique. ......................6 60

Figure 3.2 Floating crucibles: (a) single-wall (b) double-wall .................................... 61

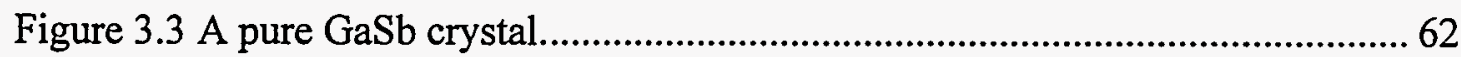

Figure 3.4 Composition profiles in a $\mathrm{Ga}_{1-x} \mathrm{In}_{\mathrm{x}} \mathrm{Sb}$ crystal : (a) axial; (b) lateral. ........... 63

Figure 3.5 Composition profiles in another $\mathrm{Ga}_{1-x} \mathrm{In}_{x} \mathrm{Sb}$ crystal : (a) axial; (b) lateral. 64

Figure 3.6 Composition of Bi-Sb melts: (a) before growth; (b) after growth.............. 65

Figure 3.7 Composition profiles in a $\mathrm{Bi}_{1-x} \mathrm{Sb}_{\mathrm{x}}$ crystal : (a) axial; (b) lateral. ................66

Figure 3.8 Composition profiles in another $\mathrm{Bi}_{1-x} \mathrm{Sb}_{\mathrm{x}}$ crystal : (a) axial; (b) lateral. .... 67

Figure 4.1 Schematic illustration of Czochralski pulling by pressure-differential

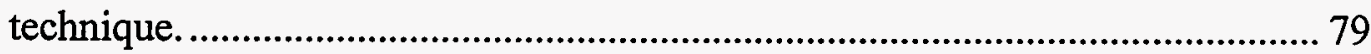

Figure 4.2 Composition profiles in a $\mathrm{Bi}_{1-x} \mathrm{Sb}_{x}$ crystal of around 4 at\% $\mathrm{Sb}$ : (a)axial ;

(b) lateral. 80

Figure 4.3 Composition profiles in a $\mathrm{Bi}_{1-x} \mathrm{Sb}_{\mathrm{x}}$ crystal grown by conventional Czochralski : (a)axial ; (b) lateral. 81

Figure $4.4 \mathrm{~A} \mathrm{Ga}_{1-x} \mathrm{In}_{\mathbf{x}} \mathrm{Sb}$ single crystal with about 2 mole\% $\mathrm{InSb}$.............................. 82

Figure 4.5 Composition profiles in the crystal in Fig. 4.4 : (a) axial; (b) lateral........ 83

Figure $4.6 \mathrm{~A} \mathrm{Ga}_{1-x} \mathrm{In}_{x} \mathrm{Sb}$ single crystal with about 4 mole\% InSb................................ 84

Figure 4.7 Composition profiles in the crystal in Fig. 4.6 : (a) axial; (b) lateral........ 85 
Figure 4.8 Curves of composition vs. fraction solidified in the crystal in Fig. 4.6 and a conventional Czochralski crystal. 86

Figure 4.9 Composition profiles in a $\mathrm{Ga}_{1-\mathrm{x}} \mathrm{In}_{\mathrm{x}} \mathrm{Sb}$ single crystal with nearly 5 mole\%

InSb : (a) axial; (b) lateral.

Figure 4.10 $\mathrm{A} \mathrm{Ga}_{1-\mathrm{x}} \mathrm{In}_{\mathrm{x}} \mathrm{Sb}$ single crystal with about $5 \mathrm{~mole} \% \mathrm{InSb}$. 88

Figure 4.11 Composition profiles in the crystal in Fig. 4.10 : (a) axial; (b) lateral.... 89

Figure 6.1 Apparatus of transparent Czochralski puller. 102

Figure 6.2 Bi single crystal. 103

Figure 6.3 Etched (111)A surface of GaSb - 2 mole\% InSb single crystal. The surface was etched with a solution of $1 \mathrm{HF}+9 \mathrm{HNO}_{3}+20 \mathrm{CH}_{3} \mathrm{COOH}$ and then etched with $2 \%$ Br-methonal solution. 104

Figure 6.4 Etched GaSb - 50 mole\% InSb Ingots (a) furnace-cooled (b) quenched. 105 Figure 6.5 Crystals sliced along the growth direction $<111>$ (a) nominal composition 19 mole\% InSb; (b) nominal composition 16 mole\% InSb. 106

Figure 6.6 Segregation coefficient of $\mathrm{Bi}_{1-\mathrm{x}} \mathrm{Sb}_{\mathrm{x}}$ 107

Figure 6.7 Segregation coefficient of $\mathrm{Ga}_{1-\mathrm{x}} \mathrm{In}_{\mathrm{x}} \mathrm{Sb}$. 108

Figure 6.8 Etched surface of $\mathrm{GaSb}$ - 10 mole\% InSb sliced perpendicular to growth direction $<111>$. 109

Figure 6.9 Etched surface of GaSb - 10 mole\% InSb sliced parallel to growth direction $<111>$ 110

Figure 6.10 Etched surface of grown crystal sliced parallel to growth direction $\langle 111\rangle$. 
Seed : 7.4 mole\% InSb; Crystal : 4.6 mole\% InSb. .................................... 111

Figure 6.11 Etched surface of grown crystal sliced parallel to growth direction $<111>$. 112

Figure 6.12 Schematic pseudo binary phase diagram of $\mathrm{Ga}_{1-x} \mathrm{In}_{\mathrm{x}} \mathrm{Sb} \ldots \ldots \ldots \ldots \ldots \ldots \ldots 113$ 


\section{INTRODUCTION}

Great interest has been shown for alloy crystals such as $\mathrm{Ga}_{1-x} \mathrm{In}_{x} \mathrm{Sb}, \mathrm{Si}_{1-x} \mathrm{Ge}_{x}$, and $\mathrm{Ga}_{1-\mathrm{x}} \mathrm{In}_{\mathrm{x}}$ As etc. ${ }^{(1-8)}$. It is well known that alloy single crystals are much more difficult to grow than pure or doped ones. Table 1 shows a review of several recent approaches in this research area. Growing alloy single crystal is very attractive in many applications such as laser diodes, photodetectors, etc. In the growth of $\mathrm{Ga}_{1-x} \mathrm{In}_{\mathrm{x}} \mathrm{Sb}$ single crystals, the high oxidizing tendency of the melt makes the growth system technologically difficult to handle, and the strong solute segregation during crystal pulling often results in constitutional supercooling and polycrystalline growth. An important parameter determining the applicability of alloy crystals is the homogeneity of the material. Inhomogeneous composition in the as-grown crystal causes physical properties to vary significantly along the crystal. The material properties of $\mathrm{Ga}_{1 \cdot x} \mathrm{In}_{\mathrm{x}} \mathrm{Sb}$ and $\mathrm{Bi}_{1-\mathrm{x}} \mathrm{Sb}_{\mathrm{x}}$ shown in Tables 2-4 are useful references for a crystal grower.

\subsection{Fundamental of Czochralski Growth}

The technique of crystal pulling from melt, first developed by Czochralski ${ }^{(9)}$, is the most important bulk crystal growth process. The Czochralski (CZ) apparatus is shown schematically in Fig.1.1. Basically, the material to be grown is melted in the crucible and then the melt temperature is adjusted for seed dipping. After reaching the thermal equilibrium, the seed is then slowly withdrawn and rotated. 


\subsubsection{Liquid phase: melt}

The equations governing motion, heat transfer, and segregation in the melt are well

known ${ }^{(24)}$. The Boussinesq approximation is based on the hypotheses that fluid is Newtonian and that variations of melt density are negligible. Letting $\mathbf{v}$ and $\mathrm{p}$ denote the velocity and pressure fields in the melt:

$$
\begin{aligned}
& \nabla \cdot \mathrm{v}=0 \\
& \rho_{\ell} \frac{\mathbf{D v}}{\mathbf{D t}}=-\nabla \mathrm{p}+\eta \nabla^{2} \mathbf{v}+\rho_{\ell} g\left[1-\beta_{\mathrm{T}}\left(\mathrm{T}-\mathrm{T}_{0}\right)+\beta_{\mathrm{C}}\left(\mathrm{C}-\mathrm{C}_{0}\right)\right]
\end{aligned}
$$

where $\eta$ is the dynamic viscosity, $g$ is the acceleration of gravity vector, $\beta_{\mathrm{T}}$ and $\beta_{\mathrm{c}}$ are the thermal and solutal expansion coefficients, and $T_{0}$ and $C_{0}$ are the reference values for temperature and concentration.

The heat transfer in the melt is governed by:

$$
\rho_{\ell} C_{p \ell} \frac{\mathbf{D T}}{\mathbf{D} \mathrm{t}}=\nabla \cdot \mathrm{K}_{\ell} \nabla \mathrm{T}
$$

The diffusion in the melt is governed by:

$$
\rho_{\ell} \frac{\mathbf{D C}}{\mathbf{D t}}=\nabla \cdot\left[\rho_{\ell} \frac{\mathrm{D}_{\ell}}{\alpha} \nabla(\alpha \mathrm{C})\right]
$$

where $\mathrm{D}$, is the diffusion coefficient and $\alpha$ has value 1 if the Soret effect is negligible. 


\subsubsection{Solid phase: grown crystal}

In order to understand the relationship between crystal quality and the processing conditions, several complex phenomena occurring in the solid phase must be taken into account. The heat transfer in the crystal governed by the energy equation is:

$$
\rho_{\mathrm{s}} \mathrm{C}_{\mathrm{ps}} \frac{\mathrm{DT}}{\mathrm{Dt}}=\nabla \cdot\left(\mathrm{K}_{\mathrm{s}} \nabla \mathrm{T}-\mathrm{q}_{\mathrm{R}}\right)
$$

where $\mathrm{T}$ is temperature; $\rho_{\mathrm{s}}, \mathrm{C}_{\mathrm{ps}}$, and $\mathrm{K}_{\mathrm{s}}$ are for the specific mass, specific heat and thermal conductivity of the crystal, respectively; and $\mathbf{q}_{\mathbf{R}}$ is the radiative heat flux vector.

To understand the dislocation formation in the crystal, two basic methods: thermoelastic and thermoplastic models have been introduced. The rate of plastic strain can be represented as :

$$
\frac{\mathrm{D} \varepsilon_{\mathrm{p}}}{\mathrm{Dt}}=\mathrm{Fbv}_{\mathrm{d}} \mathrm{N}
$$

where $\mathrm{F}$ is a geometrical factor, $\mathrm{b}$ is the magnitude of Burgers vector, $\mathrm{v}_{\mathrm{d}}$ and $\mathrm{N}$ are the speed and density of dislocations, respectively. The rate of multiplication of dislocations and dislocation speed are :

$$
\begin{aligned}
& \frac{D N}{D t}=B v_{d} N \tau_{\text {eff }} \quad \text { and } \\
& v_{d}=B_{0} \exp (-Q / k T) \tau_{\text {eff }}^{m}
\end{aligned}
$$


where $\mathrm{B}$ and $\mathrm{B}_{0}$ are the empirical constants; and $\tau_{\text {eff }} \mathrm{m}$, and $\mathrm{Q}$ are the effective stress experienced by dislocations, strain hardening constant, and activation energy, respectively.

\subsubsection{Interfaces}

\subsection{3.a. Crystal/melt interface}

With respect to the melt, the crystal may be assumed to be a rigid body. The thermal condition holding on the solidification front expresses heat flux balance as:

$$
\mathrm{K}_{\ell} \nabla \mathrm{T}_{\ell} \cdot \mathbf{n}-\mathrm{K}_{\mathrm{s}} \nabla \mathrm{T}_{\mathrm{s}} \cdot \mathbf{n}=\rho_{\mathrm{s}} \mathrm{v}_{\mathrm{g}} \Delta \mathrm{H}
$$

where $\Delta \mathrm{H}$ is the latent heat of fusion.

In the case of an alloy solution, the species conservation is expressed as:

$$
-\rho_{\ell} \frac{D_{\ell}}{\alpha} \nabla(\alpha C) \cdot \mathbf{n}+\rho_{s} C_{\ell} v_{g}=\rho_{s} C_{s} v_{g}
$$

where diffusion in the crystal has been neglected.

\subsection{3.b. Free surface}

The heat loss from free surface is described as:

$$
\mathrm{K}_{\ell} \nabla \mathrm{T}_{\ell} \cdot \mathbf{n}=\mathrm{h}_{\ell}\left(\mathrm{T}-\mathrm{T}_{\mathrm{g}}\right)+\varepsilon_{\ell} \sigma\left(\mathrm{T}^{4}-\mathrm{T}_{\mathrm{g}}^{4}\right)
$$

where $h_{\ell}$ is the heat transfer coefficient, $\varepsilon_{\ell}$ is the emissivity, $\sigma$ is the StefanBoltzmann constant, and $\mathrm{T}_{\mathrm{g}}$ is the effective ambient temperature. 
The menicus separating the melt from its environment is a supplementary interface in Czochralski pulling. Typically, a meniscus shape is governed by the YoungLaplace equation :

$$
\gamma_{0} \chi_{m}+\left(\rho_{g}-\rho_{\ell}\right) g\left(z_{m}-z_{0}\right)=0
$$

where $z_{m}$ is the vertical position of the interface, $\chi_{m}$ is the interface curvature, $\rho_{\mathrm{g}}$ is the environment specific mass, and $z_{0}$ is the theoretical axial position at which $\chi_{\mathrm{m}}$ vanishes.

\subsection{Difficulties in Czochralski Growth of Alloy Crystal}

There are several problems about preparing homogeneous binary or pseudo binary alloy single crystals.

\subsubsection{Oxide Film}

Concerning the growth of $\mathrm{Ga}_{1-x} \mathrm{In}_{\mathrm{x}} \mathrm{Sb}$ single crystals, many techniques have been tried. The problem in pulling $\mathrm{Ga}_{1-x} \mathrm{In}_{\mathrm{x}} \mathrm{Sb}$ crystals is that a thin oxide film exists on the surface of the melt, which is obstructive in seeding. In the past, the double crucible method ${ }^{(25)}$ was applied to eliminate the oxide film.

Thermodynamic calculations ${ }^{(26)}$ show that a presence of even $10^{-3}$ mole of oxygen results in an $\sim 50 \AA$ thick $\mathrm{Ga}_{2} \mathrm{O}_{3}$ surface layer on the melt. $\mathrm{Ga}_{2} \mathrm{O}_{3}$ and $\mathrm{H}_{2}$ were established to exist in equilibrium, which strongly depends on temperature and which indicates that $\mathrm{Ga}_{2} \mathrm{O}_{3}$ is reduced to gaseous $\mathrm{Ga}_{2} \mathrm{O}$ and $\mathrm{GaOH}$ near the melting point of $\mathrm{GaSb}$. Therefore, the hydrogen gas was used to prevent the formation of this layer, 
giving a clean melt surface that is characterized by high reflectivity which could be seeded reproducibly and which permits the growth of crystals.

The main source of oxygen can be water, which is contained in the hydrogen atmosphere in the chamber. Oxygen also forms as a result of degassing the internal surfaces of the chamber and fixtures inside the chamber; the starting materials can also contain oxygen.

\subsubsection{Availability of Seed Crystal}

In order to avoid the lattice mismatch, causing high dislocation density at the seed end of the crystal, it is very important to use seed of the desired composition. Unfortunately, such seeds are not readily available, and hence have to be prepared in a stepwise manner. For instance, Tanaka et al. ${ }^{(6)}$ used a compositional graded seed to grow $\mathrm{Ga}_{1-x} \operatorname{In}_{x} \mathrm{Sb}$ crystals.

Goss et al. ${ }^{(27)}$ have evaluated the density of dislocations formed for a given abrupt change in concentration, on the assumption that all the macroscopic elastic strain is relieved by forming dislocations. The density $\delta$ can be expressed as:

$$
\delta=\Delta C\left(\frac{\mathrm{da}_{0}}{\mathrm{dC}}\right) \frac{1}{\mathrm{a}_{0} \mathrm{~b}}
$$

where $\Delta \mathrm{C}$ is the abrupt change in concentration, $\mathrm{da}_{0} / \mathrm{dC}$ is the change in lattice parameter per unit change in concentration, $a_{0}$ is the lattice parameter, and $b$ is the magnitude of Burgers vector. 
Schilz et al. ${ }^{(28)}$ mentioned that strain originating from a lattice mismatch is released by the production of dislocations in the $\mathrm{Si}_{1-\mathrm{x}} \mathrm{Ge}_{\mathrm{x}}$ growth. When the step between seed and crystal approaches 15 at\%, the interface becomes rough and acts as a source for twinning. However, the growth of $\mathrm{Ga}_{1-\mathrm{x}} \mathrm{In}_{\mathrm{x}} \mathrm{Sb}$ single crystals with higher In content than $\mathrm{x}=0.03$ becomes very difficult when $\mathrm{GaSb}$ is used as the seed crystal ${ }^{(6)}$.

\subsubsection{Constitutional Supercooling}

Crystal growth of alloy crystals requires knowledge of the critical growth rates depending on composition to avoid instabilities of the interface. Tiller et al. ${ }^{(29)}$ developed the concept of constitutional supercooling as an important cause of interface breakdown:

$$
\frac{\mathrm{G}_{\ell}}{\mathrm{v}} \geq-\frac{\mathrm{mC}_{\infty}}{\mathrm{D}_{\ell}} \frac{1-\mathrm{k}}{\mathrm{k}}
$$

For stirred melt, Hurle ${ }^{(30)}$ showed that by appropriately changing the boundary conditions the result could be described as:

$$
\frac{\mathrm{G}_{\ell}}{\mathrm{v}} \geq-\frac{\mathrm{mC}_{\infty}}{\mathrm{D}_{\ell}} \frac{1-\mathrm{k}}{\mathrm{k}} \mathrm{k}_{\text {eff }}
$$

Sekerka ${ }^{(31)-(32)}$ developed a Morphological Stability that superposes a sinusoidal perturbation to the flat interface. When convective flows, kinetical barriers, and crystallographic anisotropy are neglected, the stability criterion is given by:

$$
\frac{\mathrm{G}_{\ell}}{\mathrm{v}}+\frac{\Delta \mathrm{H}}{2 \mathrm{~K}_{\ell}} \geq \frac{-\mathrm{mC}_{\infty}}{\mathrm{D}_{\ell}} \frac{1-\mathrm{k}}{\mathrm{k}} \frac{\mathrm{K}_{\mathrm{s}}+\mathrm{K}_{\ell}}{2 \mathrm{~K}_{\ell}} \mathrm{S}(\mathrm{A}, \mathrm{k})
$$


where $\Delta \mathrm{H}$ is the latent heat, $\mathrm{K}_{\mathrm{s}}$ is the thermal conductivity of crystal, $\mathrm{K}$, is the thermal conductivity of the melt, and $\mathrm{S}(\mathrm{A}, \mathrm{k})$ is the so-called stability function. Considering that $\frac{\Delta \mathrm{H}}{2 \mathrm{~K}_{\ell}}$ can be neglected, when $\mathrm{S} \rightarrow 1$ :

$$
\frac{\mathrm{G}}{\mathrm{v}}=\frac{1}{\mathrm{v}}\left(\frac{\mathrm{K}_{\mathrm{s}} \mathrm{G}_{\mathrm{s}}+\mathrm{K}_{\ell} \mathrm{G}_{\ell}}{\mathrm{K}_{\mathrm{s}}+\mathrm{K}_{\ell}}\right) \geq-\frac{\mathrm{mC}_{\infty}}{\mathrm{D}_{\ell}} \frac{1-\mathrm{k}}{\mathrm{k}}
$$

Equations (14) and (17) coincide if $G_{\ell}$ is replaced by a weighted average thermal gradient G.

Dismukes et al. ${ }^{(23)}$ pointed out that the difference of the calculated critical growth rates between the Tiller theory and the Mullins-Sekerka theory is relatively small. Thus, the simpler Tiller theory can be used as a useful first approximation to predict conditions for planar growth. According to the Tiller theory, the critical growth rate to prevent constitutional supercooling is:

$$
\mathrm{v}_{\mathrm{c}}=\frac{\mathrm{G}_{\ell} \mathrm{kD} \mathrm{D}_{\ell}}{-\mathrm{m}(1-\mathrm{k}) \mathrm{C}_{\infty}}
$$

The calculated results, are shown in the form of curves for critical growth $v_{c}$ as a function of alloy composition for $\mathrm{Bi}_{1-x} \mathrm{Sb}_{x}$, and $\mathrm{Ga}_{1-x} \mathrm{In}_{x} \mathrm{Sb}$ systems in Fig.1.4 and Fig.1.5, respectively. The $\mathrm{G}_{\ell}$ estimated at about $25^{\circ} \mathrm{C} / \mathrm{cm}$ for both systems. $D_{\ell}$ is $1.62 \times 10^{-5} \mathrm{~cm}^{2} / \mathrm{s}$ for $\mathrm{Sb}$ in the $\mathrm{Bi}_{1-\mathrm{x}} \mathrm{Sb}_{\mathrm{x}}$ system ${ }^{(23)}$ and $2.8 \times 10^{-5} \mathrm{~cm}^{2} / \mathrm{s}$ for In in the $\mathrm{Ga}_{1-}$ ${ }_{x} \mathrm{In}_{x} \mathrm{Sb}$ system ${ }^{(56)}$. For conventional $\mathrm{CZ}$ pulling, i.e., without melt replenishment:

$$
v_{c}=\frac{G_{\ell} k D_{\ell}\left[1-\left(\frac{\rho_{s}}{\rho_{\ell}}\right) f\right]^{1-k}}{m(1-k) C_{0}}
$$


However, the real pulling rate is not equal to the growth rate in the conventional $\mathrm{CZ}$ pulling because the melt level drops ${ }^{(33)}$ by:

$$
v_{p}=v \frac{\left(\rho_{\ell} R^{2}-\rho_{s} r^{2}\right)}{\rho_{\ell} R^{2}}
$$

Substituting Equation (20) into Equation (19) yields:

$$
v_{p, c}=\frac{G_{\ell} k\left(\rho_{\ell} R^{2}-\rho_{s} r^{2}\right)\left[1-\left(\rho_{s} / \rho_{\ell}\right) f\right]^{1-k}}{\rho_{\ell} R^{2} m(1-k) C_{0}}
$$

Figures 1.6 and 1.7 show the relationships between critical pulling rates and solidified fractions of melt for $\mathrm{Bi}_{1-x} \mathrm{Sb}_{x}$, and $\mathrm{Ga}_{1-x} \mathrm{In}_{x} \mathrm{Sb}$ systems in conventional $\mathrm{CZ}$ pulling. Both $\mathrm{r}=0.5 \mathrm{~cm}$ and $\mathrm{R}=1.7 \mathrm{~cm}$ were used for calculations in each case. It is obvious that the constant pulling rate is not satisfied for the planar growth. Therefore, one should change the pulling rate during crystal growth to prevent constitutional supercooling.

\subsubsection{Segregation}

The segregation involved in the $\mathrm{CZ}$ growth of alloy crystals can be learned by considering the phase diagrams. Binary $\mathrm{Bi}_{1-x} \mathrm{Sb}_{\mathrm{x}}$ and pseudo-binary $\mathrm{Ga}_{1-x} \mathrm{In}_{x} \mathrm{Sb}$ alloys are totally miscible, both in the liquid and solid state, thus allowing for the physical properties of the alloys, such as band gap and lattice constant, to vary continuously with the solute composition. The equilibrium phase diagrams of the binary $\mathrm{Bi}_{1-x} \mathrm{Sb}_{x}{ }^{(10)}$ and pseudo-binary $\mathrm{Ga}_{1-\mathrm{x}} \mathrm{In}_{\mathrm{x}} \mathrm{Sb}{ }^{(11)}$ systems are represented in Fig.1.2 and Fig.1.3, respectively. Due to the large separation of the solidus and liquidus lines in the phase 
diagram, the grown crystal is shown as strongly segregating. For example, attempts to grow a $\mathrm{Ga}_{1-x} \mathrm{In}_{\mathrm{x}} \mathrm{Sb}$ alloy crystal from a melt with 22 mole\%InSb yields a solid whose composition starts at about 4 mole\%InSb. It then follows the solidus line, thus showing an increase in InSb content along the growth direction of the crystal. The composition profile along the axial direction is represented by the well-known Scheil Equation ${ }^{(34)}$ in the normal freezing case:

$$
\mathrm{C}_{\mathrm{s}}=\mathrm{kC}_{0}\left[1-\left(\frac{\rho_{\mathrm{s}}}{\rho_{\ell}}\right) \mathrm{f}\right]^{\mathrm{k}-1}
$$

where $C_{s}$ is the solute concentration in the solid, $C_{0}$ is the initial concentration in the melt, $\mathrm{k}$ is the equilibrium segregation coefficient, $\rho_{s}$ is the density of solid, $\rho_{\ell}$ is the density of the melt, and $\mathrm{f}$ is the fraction of melt solidified.

However, where segregation occurs there is a diffusion boundary layer in front of interface and $\mathrm{k}$ should be replaced by $\mathrm{k}_{\mathrm{eff}}$, the effective segregation coefficient:

$$
\mathrm{k}_{\mathrm{eff}}=\frac{\mathrm{k}}{\mathrm{k}+(1-\mathrm{k}) \mathrm{e}^{\frac{-\mathrm{v}}{\mathrm{D}_{\ell}}\left(\frac{\rho_{s}}{\rho_{\ell}}\right) \delta}}
$$

which is the so-called Burton-Prim-Slichter (BPS) equation ${ }^{(35)}$, where $v$ is the growth rate, $D_{\ell}$ is the diffusion coefficient of the solute in the melt, $\delta=1.6 \mathrm{D}_{\ell}^{1 / 3} v^{1 / 6} \omega^{-1 / 2}$ is the thickness of the diffusion boundary layer, $v$ is the kinematic viscosity of the melt, and $\omega$ is the crystal rotation rate. For the $\mathrm{Ga}_{1-x} \mathrm{In}_{x} \mathrm{Sb}$ case at the $\mathrm{GaSb}$ side of the phase diagram, $\mathrm{C}_{\ell}=7.5 \mathrm{~mole} \% \mathrm{InSb}$, the equilibrium segregation coefficient $\mathrm{k}$ obtained 
from the phase diagram is about 0.133 ; and $\delta=1.6 \mathrm{D}_{\ell}^{1 / 3} v^{1 / 6} \omega^{-1 / 2}=0.032 \mathrm{~cm}$, where $\mathrm{D}_{\ell}=2.8 \times 10^{-5} \mathrm{~cm}^{2} / \mathrm{s}, \quad \nu=0.0035 \mathrm{~cm}^{2} / \mathrm{s}$, and $\omega=2^{\circ} 0 \mathrm{rpm}$. When the growth rate is extremely low, $1 \mathrm{~mm} / \mathrm{hr}, \mathrm{k}_{\text {eff }} \approx \mathrm{k}=0.133$.

Solute segregation can be aggravated by convection in the melt during crystal pulling, which in the case of $\mathrm{CZ}$ pulling is affected by gravity and crystal rotation. The dimensionless driving force for thermal convection is measured by the Grashof number:

$$
\mathrm{Gr}=\frac{\mathrm{g} \beta \Delta \mathrm{TR}^{3}}{v^{2}}
$$

where $g$ is the acceleration of gravity, $\beta$ is the thermal expansion coefficient, $\Delta \mathrm{T}$ is the temperature difference across the melt, and $\mathrm{R}$ is the crucible inner radius. The dimensionless driving force for forced convection is measured by the Reynolds number:

$$
\operatorname{Re}=\frac{\pi \omega r^{2}}{v}
$$

where $\mathbf{r}$ is the crystal radius.

\subsection{Techniques for Reducing Segregation in Czochralski Growth}

In $\mathrm{CZ}$ pulling the melt composition can be kept constant by melt replenishing with a feed of the same crystal composition at the same rate as the pulled crystal from the melt. Several melt replenishing techniques have been proposed to reduce the segregation problem. 


\subsubsection{Double-Crucible or Floating-Crucible Technique}

Generally, a pulling technique known as a double-crucible or floating-crucible technique has been proposed to obtain the uniform impurity concentration in the longitudinal direction of the pulled crystal ${ }^{(36)(38)}$. Leverton ${ }^{(39)}$ and Goorissen ${ }^{(40)}$ described floating crucibles, which maintain a constant concentration of impurity to be grown into a crystal. Ciszek ${ }^{(10)}$ patented that III-V ternary alloy crystals can be grown by a floating-crucible technique where the floating crucible has a narrow, meltpassing channel in its bottom wall. However, the double-crucible or floating-crucible technique has a disadvantage. If the passageway between the melt in the floating crucible and the melt in the main crucible is too narrow then the melt, especially a nonwetting one, cannot pass through it. The passageway is a hole or a short tube at the bottom of the floating. On the other hand, if it is too wide then the melt passing through the floating crucible has too low a velocity to override back diffusion inside the passageway.

Matre ${ }^{(41)}$ discussed the criteria for back diffusion of solute from the floating crucible to the main crucible. If the connecting tube is of length $\mathrm{L}$ and the fluid velocity is $v_{f}$, then the condition for no back diffusion is:

$$
\mathrm{D}_{\ell} \ll \mathrm{v}_{\mathrm{f}} \mathrm{L}
$$

Blackwell ${ }^{(42)}$ gave a rigorous analysis, which is:

$$
\mathrm{v}>\frac{5 \pi \mathrm{r}_{\mathrm{c}}^{2} \mathrm{D}}{\mathrm{L}}
$$


Figure1. ${ }^{(37)}$ shows, in the phosphorus doped silicon crystal growth case, the relationship between the length of passageway and the ratio of phosphorus concentration of the melt in the outer crucible and that of the melt in the inner crucible.

Lin et al ${ }^{(43)}$ successfully developed floating crucibles with a very long passageway between the melt in the floating crucible and the bulk melt to suppress dopant back diffusion. In this way the compositions of the melts, and hence the crystal are kept constant throughout pulling.

\subsubsection{Push-Pull Technique}

Several researchers have reported various push-pull methods to control the supply of solute to the melt. Typically, Nakajima et al. ${ }^{(44)}$ showed a method to feed the depleted solute by the use of a rod-shaped starting material. However, it is very difficult to maintain a large radial temperature gradient in the crucible to melt the rod with the molten liquid in the crucible. Nakajima et al. ${ }^{(1)}$ also developed the feeding technique where a crucible for melting the starting material is separated from another crucible, for growing a single crystal, to which the molten material is transported. Another dual-crucible version of the push-pull technique has been used, where one crucible contains the melt into which the feed rod is pushed and the other the melt from which the crystal is pulled. These crucibles are held in two separate chambers, and a pressure differential between the two chambers is applied to force the pulling crucible through a heated connecting tube ${ }^{(45)}$. 


\subsubsection{Drop-Pull Technique}

The drop-pull technique is similar to the push-pull technique, the main difference being the use of solid powder or liquid feeding rather than rod feeding. To minimize the disturbance from drop feeding, the portion of the melt to which the drops are fed is separated from where the crystal is pulled. In one case, this was done by immersing a stationary patron cylinder ${ }^{(46)}$ in the melt, whereas, in another by immersing a movable crucible having a short inlet passageway ${ }^{(47)}$ in the melt. Klingshirn et al. ${ }^{(48)}$ investigated a system to supply a liquid replenishing material to the growth crucible. The supply crucible, connected to the growth crucible, has a capillary at the bottom where the replenishing melt drops fall into the growth crucible. Thus the amount of melt in the growth crucible remains approximately constant.

\subsubsection{Bottom Replenishing Technique}

Horn ${ }^{(49)}$ and Lin et al. ${ }^{(50)}$ modified the Czochralski process for melt replenishing by extending the crucible well below the heater, so that the charge in the crucible consists of a molten zone at the top and a solid feed at the bottom. By either raising the crucible or lowering the heater during pulling, the new material is fed into the melt. However, the crystal is pulled at constant temperature gradient, any attempt to adjust temperature causes a change of the melt depth which reflects on the solute concentration of the grown crystal. 


\subsubsection{Melt Injection Technique}

Tanaka et al. ${ }^{(6)}$ and Koh et al. ${ }^{(12)}$ studied a melt replenishing technique to grow homogeneous alloy crystals. Basically, a two-chamber crucible, in which a small diameter tube controls the melt supply from the source chamber to the growth chamber. A piston mechanism pushes up the source chamber to keep the volume of melt in the growth chamber constant. 


\subsection{Aim and scope}

All classical growth techniques such as zone melting, and the Czochralski, and Bridgman methods, have been tried to obtain $\mathrm{Ga}_{1-x} \mathrm{In}_{\mathrm{x}} \mathrm{Sb}$ single crystals. The Czochralski method with a hydrogen atmosphere seems to be the most advantageous to grow twin-free and higher purity single crystals.

Due to the segregation during crystal growth, the crystal shows a non-constant concentration profile, causing the material properties to vary along the crystal. Apparently, growing crystals with uniform composition would be a great interest for the application of semiconductor substrates. The simplest method for minimizing this segregation is growing small crystals from a large batch of melt, which is not economical. An elegant, but difficult way is a melt feeding procedure. A constant melt composition can also be achieved by the so-called, melt replenishing method.

It is the purpose of this investigation to grow alloy $\mathrm{Ga}_{1-x} \mathrm{In}_{\mathrm{x}} \mathrm{Sb}$ single crystals with a uniform composition along the growth direction. Two modified Czochralski growth methods, floating crucible and pressure-differential techniques, were studied in order to achieve this goal. 


\subsection{References}

1. M. Kurten and J. Schilz, J. Crystal Growth 139 (1994) 1.

2. I. Yonenaga, A. Matsui, S. Tozawa, K. Sumino and T. Fukuda, J. Crystal Growth $154(1995) 275$.

3. W. A. Bonner, R. E. Nahory, H. L. Gilchrist and E. Berry, Semi-Insulating III-V Materials, Toronto 1990, ed. A. G. Milnes and C. J. Miner, 199, Adam Hilger, Bristol.

4. J. W. Wagner, J. Electrochem. Soc., 117 (1970) 1193.

5. W. F. Micklethwaite, R. G. Fines and D. J. Freschi, SPIE Proceedings, 2554 (1995) 167

6. A. Tanaka, A. Watanabe, M. Kimura and T. Sukegawa, J. Crystal Growth 135 (1994) 269

7. J. Wollweber, D. Schulz and W. Schroder, J. Crystal Growth 163 (1996) 243.

8. A. Dahlen, A. Fattah, G. Hanke and E. Karthaus, J. crystal growth 171 (1997) 56.

9. J. Czochralski, Z. Phys. Chem., 92 (1918) 219.

10. T. F. Ciszek, U.S. Patent 5047112 (1991).

11. K. Nakajma and T. Kusunoki, J. Crystal Growth 169 (1996) 217.

12. H. J. Koh, P. Rudolph and T. Fukuda, J. Crystal growth 154 (1995) 151.

13. V. S. Zemskov, A. D. Belaya and G. N. Kozhemyakin, J. Crystal Growth 71 (1985) 243-245. 
14. G. M. Blom and T. S. Plaskett, J. Electrochem. Soc. 118 (1971) 1831.

15. W. Yuan, M. Banan, L. L. Regel and W. R. Wilcox, J. Crystal Growth 151 (1995) 235.

16. T. S. Plaskett and J. F. Woods, J. Crystal Growth, 11 (1971) 341.

17. T. Kusunoki, K. Nakajima, H. Shoji and T. Suzuki, Mat. Res. Soc. Symp. Proc. $417(1996) 315$.

18. K. Nakajima, T. Kusunoki and K. Otsubo, J. Crystal Growth 173 (1997) 42.

19. B. G. Streetman, Solid State Microelectronic Devices (Prentice-Hall, New Jersey, 1990) 439.

20. D. T. J. Hurle, Handbook of Crystal Growth 2 (North-Holland, Amsterdam, 1994) 812.

21. A. S. Jordan, J. Crystal Growth 71 (1985) 551.

22. R. Hultgren, P. D. Desai, D. T. Hawkins, M. Gleiser and K. K. Kelley, Selected Values of the Thermodynamic Properties of Binary Alloys, ASM, 1973.

23. J. P. Dismukes and W. M. Yim, J. Crystal growth 22 (1974) 287.

24. D. T. J. Hurle, Handbook of Crystal Growth 2 (North-Holland, Amsterdam, 1994) 812.

25. W. P. Allred and R. T. Bate, J. Electrochem. Soc., 108 (1961) 258.

26. K. B. Mcafee, Jr., D. M. Gay, R. S. Hozack, R. A. Laudise, G. Schwartz and W. A. Sunder, J. crystal Growth 76 (1986) 263.

27. A. J. Goss, K. E. Benson and W. G. Pfann, Acta Met. 4 (1956) 332. 
28. J. Schilz and V. N. Romanenko, J. Materials Science 6 (1995) 265.

29. W. A. Tiller, K. A. Jackson, J. W. Rutter and B. Chalmers, Acta Met. 1 (1953) 428.

30. D. T. J. Hurle, Solid State Electronics, 3 (1961) 37.

31. R.F. Sekerka, J. Applied Phys. 35 (1964) 444.

32. R.F. Sekerka, J. Applied Phys. 36 (1964) 264.

33. J. C. Brice, The Growth of Crystals from the Melt (North-Holland, Amsterdam, 1965) 138.

34. M. C. Flemings, Solidification Processing (McGraw-Hill, New York, 1974) 35.

35. J. A. Burton, R. C. Prim and W. P. Slichter, J. Chem. Phys. 21 (1953) 1987.

36. S. V. Airapetyants and G. I. Shmelev, Transl. Soviet Phys., Solid State 2, (1960) 689.

37. Y. Yamashita, M. Kojima, Y. Matsushita and M. Ogino, U.S. Patent 4894206 (1990).

38. R. M. Ware, R. A. Puechner, M. Tiernan and M. Morris, AIAA Technical Report AD-A297039 (1995).

39. W. F. Leverton, J. Appl. Phys. 29, (1958) 1241.

40. J. Goorissen, Phillips Tech. Rev. 21, (1960) 185.

41. H. F. Matare, Solid-State Electronics 5, (1962) 131.

42. G. R. Blackwell, J. Electron. Control 10, (1961) 459.

43. M. H. Lin and S. Kou, J. Crystal Growth 134 (1993) 287. 
44. K. Nakajima, T. Kusunoki and C. Takenaka, J. Crystal Growth 113 (1991) 485.

45. G. Fiegel, Solid State Technol., August (1983) 121.

46. S. Kan, M. Sakamoto, Y. Okane, K. Hosikawa and T. Fukuda, J. Crystal Growth 119 (1992) 214.

47. M. Kida, Y. Aral, N. Ono and K. Sahira, U.S. patent 5306474 (1994).

48. H. Klingshirn and R. Lang, US patent 5324488 (1994).

49. F. W. Horn, J. Electrochem. Soc. 105 (1958) 393.

50. M. H. Lin and S. Kou, J. Crystal Growth 142 (1994) 392.

51. D. Turnbull, J. Applied Phys. 21 (1950) 1022

52. K. J. Bachmann, F. A. Theil, H. Schreiber, Jr. and J. J. Rubin, J. Electronic Materials 9 (1980) 445 .

53. J. P. Garandet, T. Duffar and J. J. Favier, J. Crystal Growth 106 (1990) 426.

54. W. A. Bonner, Proc. IPRM 205 (1997) 32.

55. T. Ashley, J. A. Beswick, B. Cockayne, and C. T. Elliott, 7th Int. Conf. On Narrow Gap Semiconductors (1995) 209.

56. R. A. Lefer, W. R. Wilcox, K. R. Sarma and C. Z. Chang, Mat. Res. Bull. 13 (1978) 1181. 
Table 1 Review of various techniques for growing alloy crystals.

\begin{tabular}{|c|c|c|c|c|}
\hline Material & Method & $\begin{array}{l}\text { Composition } \\
\text { range, } x\end{array}$ & Result & Reference \\
\hline \multirow[t]{2}{*}{$\mathrm{Bi}_{1-x} \mathrm{Sb}_{\mathrm{x}}$} & Conventional CZ & 0 to 0.12 & Single crystal & (13) \\
\hline & $\mathrm{CZ}$, melt injection & 0 to 0.04 & Homogeneous & (12) \\
\hline \multirow[t]{4}{*}{$\overline{S i_{1-x} G e_{x}}$} & Conventional $\mathrm{CZ}$ & 0 to 0.2 & Single crystal & (1) \\
\hline & Conventional CZ & 0.75 to 1 & Single crystal & (2) \\
\hline & Floating zone & 0 to 0.22 & Single crystal & (7) \\
\hline & Bridgman, encapsulant & 0.006 to 0.05 & Single crystal & (8) \\
\hline \multirow[t]{6}{*}{$\mathrm{Ga}_{1-\mathrm{x}} \mathrm{In}_{\mathrm{x}} \mathrm{Sb}$} & Conventional CZ & 0.1 & $\overline{\text { Unknown }}$ & $(5)$ \\
\hline & Conventional $\mathrm{CZ}$ & 0 to 0.1 & Single crystal & $(52)$ \\
\hline & $\mathrm{CZ}$, double crucible & 0.88 to 1 & Single crystal & $(55)$ \\
\hline & $\mathrm{CZ}$, solute feeding & 0.05 & $\begin{array}{l}\text { Homogeneous, } \\
\text { twinning }\end{array}$ & (6) \\
\hline & Zone leveling & 0 to 1 & Polycrystal & (16) \\
\hline & Bridgman, vibration & 0 to 0.2 & Polycrystal & $(15)$ \\
\hline \multirow[t]{6}{*}{$\mathrm{Ga}_{1-x} \mathrm{In}_{\mathrm{x}} \mathrm{As}$} & Vertical bridgman & 0.001 to 0.1 & Polycrystal & (53) \\
\hline & LEC & 0.02 to 0.12 & Single crystal & (3) \\
\hline & LEC, floating crucible & 0.27 & Unknown & $\overline{(10)}$ \\
\hline & LEC, rod feeding & 0.07 & Single crystal & (11) \\
\hline & Zone melting & 0.2 & Polycrystal & (17) \\
\hline & Bridgman & 0.05 to 0.3 & Single crystal & $\overline{(18)}$ \\
\hline$\overline{\operatorname{InP}} P_{1-x} A s_{x}$ & $\overline{\text { LEC }}$ & 0 to 0.1 & Single crystal & (54) \\
\hline
\end{tabular}


Table 2 Physical properties of GaSb and InSb

\begin{tabular}{|c|c|c|c|}
\hline Parameter & $\mathrm{GaSb}$ & InSb & Reference \\
\hline$\rho_{\mathrm{s}}\left(\mathrm{g} / \mathrm{cm}^{3}\right)$ & 5.61 & 5.76 & (20) \\
\hline$\rho_{\theta}\left(\mathrm{g} / \mathrm{cm}^{3}\right)$ & 6.03 & 6.43 & (20) \\
\hline$a_{0}(\AA)$ & 6.094 & 6.48 & (19) \\
\hline$\gamma(\mathrm{N} / \mathrm{m})$ & 0.44 & 0.29 & (20) \\
\hline $\mathrm{T}_{\mathrm{m}}\left({ }^{\circ} \mathrm{C}\right)$ & 712 & 525 & (19) \\
\hline$\Delta \mathrm{H}_{\mathrm{m}}(\mathrm{J} / \mathrm{g})$ & 131.16 & 199.65 & (20) \\
\hline $\mathrm{K}_{\ell}(\mathrm{W} / \mathrm{cm} \cdot \mathrm{K})$ & 0.171 & 0.092 & (20) \\
\hline $\mathrm{K}_{\mathrm{s}}(\mathrm{W} / \mathrm{cm} \cdot \mathrm{K})$ & 0.078 & 0.045 & (20) \\
\hline $\mathrm{C}_{\mathrm{ps}}(\mathrm{J} / \mathrm{g} \cdot \mathrm{K})$ & 0.328 & 0.263 & (20) \\
\hline$\beta_{\mathrm{T}}(1 / \mathrm{K})$ & $9.58 \times 10^{-5}$ & $1 \times 10^{-4}$ & (20) \\
\hline$\kappa\left(\mathrm{cm}^{2} / \mathrm{s}\right)$ & 0.087 & 0.06 & (20) \\
\hline$v\left(\mathrm{~cm}^{2} / \mathrm{s}\right)$ & 0.00383 & 0.0033 & (20) \\
\hline$\eta(\mathrm{g} / \mathrm{cm} \cdot \mathrm{s})$ & 0.231 & 0.25 & (21) \\
\hline$P_{r}=v / \kappa$ & 0.044 & 0.055 & (20) \\
\hline
\end{tabular}


Table 3 Electrical properties of GaSb and $\mathrm{InSb}$

\begin{tabular}{|c|c|c|c|}
\hline Parameter & GaSb & InSb & Reference \\
\hline$E_{\mathrm{g}}(\mathrm{eV})$ & 0.7 & 0.18 & $(19)$ \\
\hline$\rho(\Omega \cdot \mathrm{cm})$ & 0.04 & 0.06 & $(19)$ \\
\hline$\mu_{\mathrm{n}}\left(\mathrm{cm}^{2} / \mathrm{V} \cdot \mathrm{s}\right)$ & 5000 & $1 \times 10^{5}$ & $(19)$ \\
\hline$\mu_{\mathrm{p}}\left(\mathrm{cm}^{2} / \mathrm{V} \cdot \mathrm{s}\right)$ & 1000 & 1700 & $(19)$ \\
\hline$\varepsilon_{\mathrm{r}}$ & 15.7 & 17.7 & $(19)$ \\
\hline
\end{tabular}


Table 4 Material properties of $\mathrm{Bi}$ and $\mathrm{Sb}$

\begin{tabular}{|c|c|c|c|}
\hline Parameter & $\mathrm{Bi}$ & $\mathrm{Sb}$ & Reference \\
\hline$\Delta \mathrm{H}_{\mathrm{m}}(\mathrm{cal} / \mathrm{g})$ & 2600 & 4690 & (22) \\
\hline $\mathrm{k}_{\ell}(\mathrm{cal} / \mathrm{cm} \cdot \mathrm{K})$ & 0.03 & 0.06 & (23) \\
\hline $\mathrm{k}_{\mathrm{s}}(\mathrm{cal} / \mathrm{cm} \cdot \mathrm{K})$ & 0.015 & 0.04 & (23) \\
\hline$\rho_{s}\left(g / \mathrm{cm}^{3}\right)$ & 9.8 & 6.684 & (23) \\
\hline$\rho_{\rho}\left(\mathrm{g} / \mathrm{cm}^{3}\right)$ & 10.03 & 6.47 & (23) \\
\hline$a_{0}(\stackrel{\AA}{A})$ & $\begin{array}{l}a=4.546 \\
c=11.86\end{array}$ & $\begin{array}{l}a=4.307 \\
c=11.273\end{array}$ & (22) \\
\hline$\gamma_{\mathrm{st}}\left(\mathrm{erg} / \mathrm{cm}^{2}\right)$ & 54.4 & 101 & (51) \\
\hline$\gamma\left({ }^{\text {dyne }} / \mathrm{cm}\right)$ & 378 & 367 & (23) \\
\hline $\mathrm{D}_{\ell}\left(\mathrm{cm}^{2} / \mathrm{s}\right)$ & $1.6 \times 10^{-5}$ & $4 \times 10^{-5}$ & (23) \\
\hline$v\left(\mathrm{~cm}^{2} / \mathrm{s}\right)$ & 0.08 & 0.155 & (23) \\
\hline $\mathrm{T}_{\mathrm{m}}\left({ }^{\circ} \mathrm{C}\right)$ & 271.4 & 630 & (22) \\
\hline
\end{tabular}




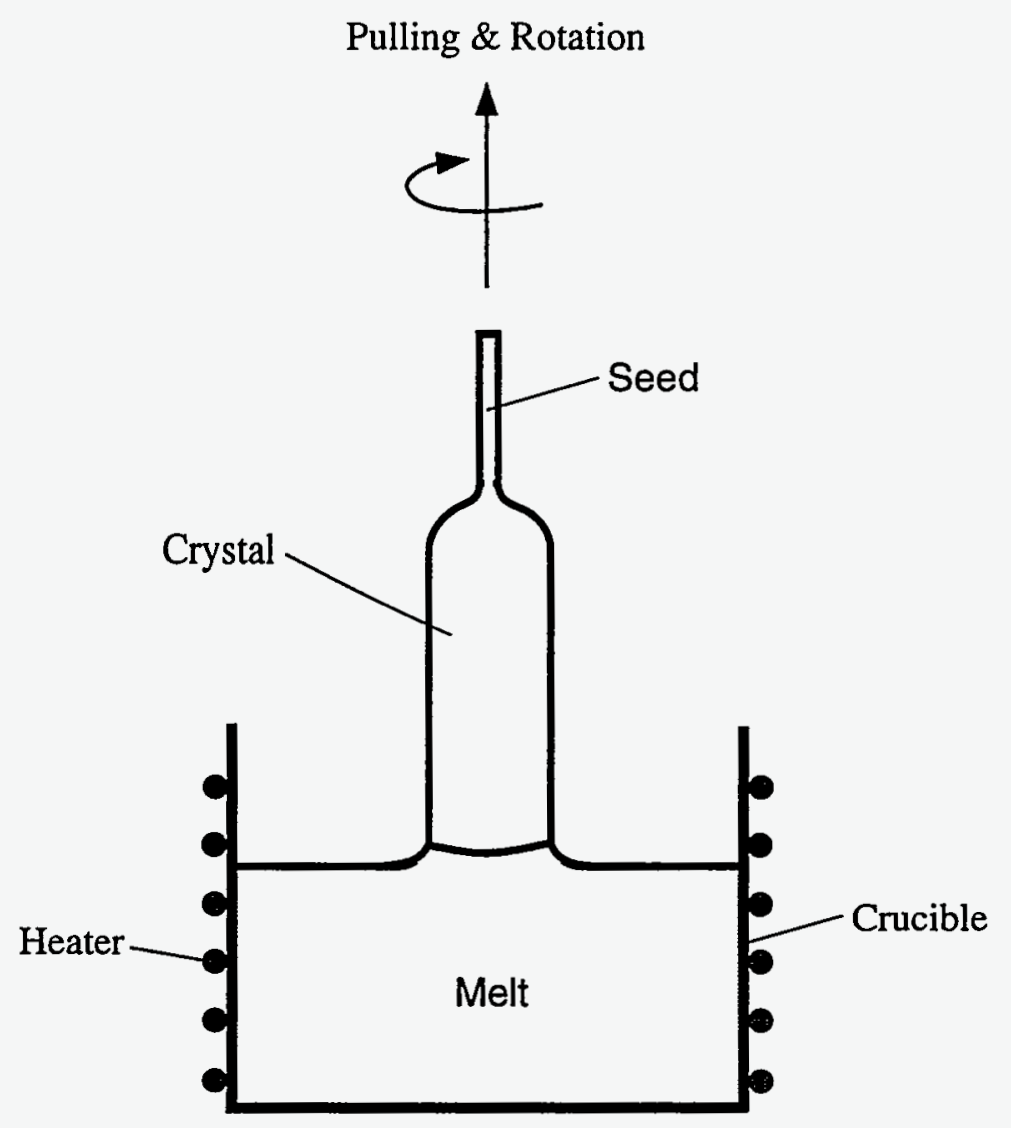

Figure 1.1 Schematic representation of conventional Czochralski pulling. 


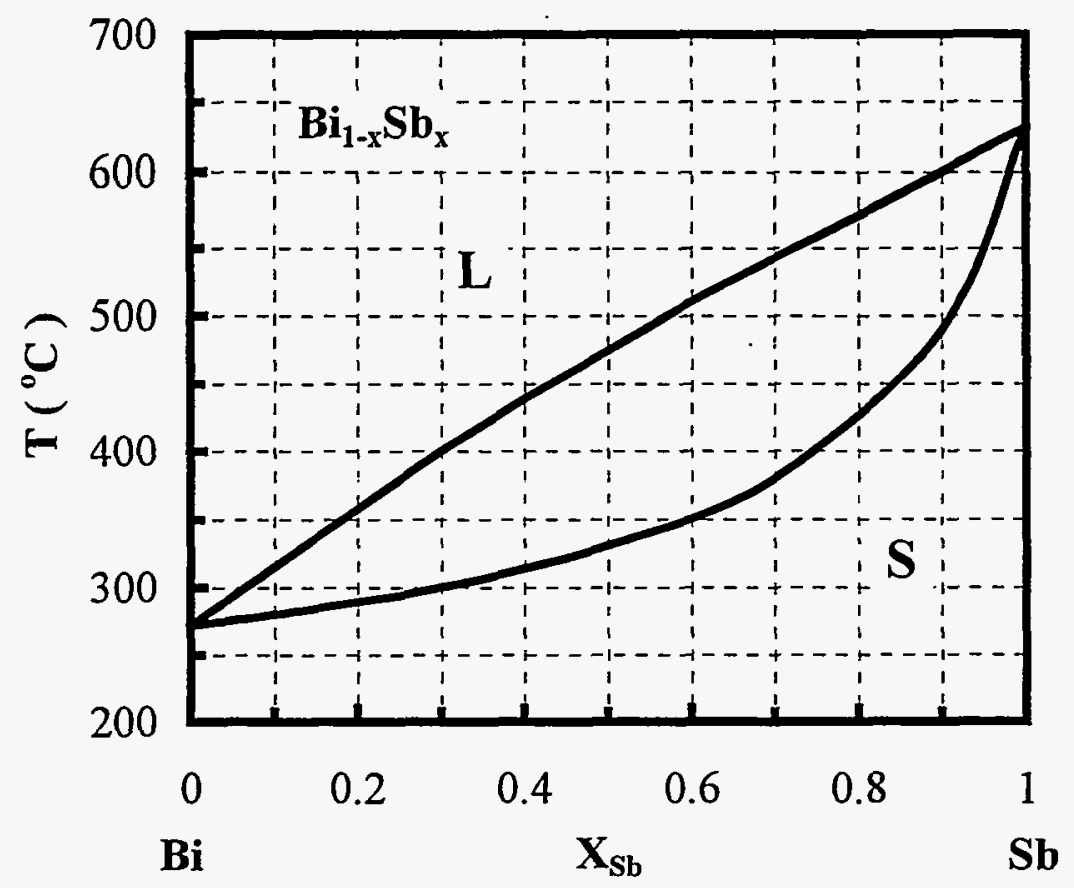

Figure 1.2 The $\mathrm{Bi}-\mathrm{Sb}$ phase diagram ${ }^{(23)}$.

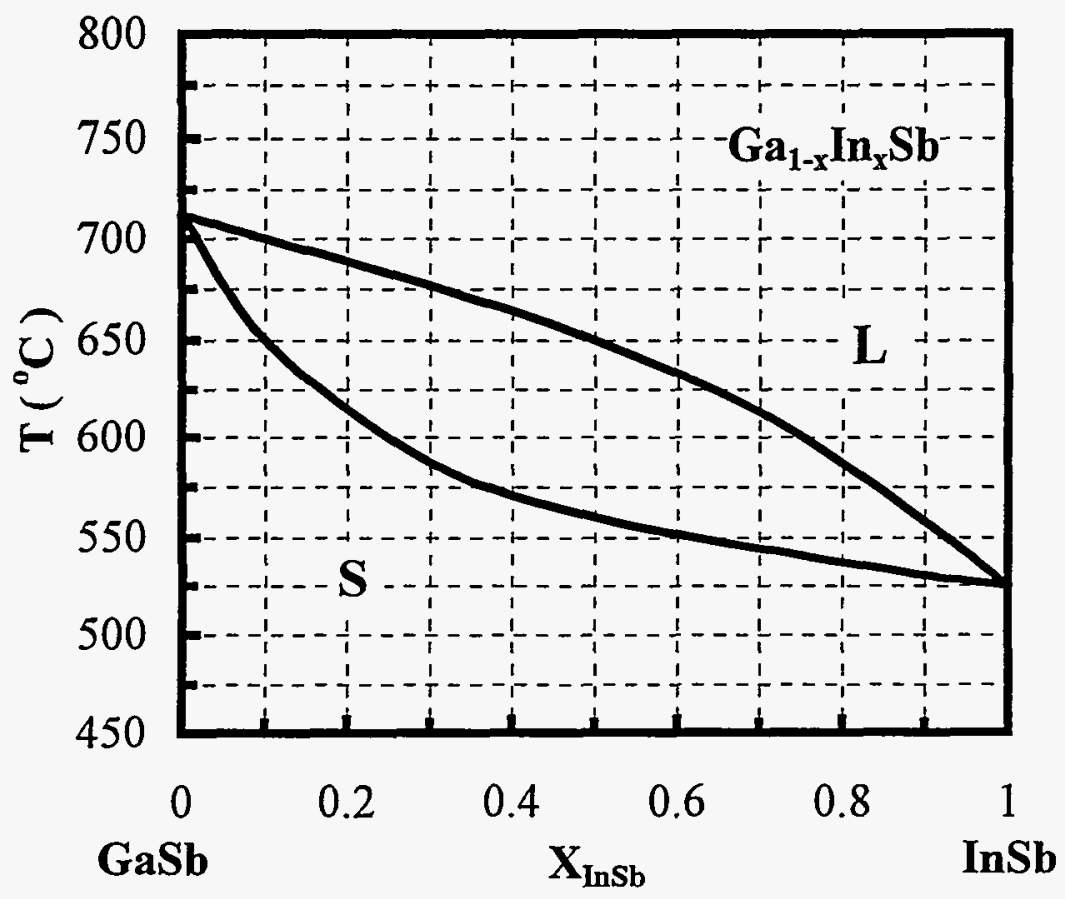

Figure 1.3 The GaInSb equilibrium phase diagram ${ }^{(14)}$. 


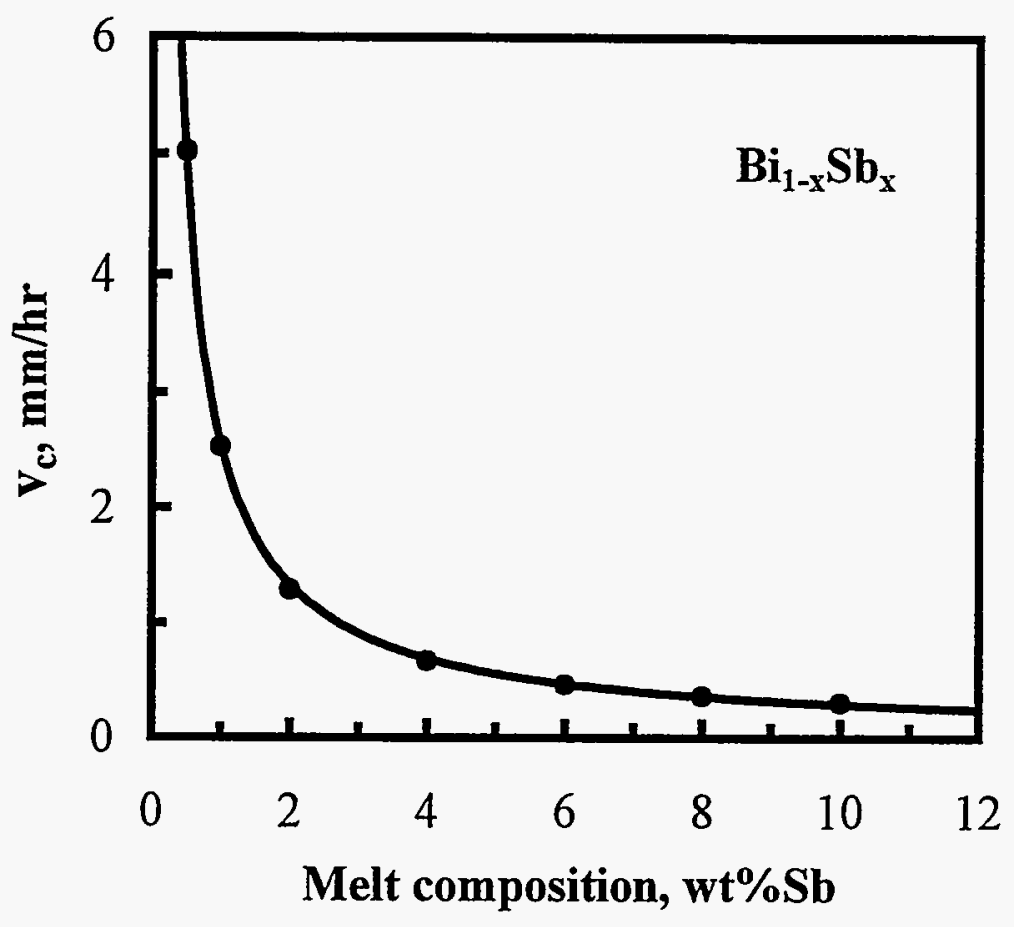

Figure 1.4 Calculated critical growth rate in $\mathrm{Bi}_{1-x} \mathrm{Sb}_{x}$ system.

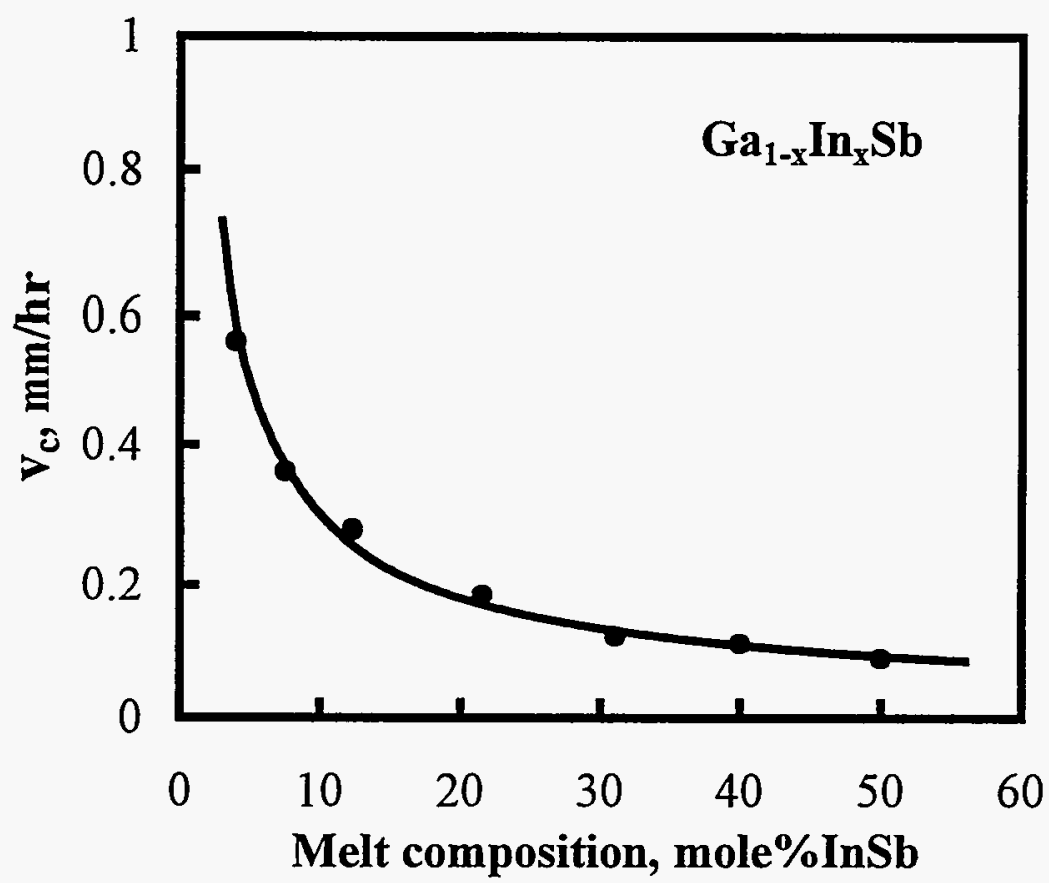

Figure 1.5 Calculated critical growth rate in $\mathrm{Ga}_{1-x} \mathrm{In}_{x} \mathrm{Sb}$ system. 


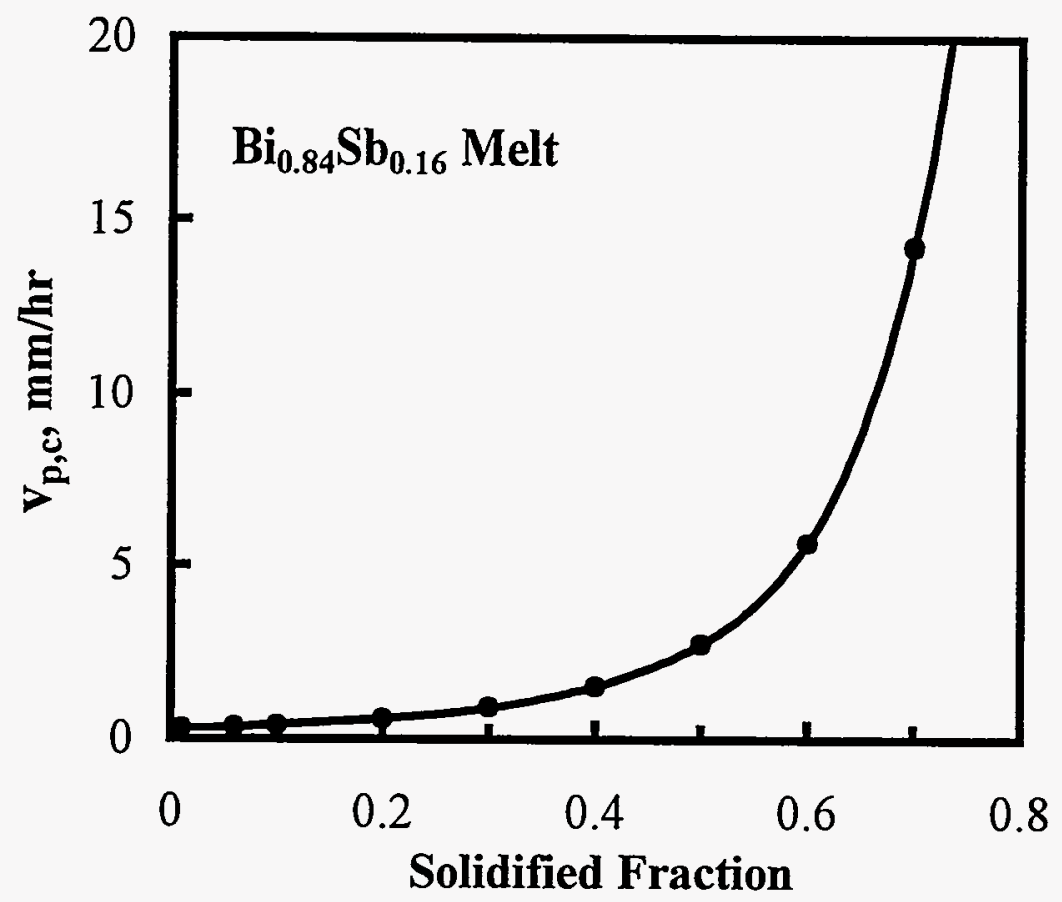

28

Figure 1.6 Calculated critical pulling rate in the $\mathrm{Bi}_{1-\mathrm{x}} \mathrm{Sb}_{\mathrm{x}}$ system.

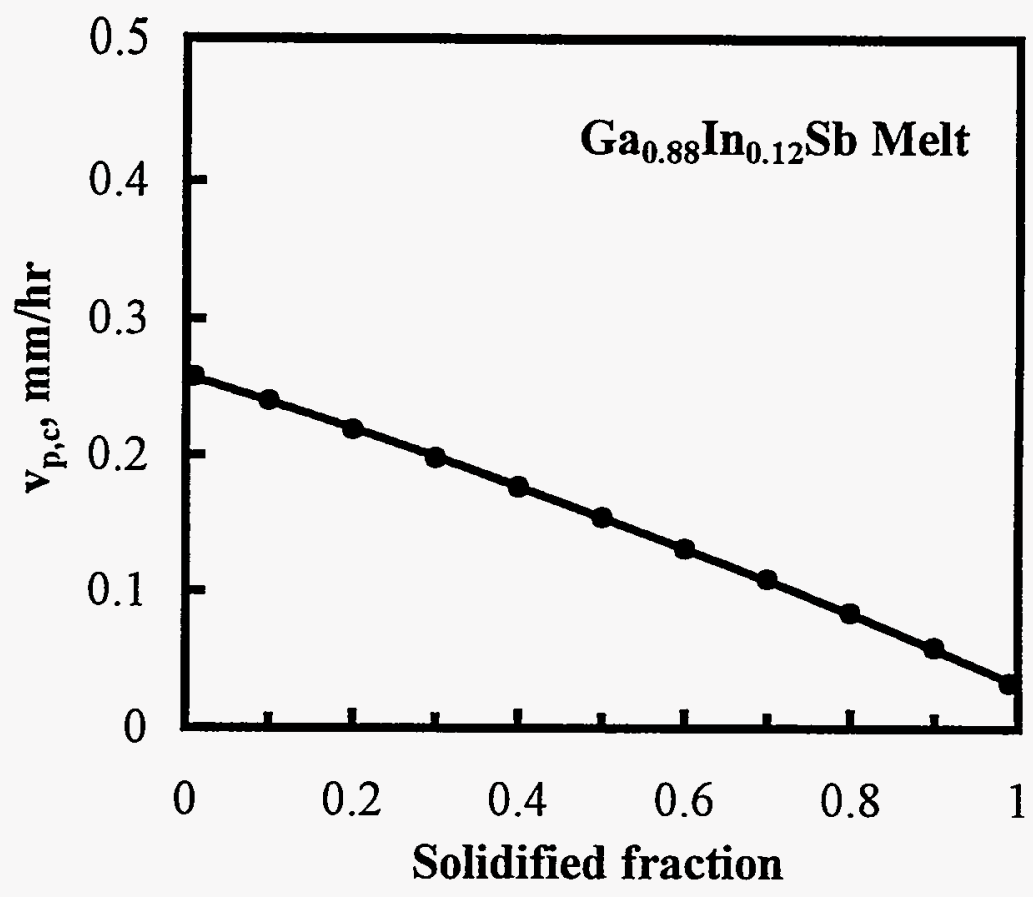

Figure 1.7 Calculated critical pulling rate in the $\mathrm{Ga}_{1-\mathrm{x}} \mathrm{In} \mathrm{n}_{\mathrm{x}} \mathrm{Sb}$ system. 


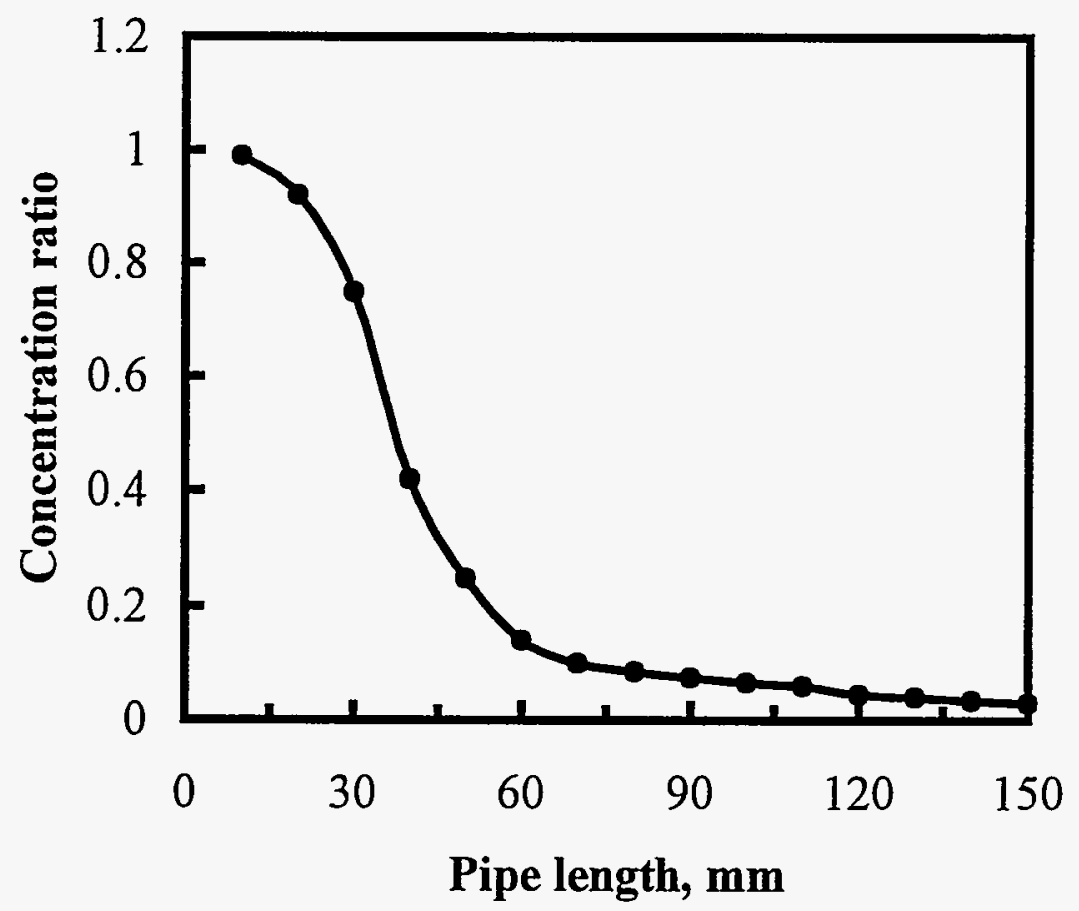

Figure 1.8 Relationship between the length of passageway and the concentration ratio of phosphorus concentration in the silicon melt ${ }^{(37)}$. 


\section{Growth of $\mathrm{Ga}_{1-\mathrm{x}} \mathrm{In}_{\mathrm{x}} \mathrm{Sb}_{\mathrm{S}}$ Crystals by Conventional CZochralski Pulling}

\subsection{Introduction}

$\mathrm{Ga}_{1-x} \mathrm{In}_{\mathrm{x}} \mathrm{Sb}$, and other alloy semiconductor crystals are attractive for many applications because the lattice parameter and the energy gap can be adjusted by adjusting the composition $\mathrm{x}$, i.e., the mole fraction of the solute InSb. Little information is available in the open literature on how to grow $\mathrm{Ga}_{1-x} \mathrm{In}_{x} \mathrm{Sb}$ crystals by the conventional Czochralski process. Czochralski growth of $\mathrm{Ga}_{1-x} \mathrm{In}_{x} \mathrm{Sb}$ single crystals with 0 to 6 mole $\% \operatorname{InSb}^{(1)}$ and 0 to $10 \mathrm{~mole} \% \operatorname{InSb}^{(2,3)}$ was mentioned, but no details were given. Bachmann et al. ${ }^{(4)}$ reported Czochralski growth of [111] crystals up to 10 mole $\%$ InSb in a flowing $85 \% \mathrm{~N}_{2}+15 \% \mathrm{H}_{2}$ atmosphere at unusually high rotation speeds $(100-200 \mathrm{rpm})$ and growth rates $(1-6 \mathrm{~mm} / \mathrm{hr})$. No composition profiles of the crystals were given. Tanaka et al. ${ }^{(5)}$ used a doublecrucible Czochralski process to grow $\mathrm{Ga}_{1-x} \mathrm{In}_{\mathrm{x}} \mathrm{Sb}$ single crystals with 0 to $5 \mathrm{~mole} \%$ InSb. A solution in contact with a solid GaSb source was injected by a graphite piston into a graphite crucible for crystal growth. The crystals grown were approximately 1 $\mathrm{cm}$ in diameter and $1.5 \mathrm{~cm}$ long.

\subsection{Experimental procedure}

The transparent furnace illustrated in Fig. 2.1 was used for the crystal growth. It consisted of, from the inside out, a $4.7 \mathrm{~cm}$ ID quartz tube as the chamber, a Kanthal wire wound around a quartz tube as the heater, and a gold-coated quartz tube as the 
radiation heat shield.

The chamber was pumped down to below $1 \times 10^{-3}$ torr and then purged with $5 \mathrm{~N}$ hydrogen at an overpressure of approximately $3 \mathrm{psi}$. This was repeated several times before the hydrogen was purged throughout the crystal growth.

The charge consisted of $\mathrm{N} \mathrm{Ga}$ and $\mathrm{Sb}$ and $5 \mathrm{~N} \mathrm{InSb}$. To compensate for the $\mathrm{Sb}$ lost by evaporation, a 1 at\% $\mathrm{Sb}$ surplus was added to the starting charge ${ }^{(6-8)}$. After synthesis the ingot was cleaned first by grinding and then by etching in a 2: 1: 1 mixture of $\mathrm{HNO}_{3}: \mathrm{HF}: \mathrm{CH}_{3} \mathrm{COOH}{ }^{(7,9)}$. The ingot was loaded into a $3 \mathrm{~cm}$ ID quartz crucible for the crystal growth.

GaSb single crystals were grown in the [111] B direction. The pulling speed was 2 $\mathrm{mm} / \mathrm{hr}$ and the rotation speed was $20 \mathrm{rpm}$. Hydrogen of $99.999 \%$ purity was purged through the chamber at 1.2 to 2 liter/min. These crystals were used as seeds for growing the $\mathrm{Ga}_{1-\mathrm{x}} \mathrm{In}_{\mathrm{x}} \mathrm{Sb}$ crystals.

Growth of the $\mathrm{Ga}_{1-\mathrm{x}} \mathrm{In}_{\mathrm{x}} \mathrm{Sb}$ crystals was as follows. After the ingot was melted and 1 hour allowed for homogenization, the seed was dipped into the melt and held for 1 hour before pulling. The pulling speed was 0.85 to $0.94 \mathrm{~mm} / \mathrm{hr}$, the rotation speed was $20 \mathrm{rpm}$, and the hydrogen purging rate was 1.2 to 2 liter $/ \mathrm{min}$.

In most experiments a conical reflector prepared from a $0.013 \mathrm{~cm}$ thick molybdenum foil was placed about $5 \mathrm{~mm}$ above the melt and coaxially around the growing crystal. The diameter of the conical reflector was about $1.8 \mathrm{~cm}$ at the bottom and $4 \mathrm{~cm}$ at the top. In the measurements of the axial temperature profiles above the 
melt surface, the diameter of the conical reflector at the bottom was reduced to about $0.7 \mathrm{~cm}$ since without a growing crystal filling most of the space in the hole, a $1.8 \mathrm{~cm}$ diameter hole would be unrealistically large. A K-type thermocouple, protected from the hostile $\mathrm{Sb}$ vapor by a one-end sealed alumina shield of $0.35 \mathrm{~cm} \mathrm{OD}$ and $0.1 \mathrm{~cm}$ wall, was used to measure the axial temperature profiles above the melt surface

The resultant $\mathrm{Ga}_{1-x} \mathrm{In}_{\mathrm{x}} \mathrm{Sb}$ crystals were cut along the axis and prepared for composition measurements by electron probe microanalysis, wavelength-dispersive spectroscopy (EPMA-WDS).

\subsection{Results and discussion}

The results of the experiments are summarized in Table 5. Single crystal seeds up to 1 to $2 \mathrm{~mole} \% \mathrm{InSb}$ were grown from essentially pure $\mathrm{GaSb}$ seeds. These single crystal seeds were in turn grown into single crystal seeds of higher InSb concentrations, i.e., up to about 2 to $5 \mathrm{~mole} \% \mathrm{InSb}$.

In Experiment $1 \mathrm{a}$ single crystal of essentially pure $\mathrm{GaSb}$ was pulled at $2 \mathrm{~mm} / \mathrm{hr}$ from a melt containing $0.3 \mathrm{~mole} \% \mathrm{InSb}$, and the resultant crystal is shown in Fig. 2.2. The InSb concentration near the seed end of the crystal was too low to be measured and $0.6 \mathrm{~mole} \%$ at the finish end.

The melt InSb concentration was raised to 21 mole\% in Experiment 2 and the pulling rate was reduced to $0.94 \mathrm{~mm} / \mathrm{hr}$. The resultant single crystal is shown in Fig. 2.3. Axial segregation is rather significant. The InSb concentration, as shown in Fig. $2.4 \mathrm{a}$, rises from about $3 \mathrm{~mole} \%$ at the seed end of the crystal to about $14 \mathrm{~mole} \%$ at the 
finish end. The composition is essentially uniform in the radial direction, as shown in Fig. $2.4 \mathrm{~b}$ at about $4 \mathrm{~mm}$ from the finish end of the crystal. Experiment 3 is similar to Experiment 2, except that the Mo conical reflector was not used. The resultant crystal is still monocrystalline, even without the reflector.

In Experiment 4 the melt InSb concentration was raised further to $28 \mathrm{~mole} \%$ and the pulling speed was reduced slightly to $0.85 \mathrm{~mm} / \mathrm{hr}$. The resultant single crystal is shown in Fig. 2.5. The InSb concentration in the resultant crystal, about 4 to 15 mole $\%$, is slightly higher than that of about 3 to $14 \mathrm{~mole} \%$ in the crystal in Experiment 2. Radial segregation is still small, as shown in Fig. 2.6b.

Experiment 5 is similar to Experiment 4, but the charge has a slightly higher InSb concentration of $30 \mathrm{~mole} \%$ and a slightly lower solidified fraction of 0.54 . The resultant single crystal is shown in Fig. 2.7. The axial and radial composition profiles, shown in Figs. 2.8a and 2.8b, are similar to those in Experiment 4.

In Experiment 6 the melt InSb concentration was raised further to $38 \mathrm{~mole} \%$, but the pulling speed remained at $0.85 \mathrm{~mm} / \mathrm{hr}$. The resultant single crystal is shown in Fig. 2.9. As shown in Fig. 2.10a, the InSb concentration rises from about 6 mole\% at the seed end to about 23 mole\% at the finish end. The composition is essentially uniform in the radial direction, as shown in Fig. $2.10 \mathrm{~b}$ at around $10 \mathrm{~mm}$ from the finish end of the crystal.

Experiment 7 is similar to Experimental 6 but no conical reflector was used. The resultant crystal, shown in Fig. 2.11, remains monocrystalline until near the end, 
where it turns polycrystalline. The composition profiles, shown in Fig. 2.12a and $2.12 \mathrm{~b}$, are similar to those in Experiment 6 .

The temperature profiles shown in Fig. 2.13 indicate that the axial temperature gradient above the melt surface can be increased significantly by the presence of the conical reflector. Perhaps in some cases the increased temperature gradient helped a growing crystal remain monocrystalline by reducing the constitutional supercooling. Analysis by an ICP-MS (Inductively Coupled Plasma-Mass Spectrometry) with a detection limit of $0.05 \mathrm{ppm}$ Mo showed no detectable Mo in the crystals.

A Ni conical reflector was used in the liquid-encapsulated Czochralski growth of $\mathrm{Pb}_{1-x} \mathrm{Sn}_{x} \mathrm{Te}^{(10)}$, not to help suppress polycrystallinity but to help the encapsulant form a coating on the crystal surface to prevent evaporation of $\mathrm{Pb}$ from the crystal surface.

According to the GaSb-InSb phase diagram shown in Fig. 1.3, the liquidus temperature of the alloy tends to decrease significantly with increasing InSb concentration. Therefore, the furnace temperature was decreased during pulling to keep the crystal growing. For example, in Experiment 6 the furnace temperature, as indicated by a thermocouple at the heater outer wall, was dropped about $80^{\circ} \mathrm{C}$. Crystals containing more than about 4 mole\% InSb were weak and cracks were observed after cutting. Further studies are needed to overcome this problem.

\subsection{Conclusions}

Single crystals of $\mathrm{Ga}_{1-x} \mathrm{In}_{\mathrm{x}} \mathrm{Sb}$ were grown in the [111] direction by the conventional Czochralski process. The crystals exhibit significant axial segregation because of the 
wide gap between the liquidus and solidus lines of the GaSb-InSb phase diagram. The maximum InSb concentration achieved is about $23 \mathrm{~mole} \%$. 


\subsection{References}

1. G. M. Blom and T. S. Plaskett, J. Electrochem. Soc. 118 (1971) 1831.

2. M. Averous, G. Bougnot and J. Calas, Phys. Stat. Sol. 29 (1968) 807.

3. W. F. Micklethwaite, R. G. Fines and D. J. Freschi, SPIE 2554 (1995) 167.

4. K. J. Bachmann, F. A. Thiel, H. Schreiber, Jr. And J. J. Rubin, J. Electronic Materials $9(1980) 445$.

5. A. Tanaka, A. Watanabe, M. Kimura and T. Sukegawa, J. Crystal Growth 135 (1994) 269.

6. W. A. Sander, R. L. Barns, T. Y. Kometani, J. M. Parsey and R. A. Laudise, J. Crystal Growth 78 (1986) 9.

7. F. Moravec, J. Crystal Growth 128 (1993) 457.

8. Y. Ohmori, K. Sugii, S. Akai and K. Matsumoto, J. Crystal Growth 60 (1982) 79.

9. A. Katsui and C. Uemura, J. Applied Physics 19 (1980) L318.

10. E. D. Bourret and A. F. Witt, J. Crystal Growth 63 (1983) 413. 
Table 5 Parameters of conventional Czochralski growth and properties of $\mathbf{G a}_{1-x} \mathbf{I n}_{\mathbf{x}} \mathbf{S b}$ crystals

\begin{tabular}{|c|c|c|c|c|c|c|c|}
\hline Experiment & 1 & 2 & 3 & 4 & 5 & 6 & 7 \\
\hline $\begin{array}{c}\text { Crystal, mole\% InSb } \\
\text { (seed end-finish end) }\end{array}$ & $0-0.6$ & $3-14$ & $3-13$ & $4-15$ & $4-17$ & $6-23$ & $6-47$ \\
\hline Single crystal & yes & yes & yes & yes & yes & yes & no \\
\hline Charge, mole\% InSb & 0.3 & 21 & 21 & 28 & 30 & 38 & 38 \\
\hline Fraction solidified, fs & 0.80 & 0.69 & 0.69 & 0.57 & 0.54 & 0.53 & 0.57 \\
\hline Pulling rate, mm/hr & 2 & 0.94 & 0.94 & 0.85 & 0.85 & 0.85 & 0.85 \\
\hline Rotation speed, rpm & 20 & 20 & 20 & 20 & 20 & 20 & 20 \\
\hline $\mathrm{H}_{2}$ flow rate, liter/min & 1.2 & 2 & 2 & 1.2 & 2 & 1.2 & 1.2 \\
\hline Conical reflector & no & yes & no & yes & yes & yes & no \\
\hline Figure number & 2.2 & 2.3 & & 2.5 & 2.7 & 2.9 & 2.11 \\
\hline
\end{tabular}




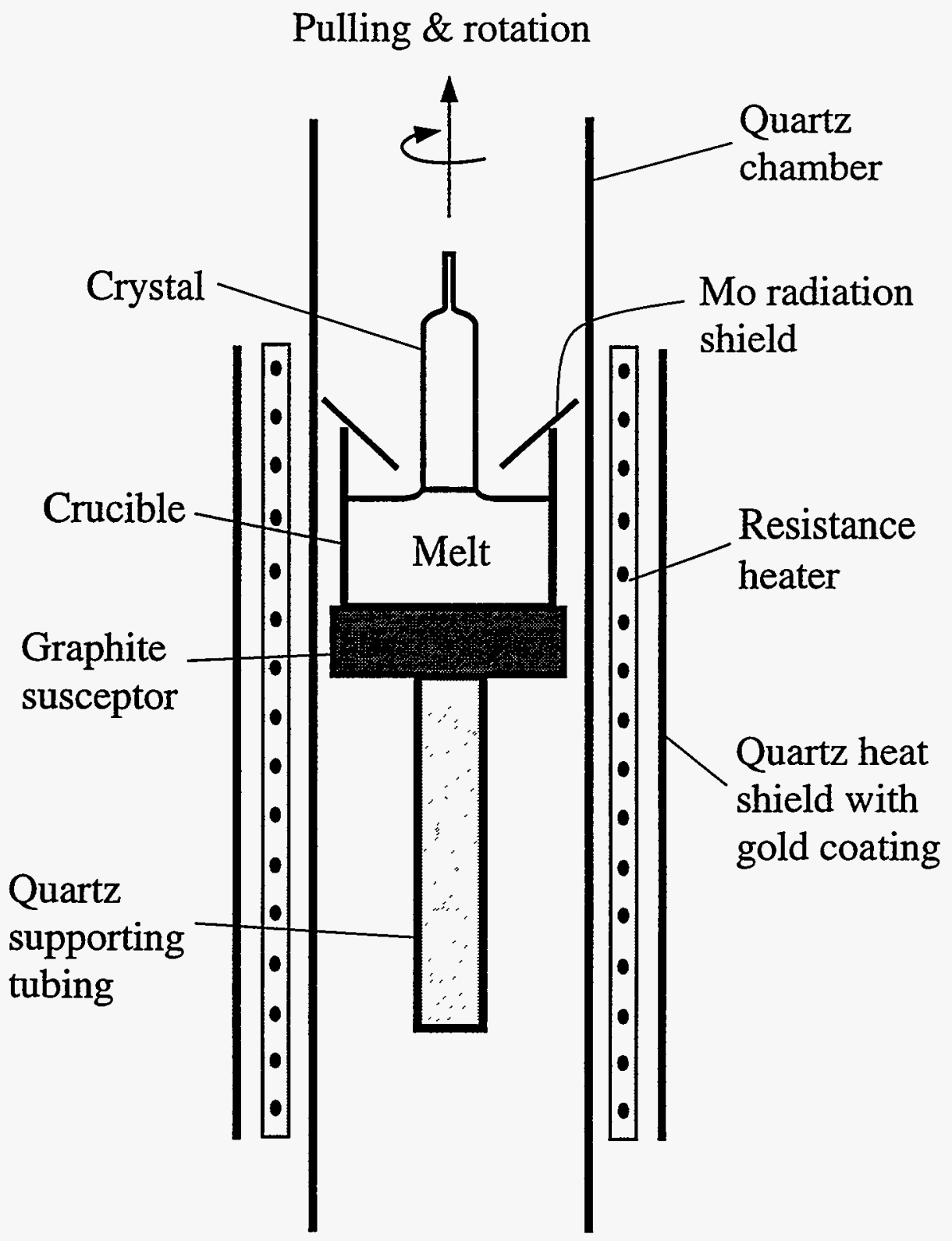

Figure 2.1 Schematic illustration of conventional Czochralski pulling with radiation shield. 


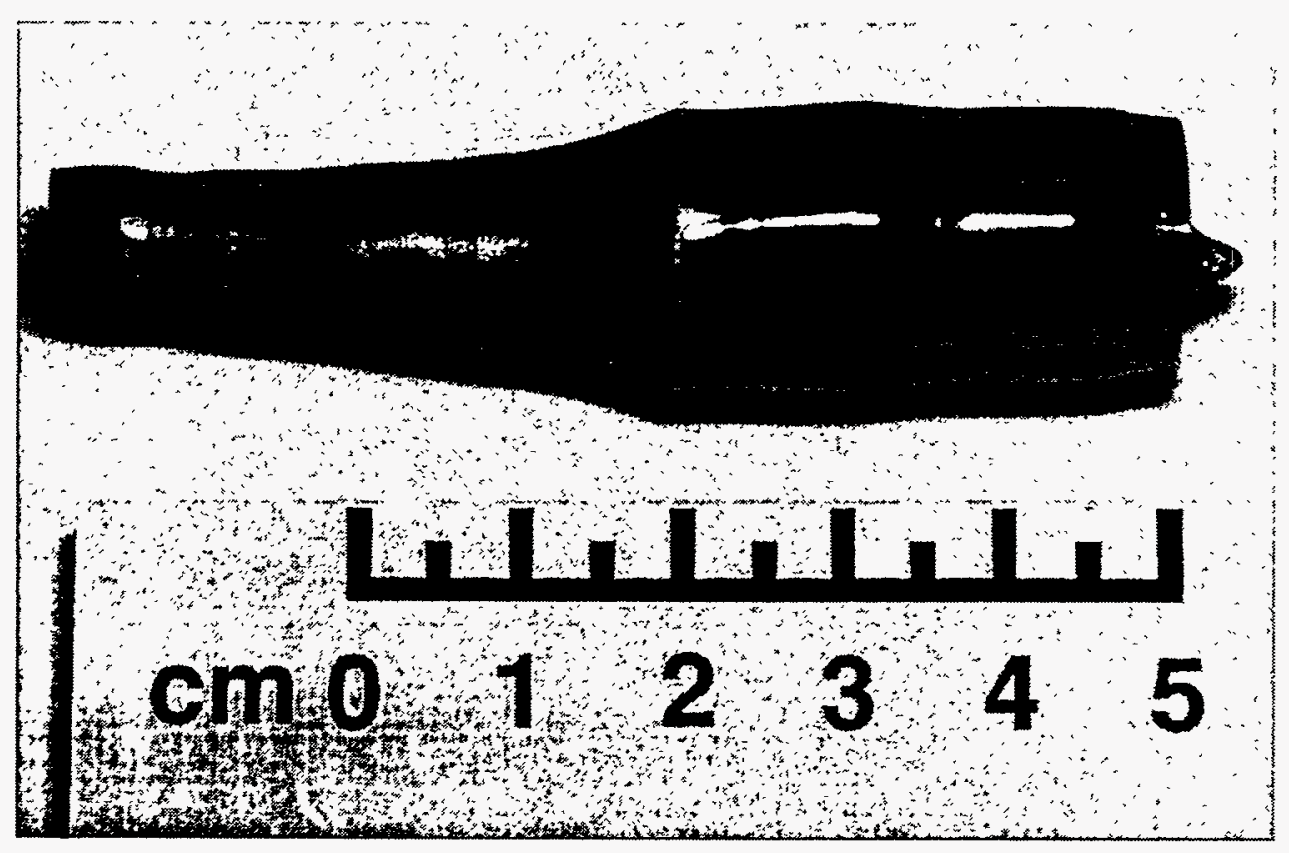

Figure 2.2 An essentially pure GaSb crystal grown in experiment 1. 


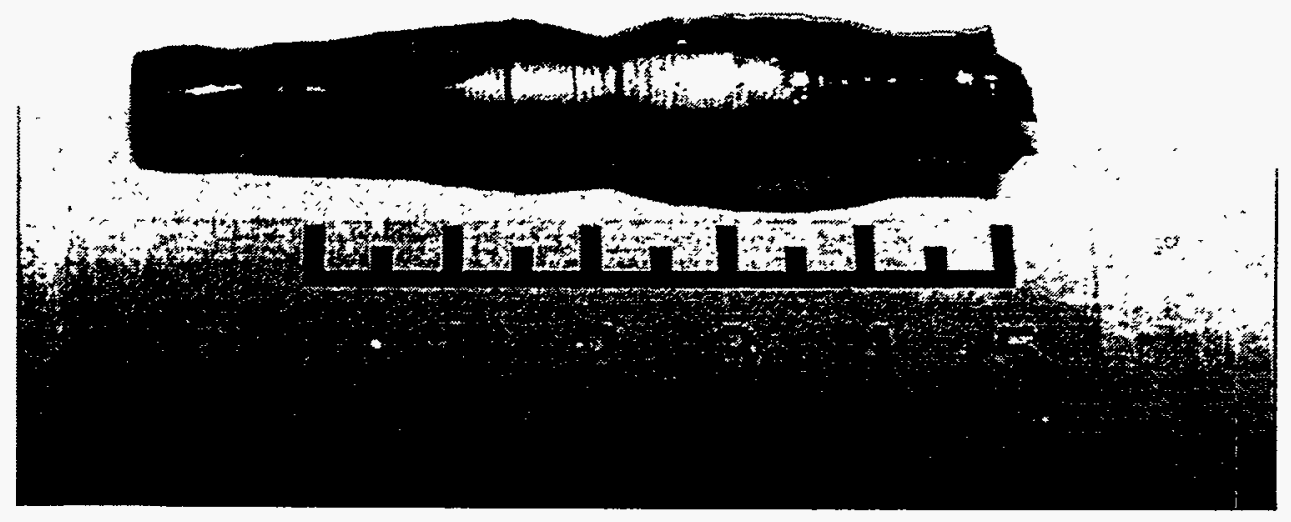

Figure $2.3 \mathrm{Ga}_{1-\mathrm{x}} \mathrm{In}_{\mathrm{x}} \mathrm{Sb}$ single crystal grown in experiment 2 . 


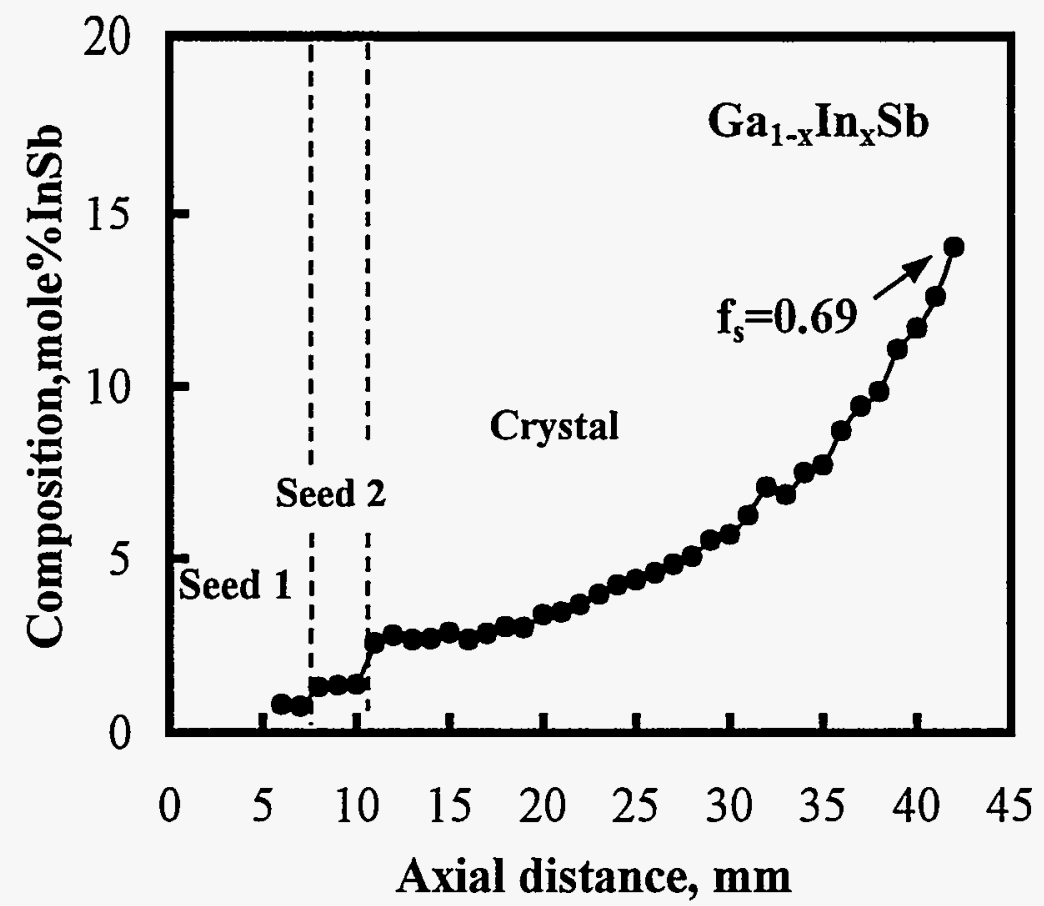

(a)

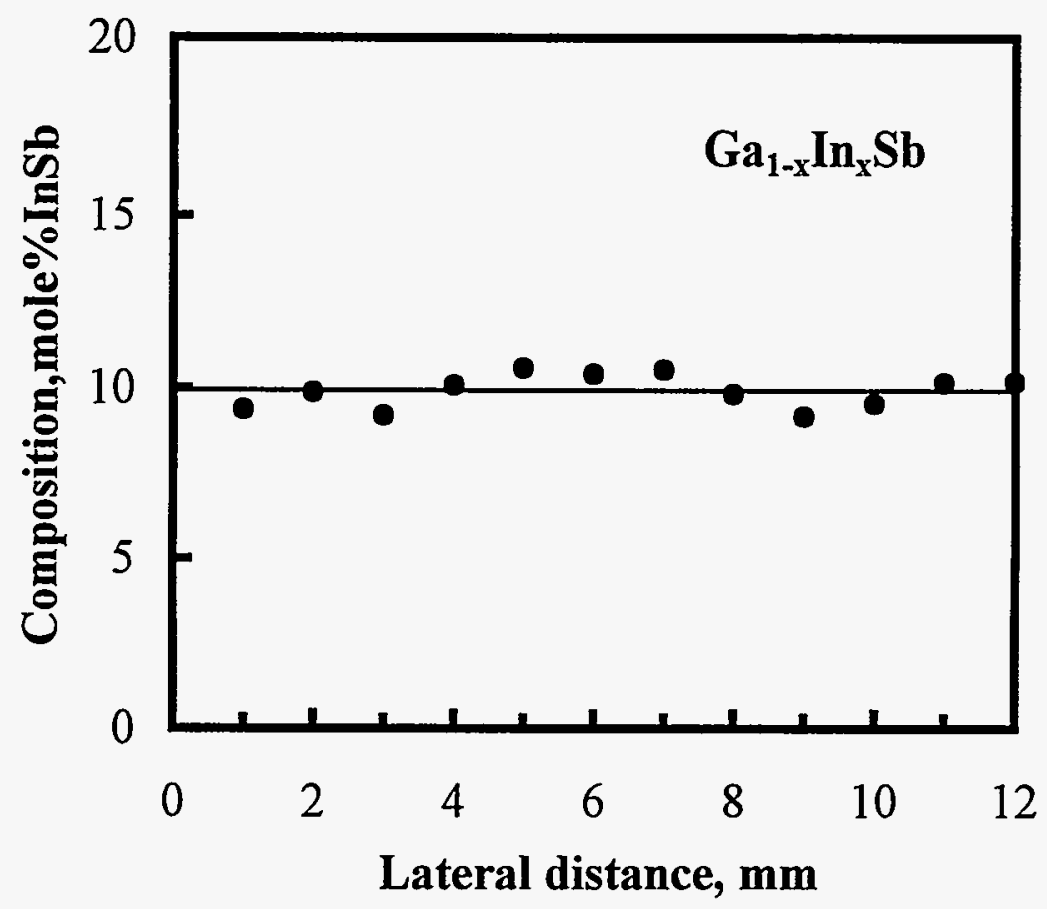

(b)

Figure 2.4 Results of experiment 2 : (a) axial and (b) lateral composition profiles. 


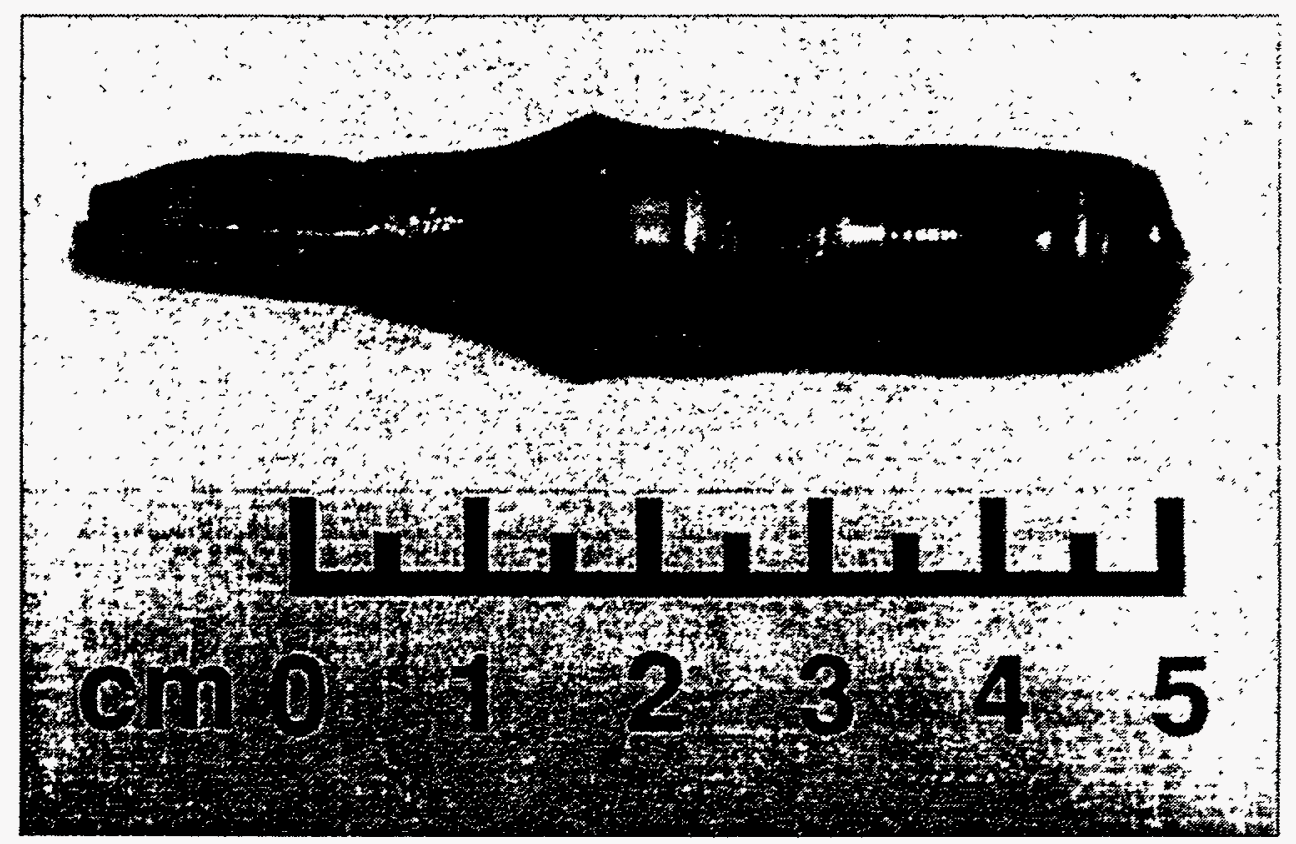

Figure $2.5 \mathrm{Ga}_{1-\mathrm{x}} \mathrm{In}_{\mathrm{x}} \mathrm{Sb}$ single crystal grown in experiment 4. 


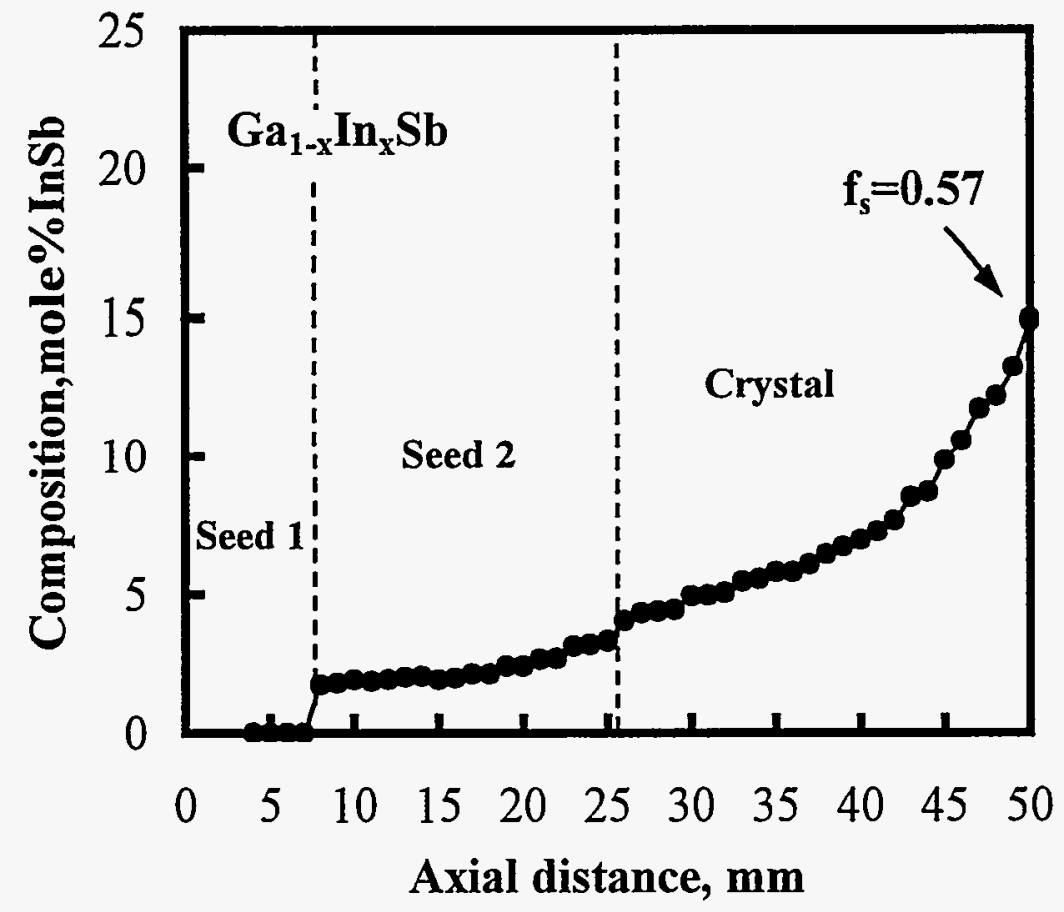

(a)

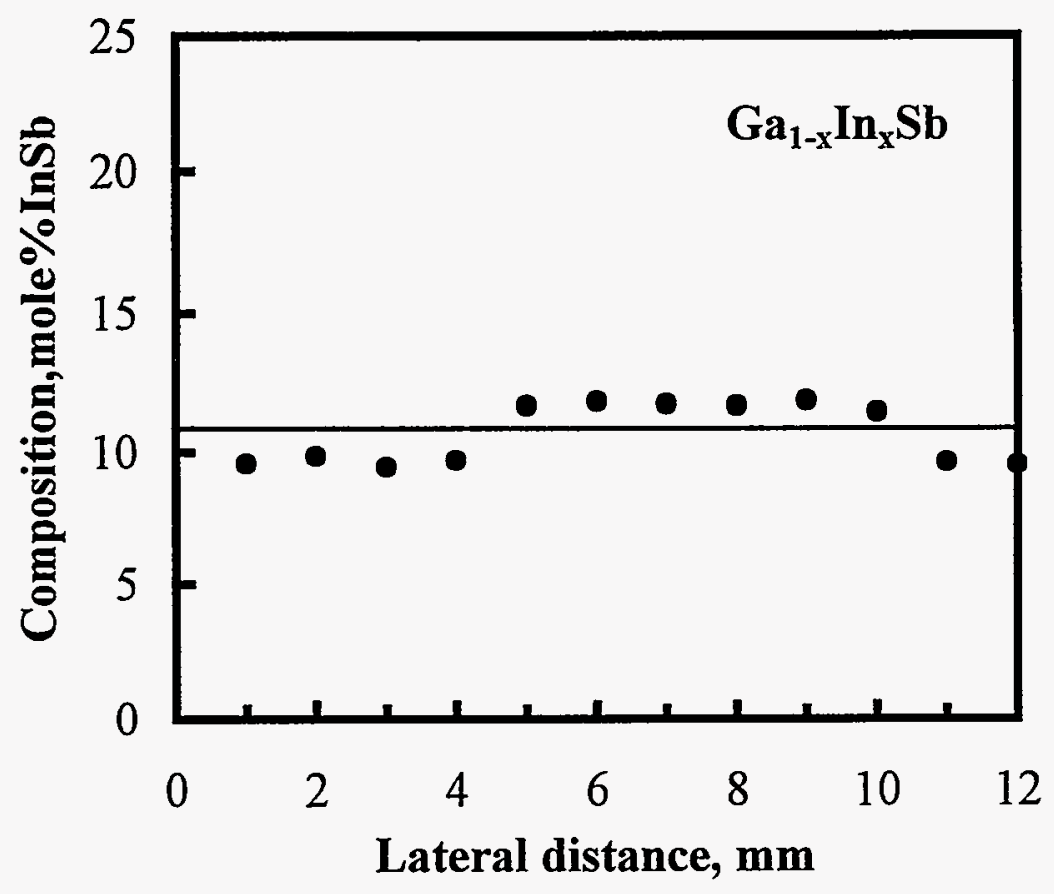

(b)

Figure 2.6 Results of experiment 4 : (a) axial and (b) lateral composition profiles. 


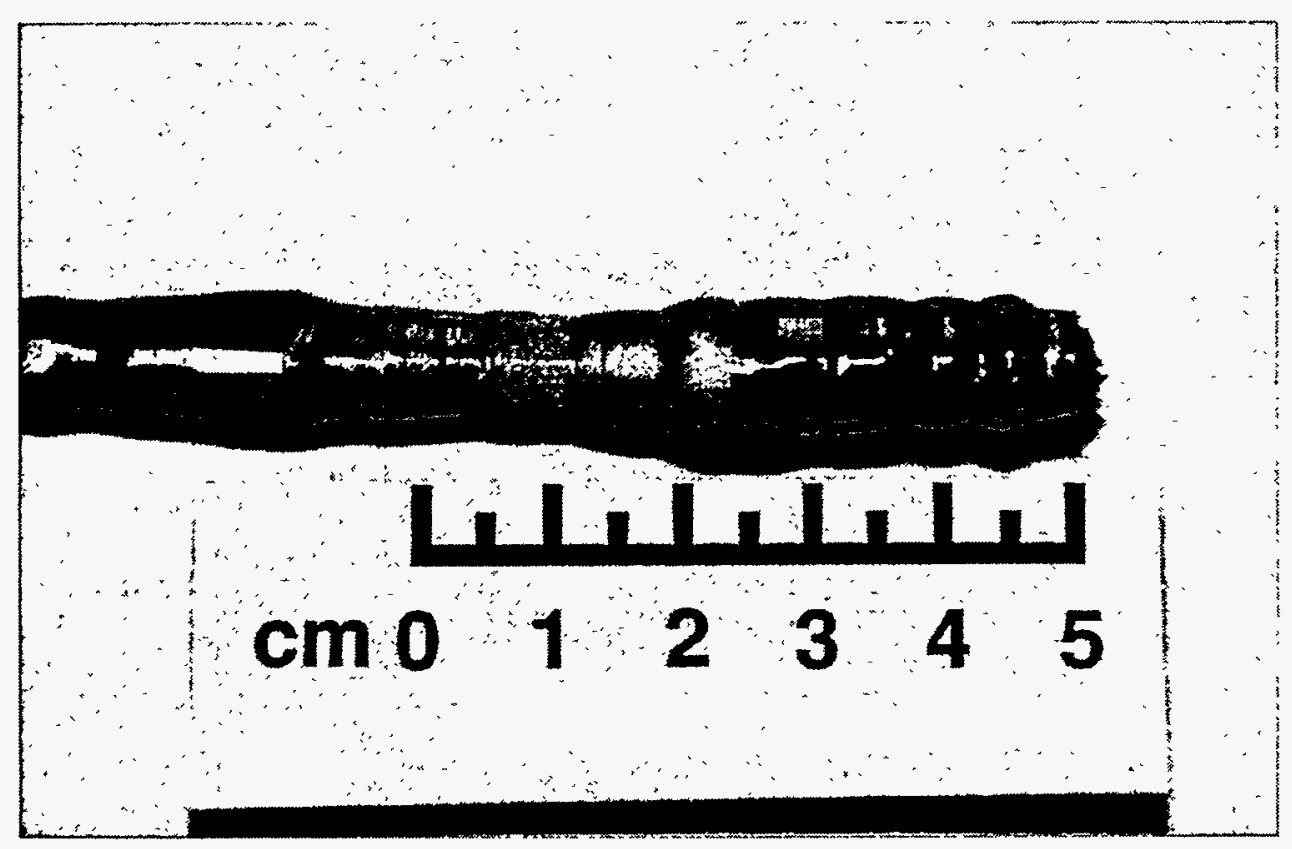

Figure $2.7 \mathrm{Ga}_{1-x} \mathrm{In}_{\mathrm{x}} \mathrm{Sb}$ single crystal grown in experiment 5 . 


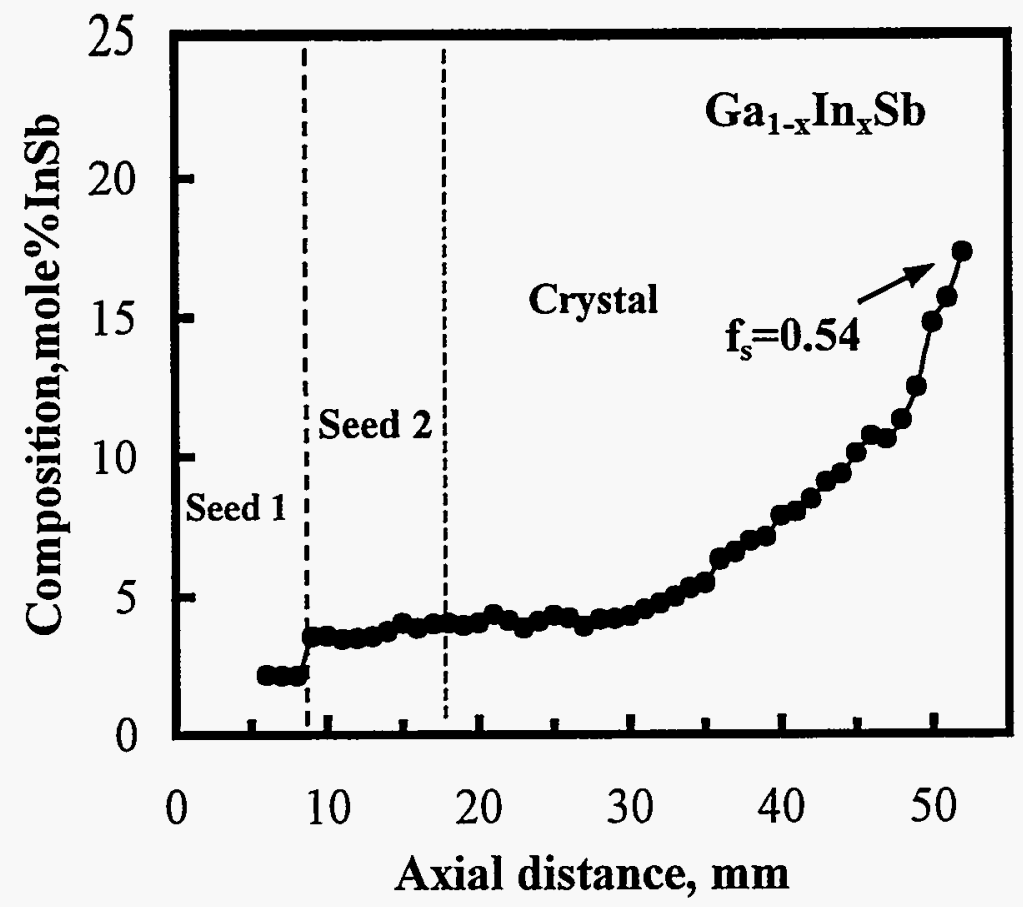

(a)

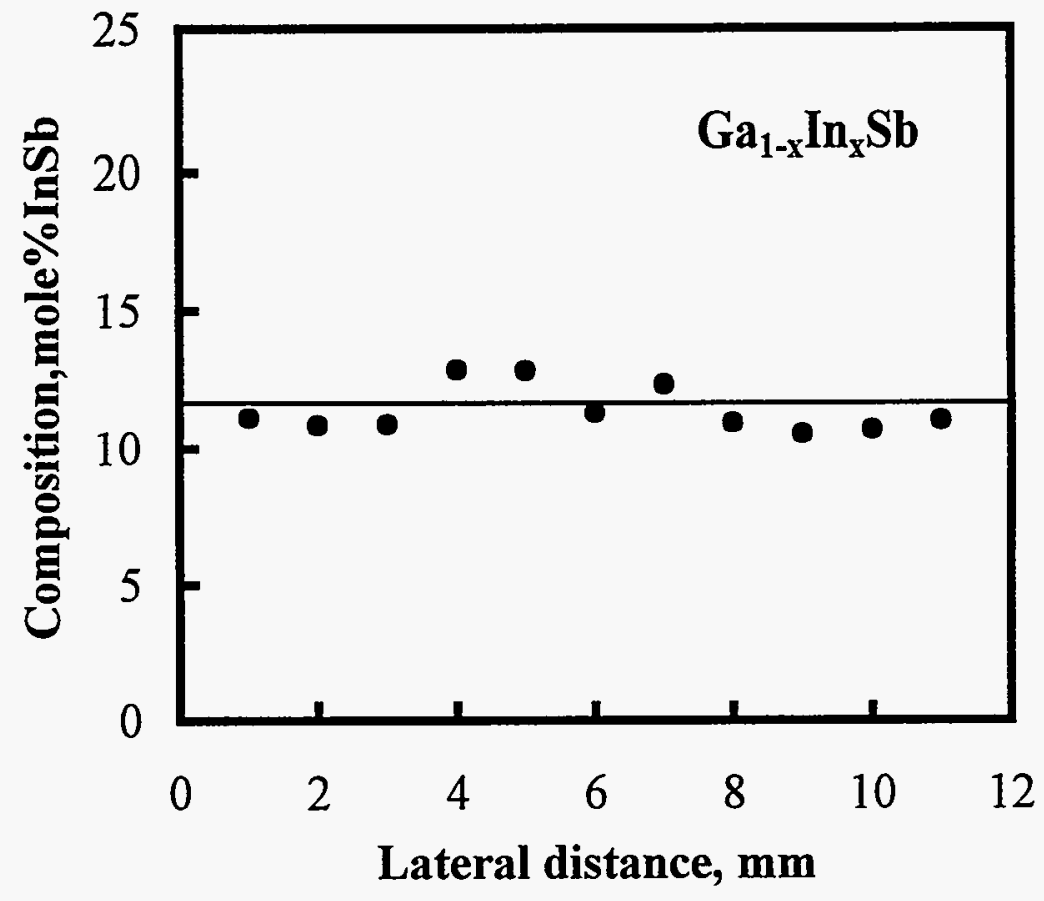

(b)

Figure 2.8 Results of experiment 5 : (a) axial and (b) lateral composition profiles. 


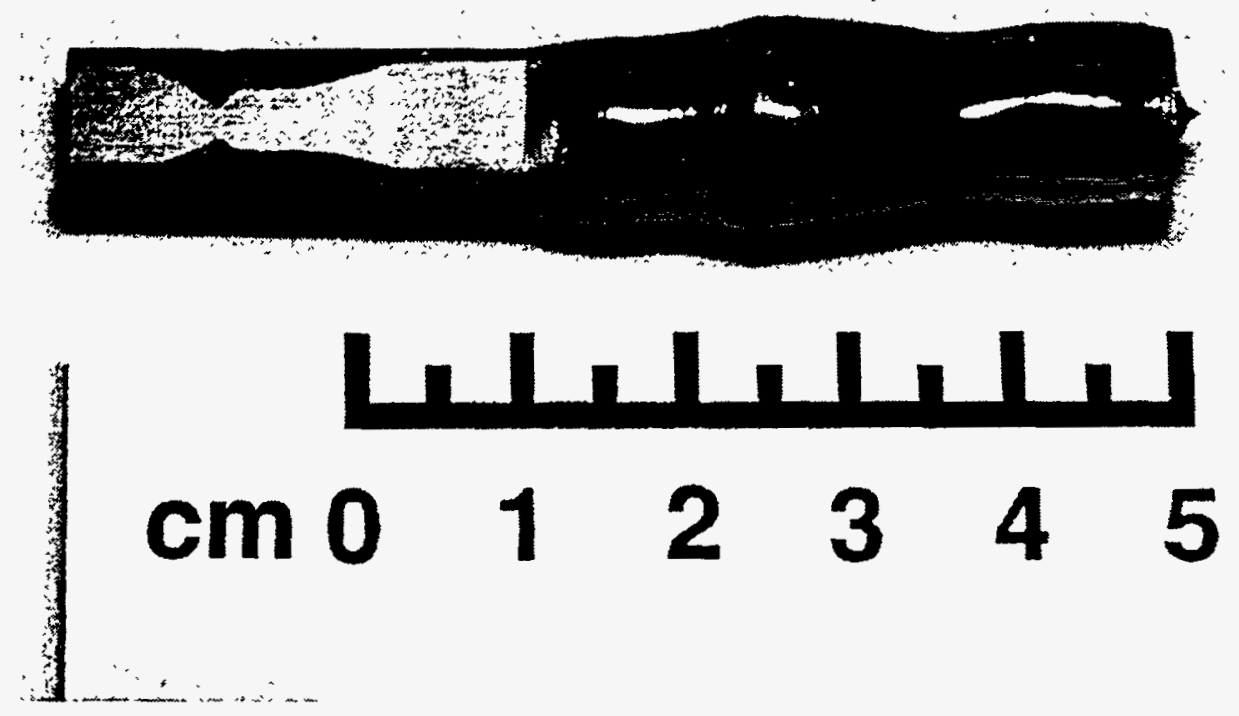

Figure $2.9 \mathrm{Ga}_{1-x} \mathrm{In}_{\mathrm{x}} \mathrm{Sb}$ single crystal grown in experiment 6 . 


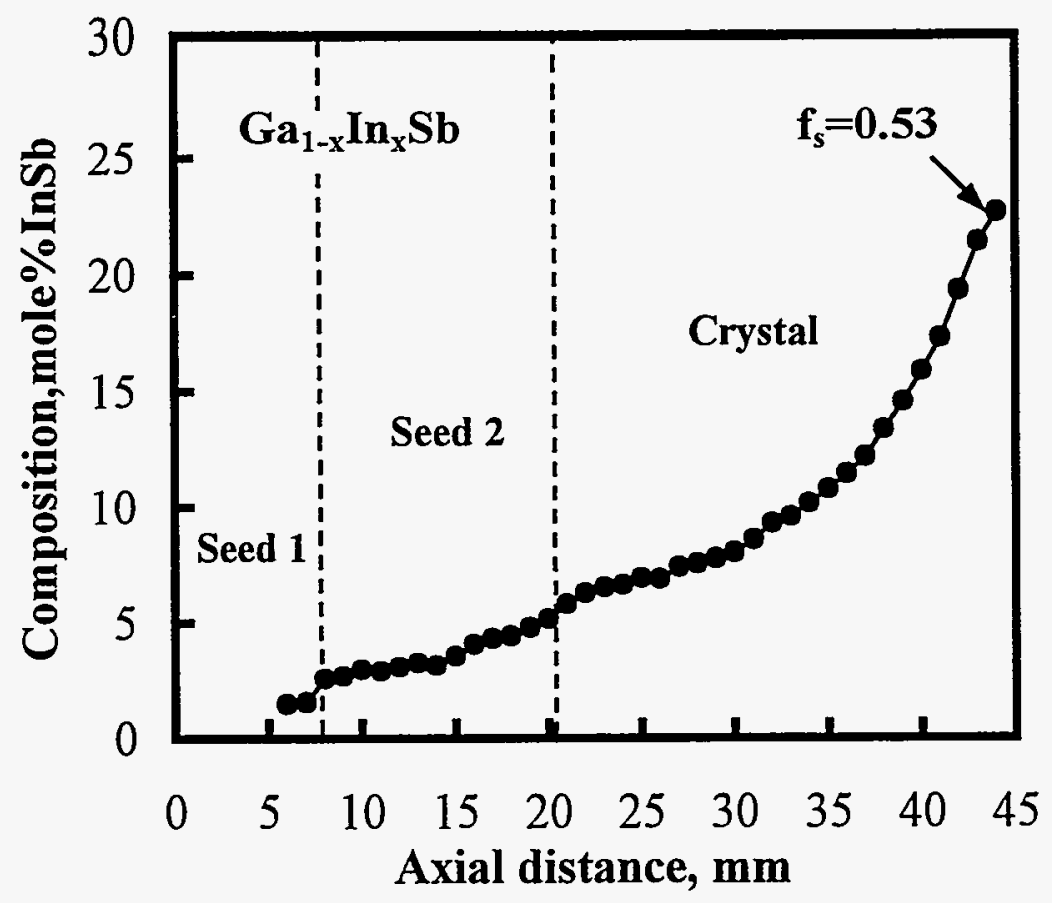

(a)

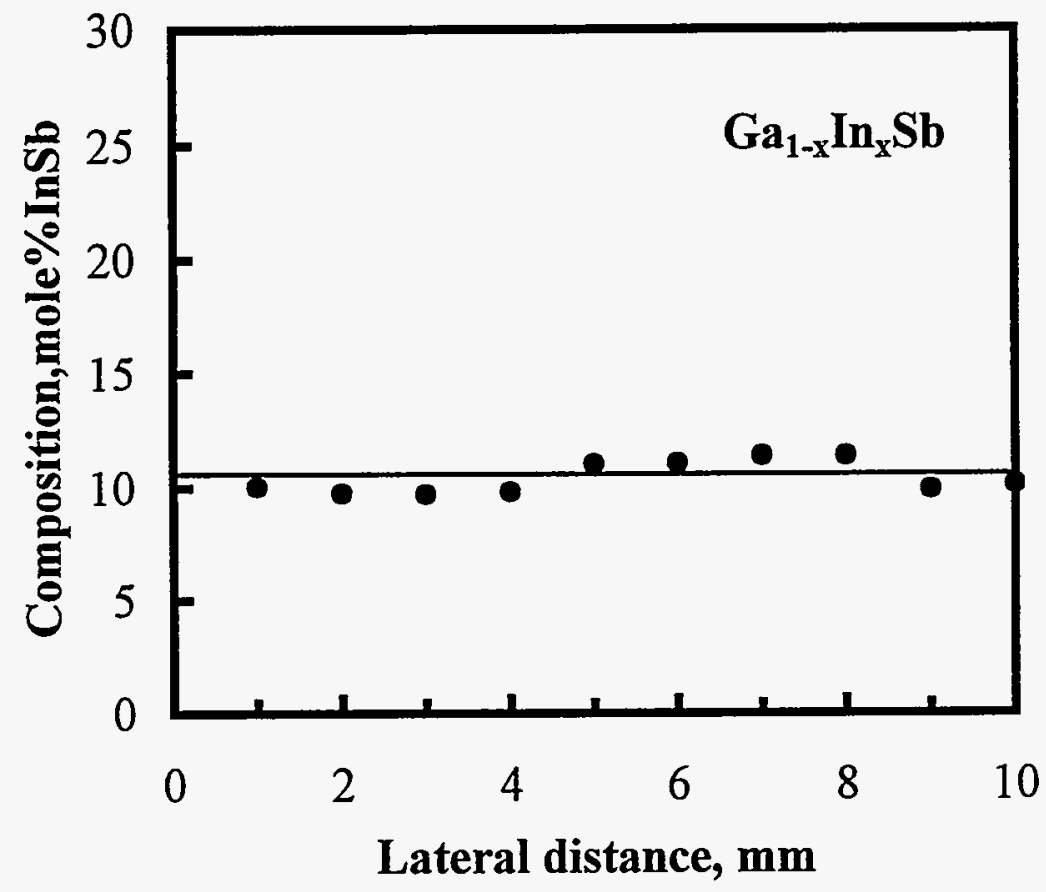

(b)

Figure 2.10 Results of experiment 6 : (a) axial and (b) lateral composition profiles. 


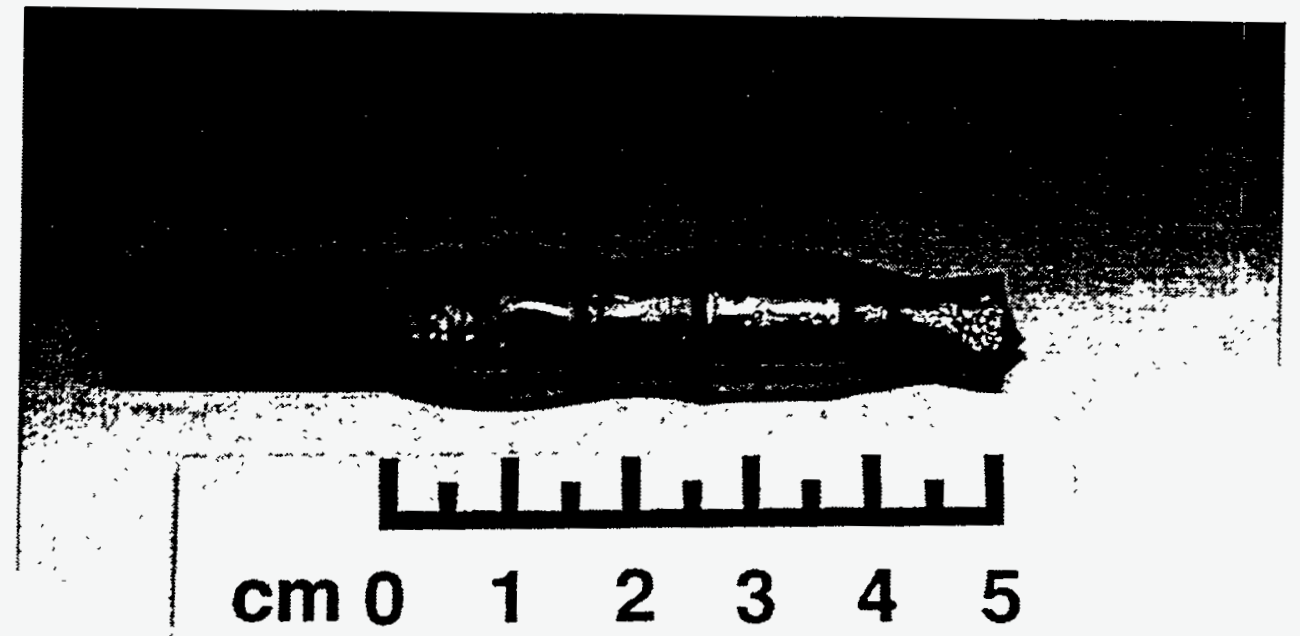

Figure $2.11 \mathrm{Ga}_{1-x} \mathrm{In}_{\mathrm{x}} \mathrm{Sb}$ crystal grown in experiment 7. 


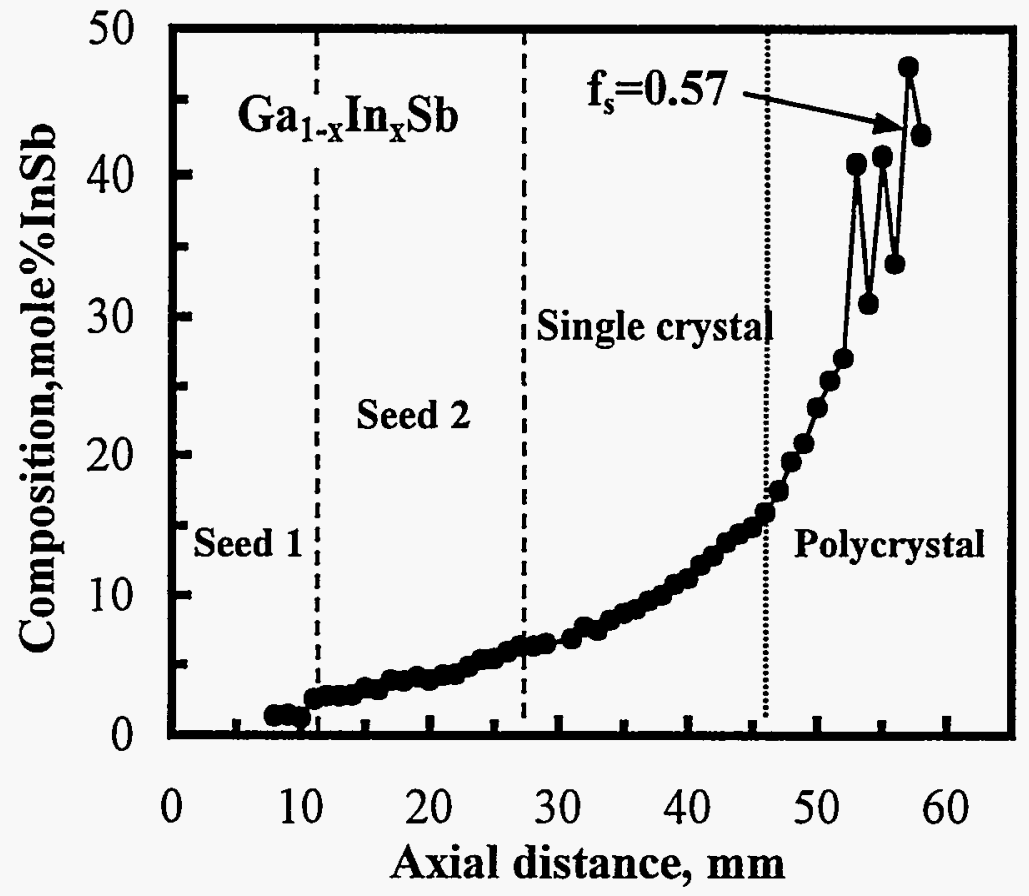

(a)

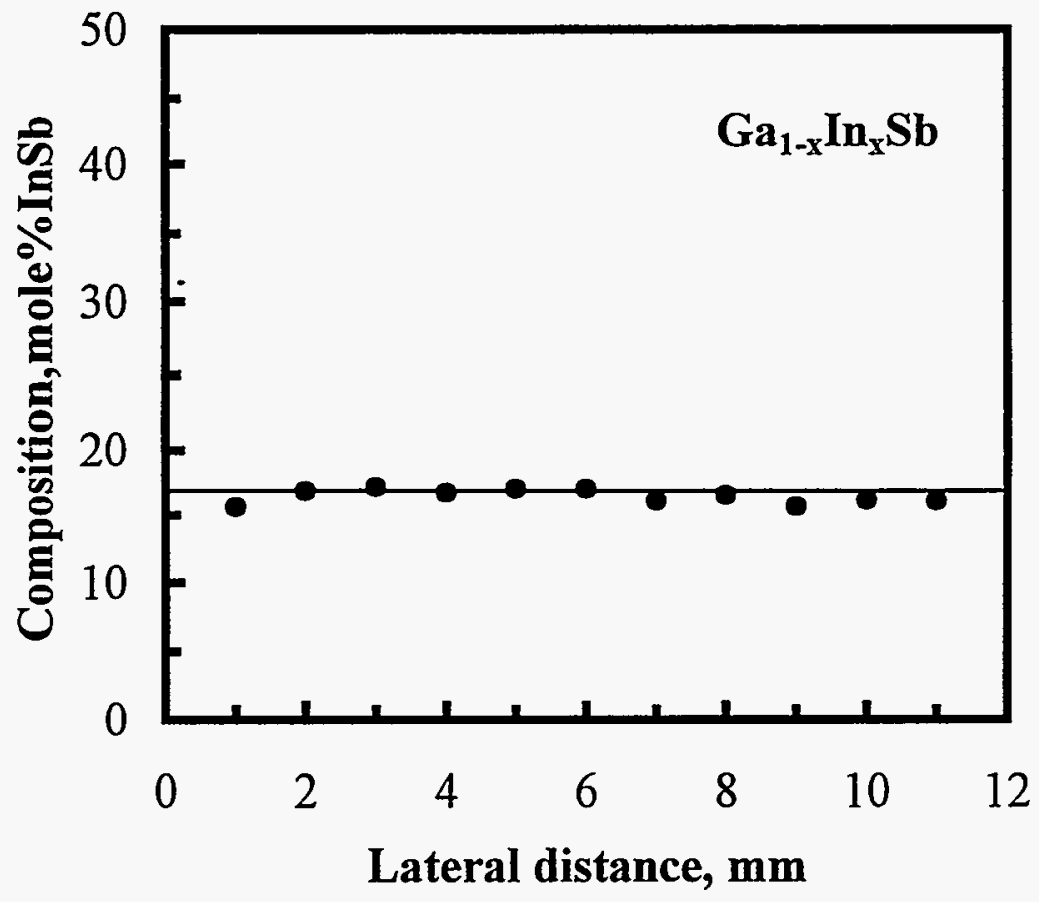

(b)

Figure 2.12 Results of experiment 7 : (a) axial and (b) lateral composition profiles. 


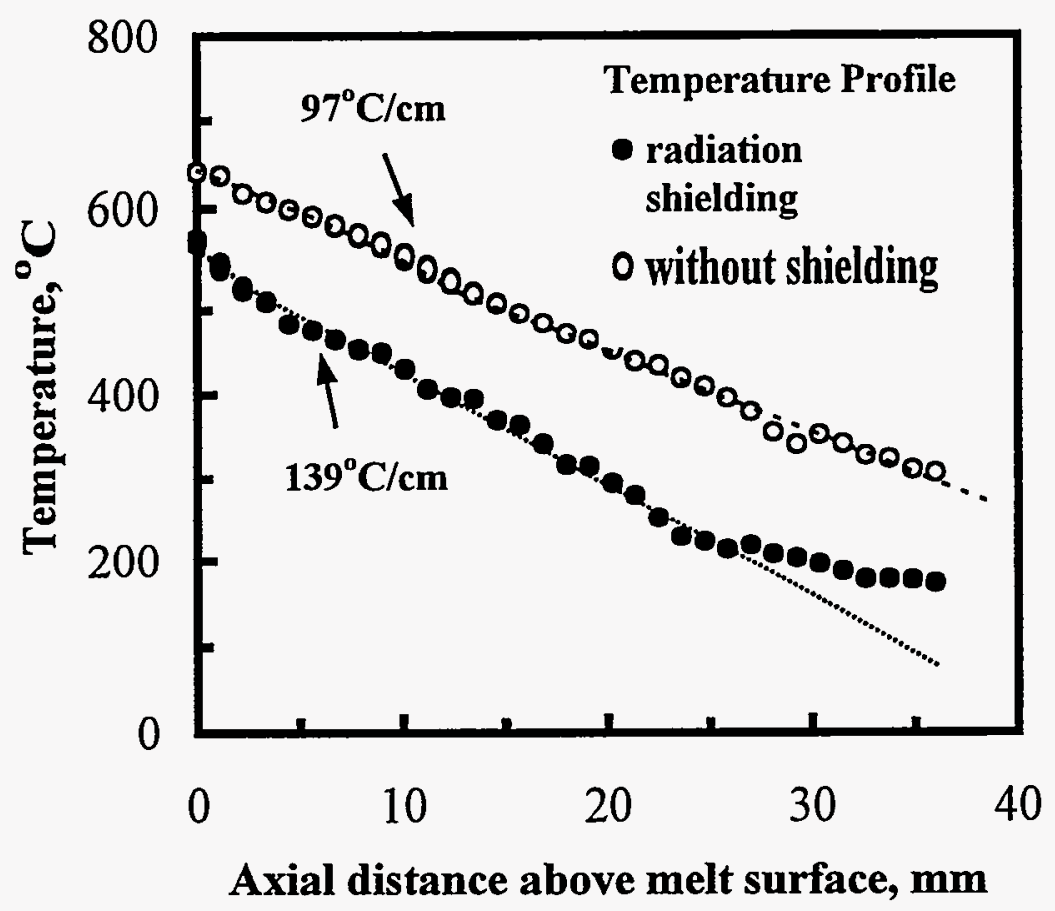

Figure 2.13 Axial temperature profiles above the melt surface. 


\section{GROWTH OF Ga $a_{1-x} I_{x} S b$ BY FLOATING-CRUCIBLE CZOCHRALSKI}

\subsection{Introduction}

In a recent study on Czochralski growth of $\mathrm{Ga}_{1-x} \mathrm{In}_{x} \mathrm{Sb}$, it was observed that severe segregation could occur ${ }^{(1)}$. For example, the InSb content increased from 4 mole $\%$ at the starting end of the single crystal to $23 \mathrm{~mole} \%$ at the finishing end.

In another recent study on Czochralski growth of Cd-doped InSb, Cd segregation was reduced very effectively by pulling the crystal from a melt in a floating crucible, which was replenished by a melt of a different composition through a spiral tube at the bottom of the floating crucible ${ }^{(2)}$. The tube was designed to be long enough to suppress $\mathrm{Cd}$ back diffusion, but wide enough to let the replenishing melt pass through (2).

The purpose of the present study is to determine how this floating-crucible technique behaves when it is applied to reduce segregation in Czochralski growth of $\mathrm{Ga}_{1-\mathrm{x}} \mathrm{In}_{\mathrm{x}} \mathrm{Sb}$

\subsection{Experimental procedure}

A transparent furnace was used for the crystal growth ${ }^{(1)}$, as shown in Fig.3.1. It consisted of a quartz tube $4.7 \mathrm{~cm}$ ID as the chamber, a Kanthal wire wound around a quartz tube as the heater and a gold-coated quartz tube as the heat shield.

The chamber was pumped to below $1 \times 10^{-3}$ torr and then purged with $5 \mathrm{~N}$ hydrogen. After repeating this several times, hydrogen purging was maintained at a 
$75 \mathrm{~cm}^{3} / \mathrm{min}$ rate and $1.2 \mathrm{psi}$ overpressure throughout crystal growth.

The top of the heater assembly was first positioned around the outer crucible so that the charge in it could melt before that in the floating crucible. After the replenishing melt entered the floating crucible, the heater assembly was raised to melt the charge in the floating crucible. After seeding the melt in the floating crucible was held for a period of three hours to homogenize before pulling started.

The composition profiles in the resultant crystals were measured by electron probe microanalysis (EPMA, WDS). Two different alloys were studied: $\mathrm{Ga}_{1-x} \mathrm{In}_{\mathrm{x}} \mathrm{Sb}$ and $\mathrm{Bi}_{1-x} \mathrm{Sb}_{x}$.

(a) $\mathrm{Ga}_{1-x} \mathbf{I n} \mathbf{x} \mathbf{S b}$

The quartz outer crucible was $3.5 \mathrm{~cm}$ ID. The quartz floating crucible, as in our previous study ${ }^{(2)}$, had a $0.4 \mathrm{~cm}$ ID and $10 \mathrm{~cm}$ long spiral tube at the bottom. A stainless steel ring, supported by three quartz arms, kept the floating crucible immersed in the replenishing melt. Two different types of floating crucibles were used: (1) the single-wall type, Fig.3.2a, was $2.8 \mathrm{~cm}$ ID by $3.2 \mathrm{~cm} \mathrm{OD}$; and (2) the double-wall type, Fig.3.2b, had an additional inner wall of $2.3 \mathrm{~cm}$ ID by $2.6 \mathrm{~cm}$ OD.

GaSb synthesized from $₫ \mathrm{~N} \mathrm{Ga}$ and $\mathrm{Sb}$, while $5 \mathrm{~N} \mathrm{InSb}$ of the desired ratio were placed in the outer crucible, and $5 \mathrm{~N}$ InSb of a predetermined quantity was placed in the floating crucible. Crystal growth was carried out in the [111]B direction with a pulling speed of $2 \mathrm{~mm} / \mathrm{hr}$ and a rotation speed of $60 \mathrm{rpm}$. 


\section{(b) $\mathrm{Bi}_{1-\mathbf{x}} \mathbf{S b}_{\mathbf{x}}$}

Two experiments were also carried out with the $\mathrm{Bi}_{1-\mathrm{x}} \mathrm{Sb}_{\mathrm{x}}$ alloy as a model material. A Pyrex crucible $3.4 \mathrm{~cm}$ ID was used as the main crucible. The floating crucible consisted of a $3.2 \mathrm{~cm}$ OD crucible and a $0.5 \mathrm{~cm}$ OD tube at the bottom that formed a spiral passageway about $13 \mathrm{~cm}$ long and $0.34 \mathrm{~cm}$ ID. Three inverse-L-shape arms were used to support the stainless steel weight. The precast ingot in the floating crucible was about $65 \mathrm{~g}$ and its $\mathrm{Sb}$ concentration was predetermined as 0.85 at\%. The precast ingot in the main crucible was about $160 \mathrm{~g}$ and its $\mathrm{Sb}$ concentration was predetermined as 4.2 at $\% . \mathrm{Bi}_{1-x} \mathrm{Sb}_{x}$ ingots were prepared from $5 \mathrm{~N}$ Bi and $6 \mathrm{~N} \mathrm{Sb}$, with rigorous stirring and subsequent rapid cooling by water to enhance macroscopic homogeneity. The ingots were cleaned by grinding, acid etching, and water rinsing. The pulling speed was $1.25 \mathrm{~mm} / \mathrm{hr}$ and the rotation speed was $30 \mathrm{rpm}$.

As soon as the crystal growth was completed, the heater was turned off to let the melts solidify quickly without any mechanical disturbance to cause mixing. The resultant ingots were separated, remelted, and stirred thoroughly before a small sample was removed and dissolved in acid for composition measurement by ICP-MS (Inductively coupled plasma-mass spectrometry). EPMA was not used because the ingots were not microscopically homogeneous; microsegregation developed during dendritic solidification. The compositions of the ingots in the crucibles before crystal growth were measured by ICP-MS in the same manner. 


\subsection{Results and discussion}

\section{(a) $\mathrm{Ga}_{1-\mathrm{x}} \mathbf{I} \mathbf{n}_{\mathbf{x}} \mathrm{Sb}$}

To test the ability of the melt to pass through the spiral tube and enter the floating crucible, experiments were first carried out with pure GaSb. Figure 3.3 shows a pure GaSb crystal grown in the floating crucible.

The $\mathrm{Bi}-\mathrm{Sb}{ }^{(4)}$ and InSb-GaSb ${ }^{(3)}$ phase diagrams are shown in Figs. 1.2 and 1.3, respectively. The molecular weight and the density of the melt are $191.47 \mathrm{~g} / \mathrm{mole}$ and $6.03 \mathrm{~g} / \mathrm{cm}^{3}$ for $\mathrm{GaSb}$, respectively; and $236.57 \mathrm{~g} / \mathrm{mole}$, and $6.43 \mathrm{~g} / \mathrm{cm}^{3}$ for InSb, respectively ${ }^{(5,6)}$.

Figure 3.4 shows the composition profiles in a crystal that was targeted at $1 \mathrm{~mole} \%$ InSb. This crystal was $38 \mathrm{~mm}$ long and $11 \mathrm{~mm}$ in diameter. The charge in the outer crucible consisted of $194 \mathrm{~g} \mathrm{GaSb}$ and $2.42 \mathrm{~g} \mathrm{InSb}$, which corresponds to $1 \mathrm{~mole} \%$ InSb. The charge in the single-wall floating crucible was $6.43 \mathrm{~g} \mathrm{InSb}$. The melt in the floating crucible was estimated (from the lower bound of the Sb vapor deposition on the crucible inner wall) to be about $2 \mathrm{~cm}$ deep. This, based on the molecular weights and densities of $\mathrm{GaSb}$ and $\mathrm{InSb}$, corresponds to a composition of about $8.65 \mathrm{~mole} \%$ InSb. Since the effective segregation coefficient measured under similar crystal growth conditions ${ }^{(7)}$ is about 0.12 at this melt composition, the crystal composition is expected to be $1 \mathrm{~mole} \%$ InSb $(8.65 \%$ x $0.12=1.0 \%)$. As shown in Fig. $3.4 \mathrm{a}$, the composition of the resultant crystal is about $1 \mathrm{~mole} \% \mathrm{InSb}$ and uniform. The radial composition profile is measured at $20 \mathrm{~mm}$ from the seed/crystal interface. 
Figure 3.5 shows the composition profiles in a crystal that was targeted at 4 mole $\%$ InSb. This crystal was $40 \mathrm{~mm}$ long and $10 \mathrm{~mm}$ in diameter. The double-wall floating crucible was used to increase the temperature difference between the growth and replenishing melts. From the phase diagram in Fig. 1.3, the difference between the liquidus temperatures of the growth and replenishing melts increases significantly with increasing InSb concentration.

The charge in the outer crucible consisted of $200 \mathrm{~g}$ of $4 \mathrm{~mole} \% \mathrm{InSb}$ alloy, while the charge in the double-wall floating crucible was $11.25 \mathrm{~g}$ InSb. The melt in the floating crucible was estimated to be about $2 \mathrm{~cm}$ deep, which corresponds to a composition of about 27.2 mole\% InSb. An effective segregation coefficient measured under similar crystal growth conditions ${ }^{(7)}$ is about 0.14 at this melt composition, which is in very good agreement with the results of an earlier study ${ }^{(8)}$. As such, the crystal composition is expected to be about 4 mole $\%$ InSb $(27.2 \% \mathrm{x}$ $0.14=3.8 \%$ ). As shown in Fig. 3.5a, however, the composition of the resultant crystal is slightly below 2 mole\% InSb, i.e., only about one-half of the targeted value. In order to understand this problem, experiments were conducted using a model material of $\mathrm{Bi}_{1-x} \mathrm{Sb}_{\mathrm{x}}$.

\section{(b) $\mathbf{B i}_{1-x} \mathbf{S b}_{\mathbf{x}}$}

Figures 3.6a and 3.6b show the compositions of the charges in the floating and outer crucibles before and after crystal growth, respectively. The composition of the charge in the outer crucible changes from 4.2 at $\% \mathrm{Sb}$ before crystal growth to 2.7 at $\%$ 
$\mathrm{Sb}$ afterward. Since the $13 \mathrm{~cm}$ long spiral tube suppresses diffusion between the growth and replenishing melts, this composition change indicates that mixing has occurred between the growth melt and the replenishing melt.

The composition profile in the resultant crystal is shown in Fig. 3.7a. The unexpectedly high $\mathrm{Sb}$ concentration, about 7 at\%, from the very beginning of the crystal suggests that mixing between the melts occurred before pulling started. The radial composition profile shown in Fig. $3.7 \mathrm{~b}$ is taken at about $5 \mathrm{~cm}$ from the starting end of the crystal.

The composition profiles in the crystal grown in a similar experiment are shown in Fig. 3.8. As shown in Fig. 3.8a, the Sb concentration in the crystal jumps abruptly from about 4 to $7 \%$ at $1.5 \mathrm{~cm}$ from the starting end. This suggests that mixing between the growth and replenishing melts did not occur before crystal growth but at some point during crystal growth. The radial composition profile shown in Fig. 3.8b is taken at $6 \mathrm{~cm}$ from the starting end of the crystal.

The density of $\mathrm{Bi}\left(9.8 \mathrm{~g} / \mathrm{cm}^{3}\right)$ is significantly larger than that of $\mathrm{Sb}\left(6.68 \mathrm{~g} / \mathrm{cm}^{3}\right)$. Since the growth melt is richer in $\mathrm{Bi}$ and cooler than the replenishing melt, it is higher in density than the replenishing melt. As such, thermosolutal convection, i.e., convection induced by density gradients caused by temperature and composition gradients, can occur and cause mixing between the melts. The higher the solute concentration the more likely that mixing caused by thermosolutal convection can occur. For segregation control in doped crystals by floating-crucible Czochralski, 
mixing due to thermosolutal convection is not a problem because the dopant is too dilute to affect the melt density significantly. For segregation control in alloy crystals by floating-crucible Czochralski, such mixing can be a problem especially at significant solute concentration levels.

In the experiment targeted at 4 mole $\%$ InSb crystal composition, the growth melt is as much as $23 \%$ InSb higher than the replenishing melt. Since the InSb melt is about $7 \%$ greater in density than $\mathrm{GaSb}$, the density of the growth melt was greater than that of the replenishing melt. In fact, this density difference could have been significant enough to cause mixing between the melts by thermosolutal convection. However, in the experiment targeted at $1 \mathrm{~mole} \%$ InSb crystal composition, the growth melt is only about 8 mole\% InSb higher than the replenishing melt. Perhaps the density difference between the two melts was not high enough to cause mixing.

In Figs. 3.7a and 3.8a the significant Sb concentration drop in the second half of both crystals is due to the decrease in replenishing because the floating crucible stuck to the outer crucible. Thus the floating crucible was not able to lower itself automatically to allow replenishing. When the heater power was low enough to allow crystal growth, the portion of the replenishing melt in the annular space between the two crucibles froze and literally soldered them together. However, when the heater power was raised to free the floating crucible from the outer crucible, the growth melt became too hot for crystal growth. Apparently, the use of the single-wall floating crucible does not provide a significant enough temperature drop from the replenishing 
melt to the growth melt. According to the phase diagram shown in Fig. 1.2, the liquidus temperatures of the melts of 0.85 and 4.2 at\% Sb are about 275 and $290{ }^{\circ} \mathrm{C}$, respectively. It appears that the single-wall floating crucible is not sufficient to produce a $15^{\circ} \mathrm{C}$ temperature difference across the crucible wall. The need to have a thick enough wall for floating-crucible Czochralski has been pointed out recently ${ }^{(9)}$.

\subsection{Conclusions}

A floating-crucible technique effective for segregation reduction in doped crystals may not be as effective in alloy crystals such as $\mathrm{Ga}_{1-x} \mathrm{In}_{\mathbf{x}} \mathrm{Sb}$ as in doped crystal, especially at significantly high InSb concentration levels. The growth of a model alloy $\mathrm{Bi}_{1-x} \mathrm{Sb}_{\mathrm{x}}$ demonstrates that two fundamental issues exist in floating-crucible Czochralski growth of alloyed crystals. First, mixing between the growth and replenishing melts can be induced by thermosolutal convection and render the compositions of the melts; and, hence, the resultant crystal unpredictable. Second, the difference in the liquidus temperatures of the melts can cause the floating crucible to stick to the outer crucible and the crystal to grow without adequate replenishing. These two issues become more significant as the desired solute concentration level of the crystal increases. 


\subsection{References}

1. S. C. Tsaur and S. Kou, J. Crystal Growth, to be submitted.

2. M. H. Lin and S. Kou, J. Crystal Growth 152 (1995) 256.

3. J. P. Garandet, T. Duffar and J. J. Favier, J. Crystal Growth 106 (1990) 426.

4. J. P. Dismukes and W. M. Yim, J. Crystal Growth 22 (1974) 287.

5. A. S. Jordan, J. Crystal growth 71 (1985) 551.

6. S. Nakamura and T. Hibiya, Int. J. Thermophys. 13 (1992) 1061.

7. S. C. Tsaur and S. Kou, unpublished research.

8. K. J. Bachmann, F. A. Thiel, H. Schreiber and J. J. Rubin, J. Electronic Materials $9(1980) 445$.

9. T. F. Ciszek, US Patent 5,047,112, 1991. 


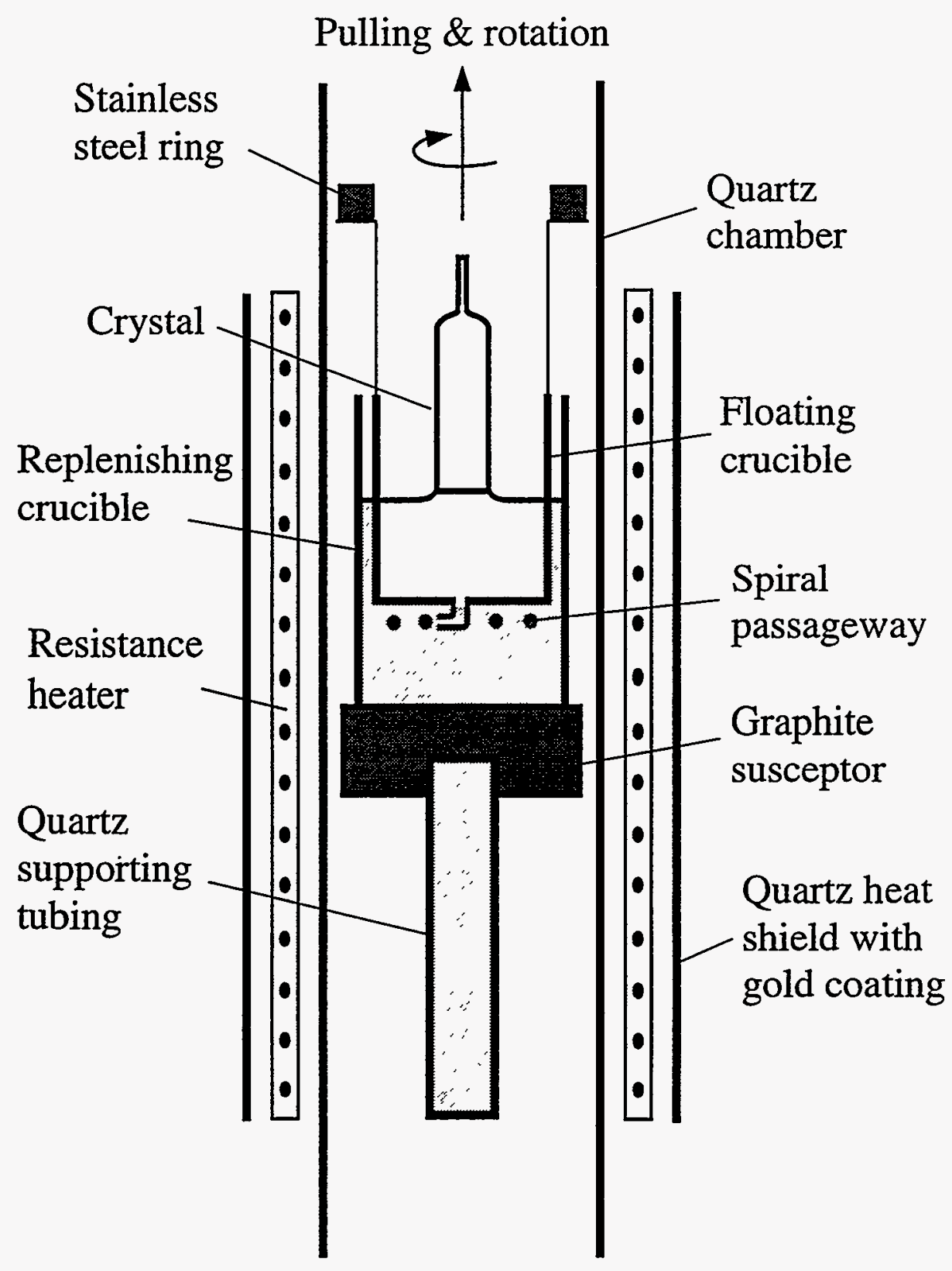

Figure 3.1 Illustration of CZ Pulling with floating-crucible technique. 


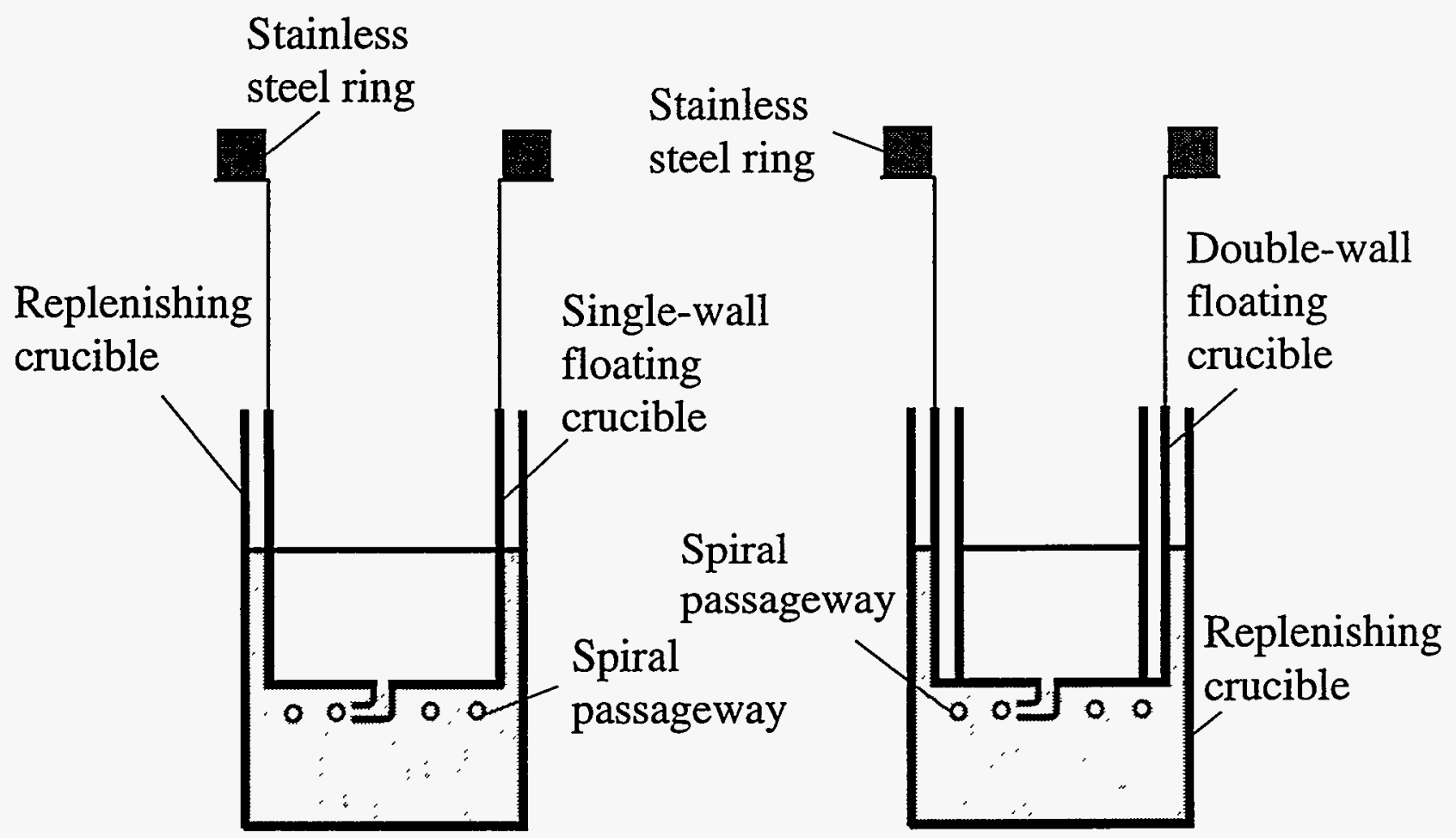

(a)

(b)

Figure 3.2 Floating crucibles: (a) single-wall (b) double-wall. 


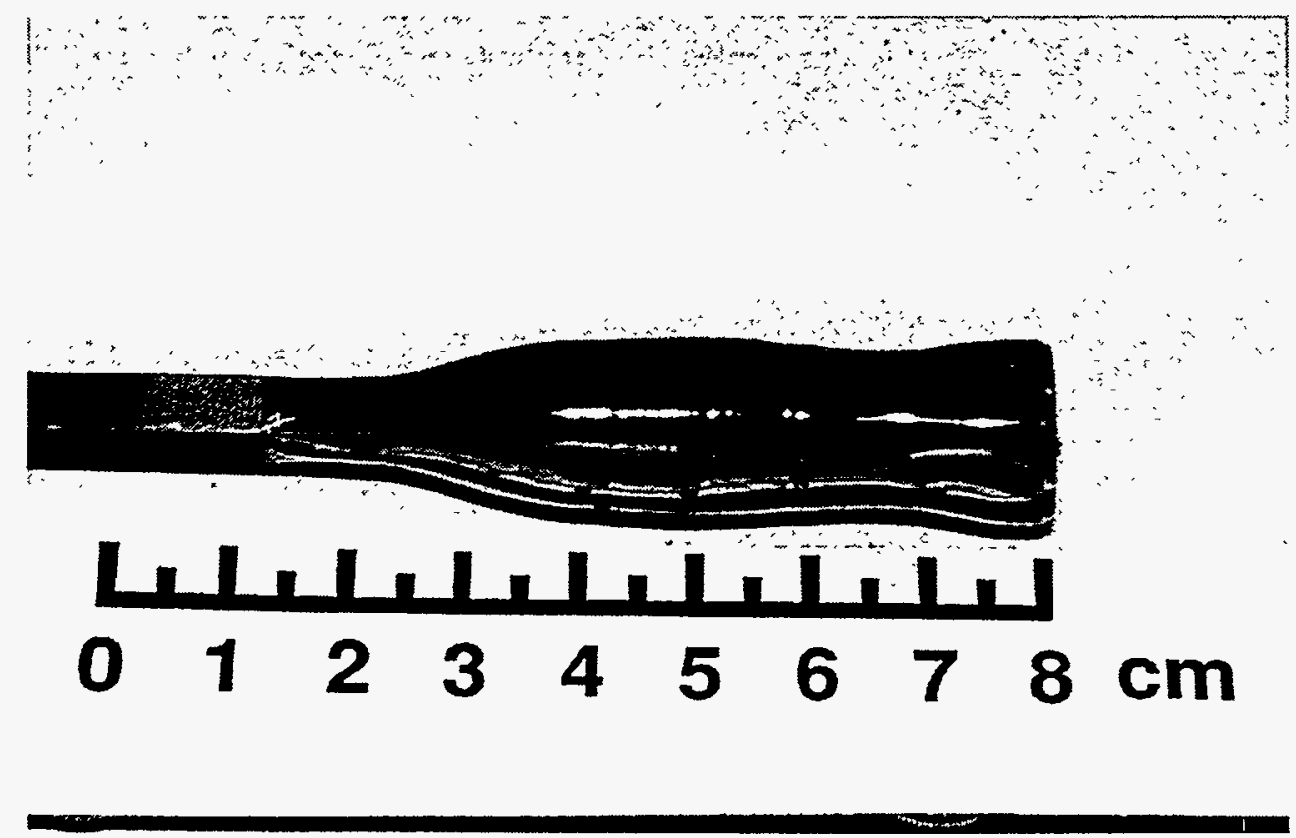

Figure 3.3 A pure GaSb crystal. 


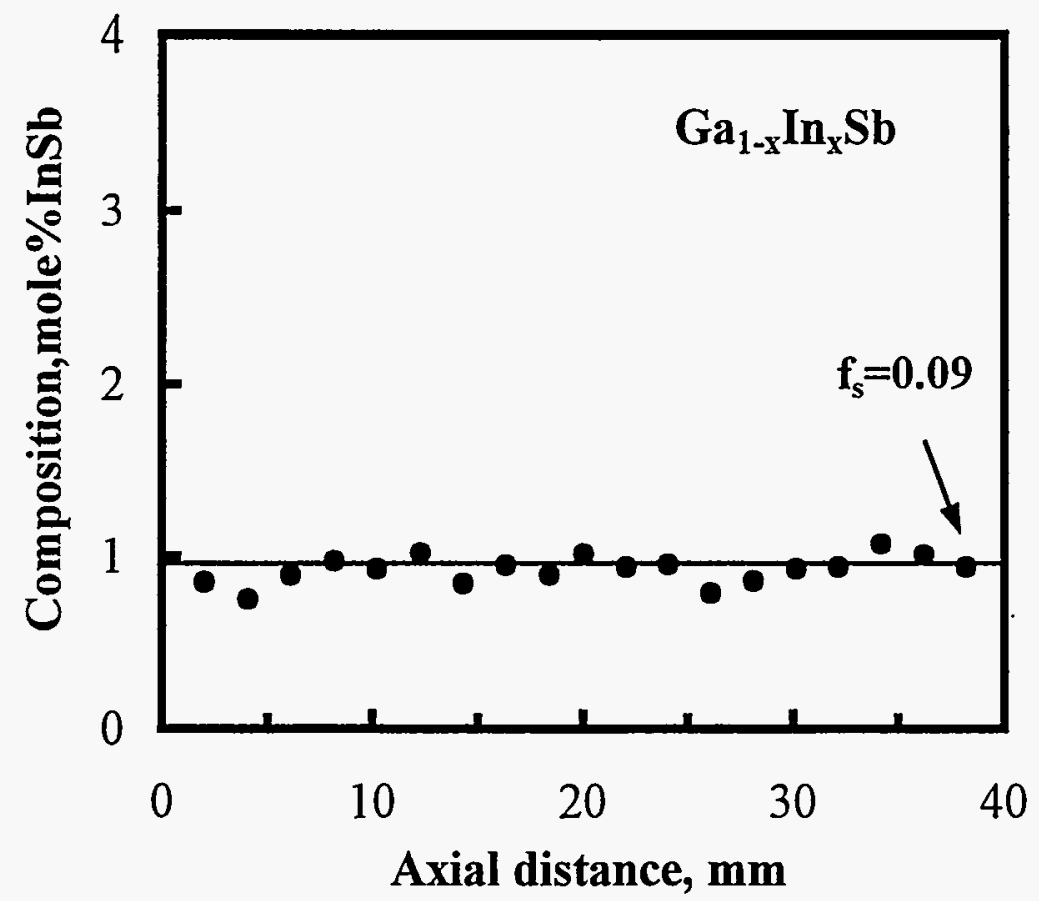

(a)

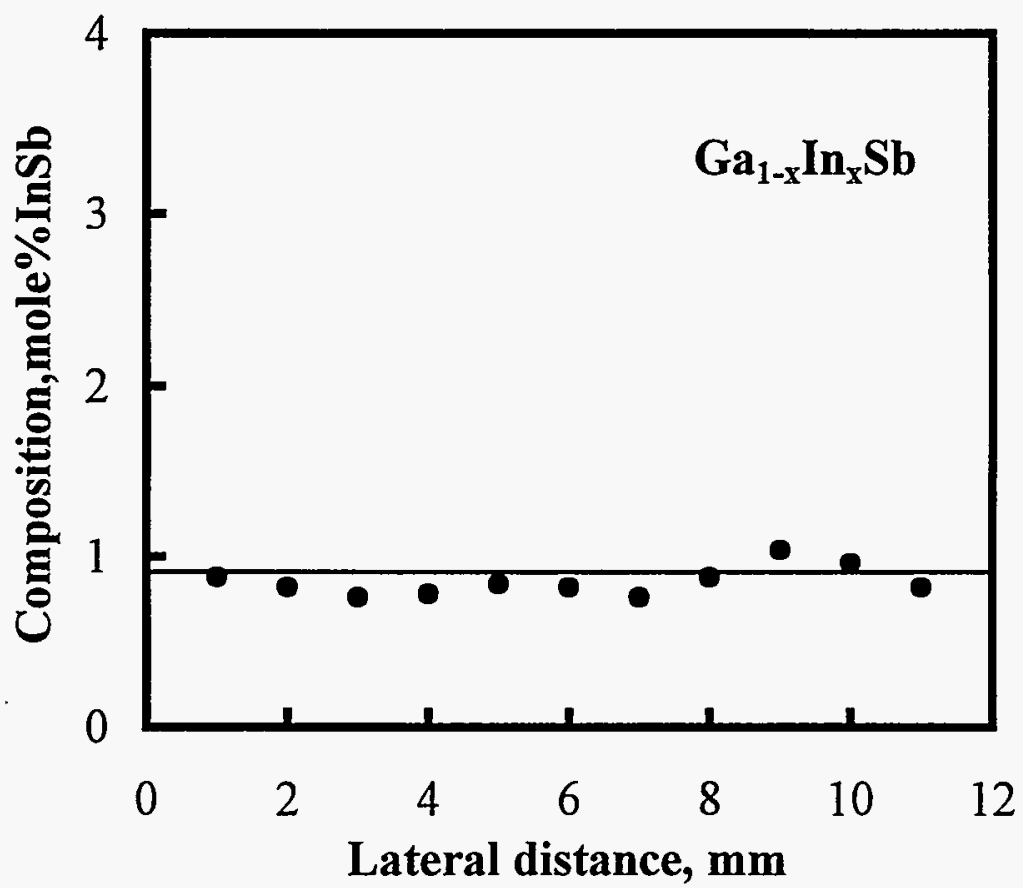

(b)

Figure 3.4 Composition profiles in a $\mathrm{Ga}_{1-\mathrm{x}} \mathrm{In}_{\mathrm{x}} \mathrm{Sb}$ crystal: (a) axial; (b) lateral. 


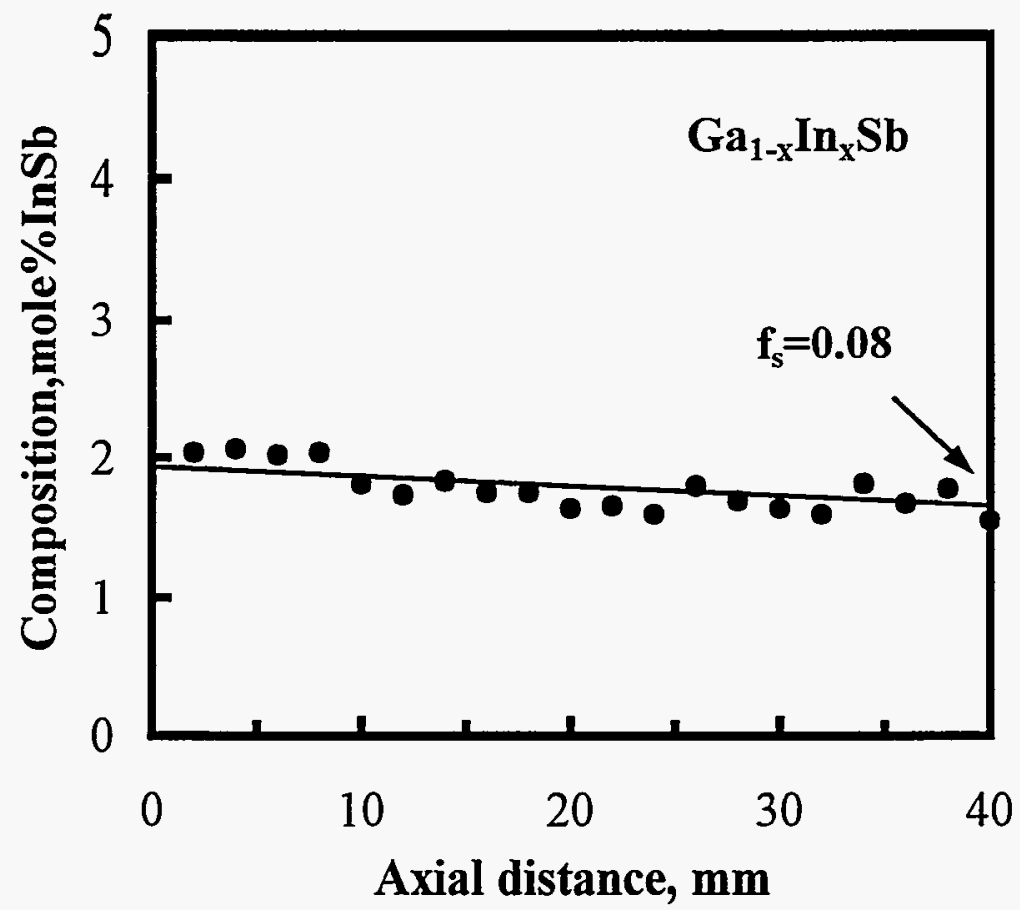

(a)

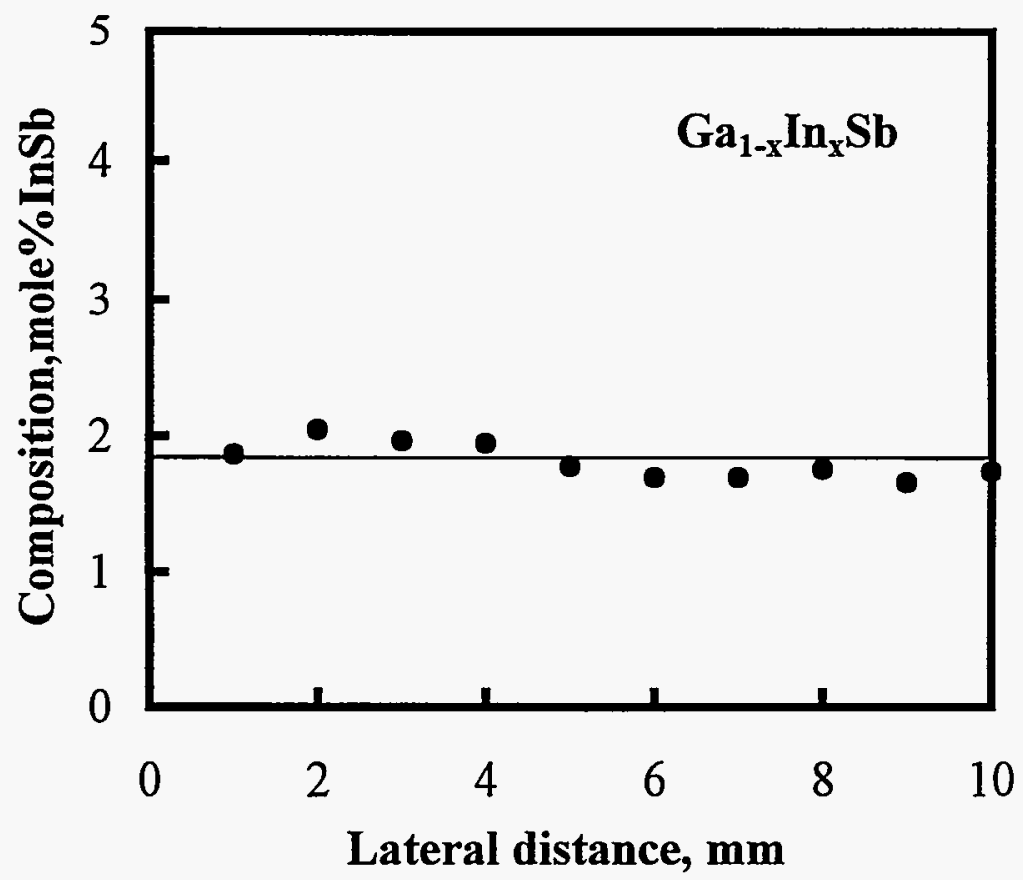

(b)

Figure 3.5 Composition profiles in another $\mathrm{Ga}_{1-x} \mathrm{In}_{\mathrm{x}} \mathrm{Sb}$ crystal: (a) axial; (b) lateral. 


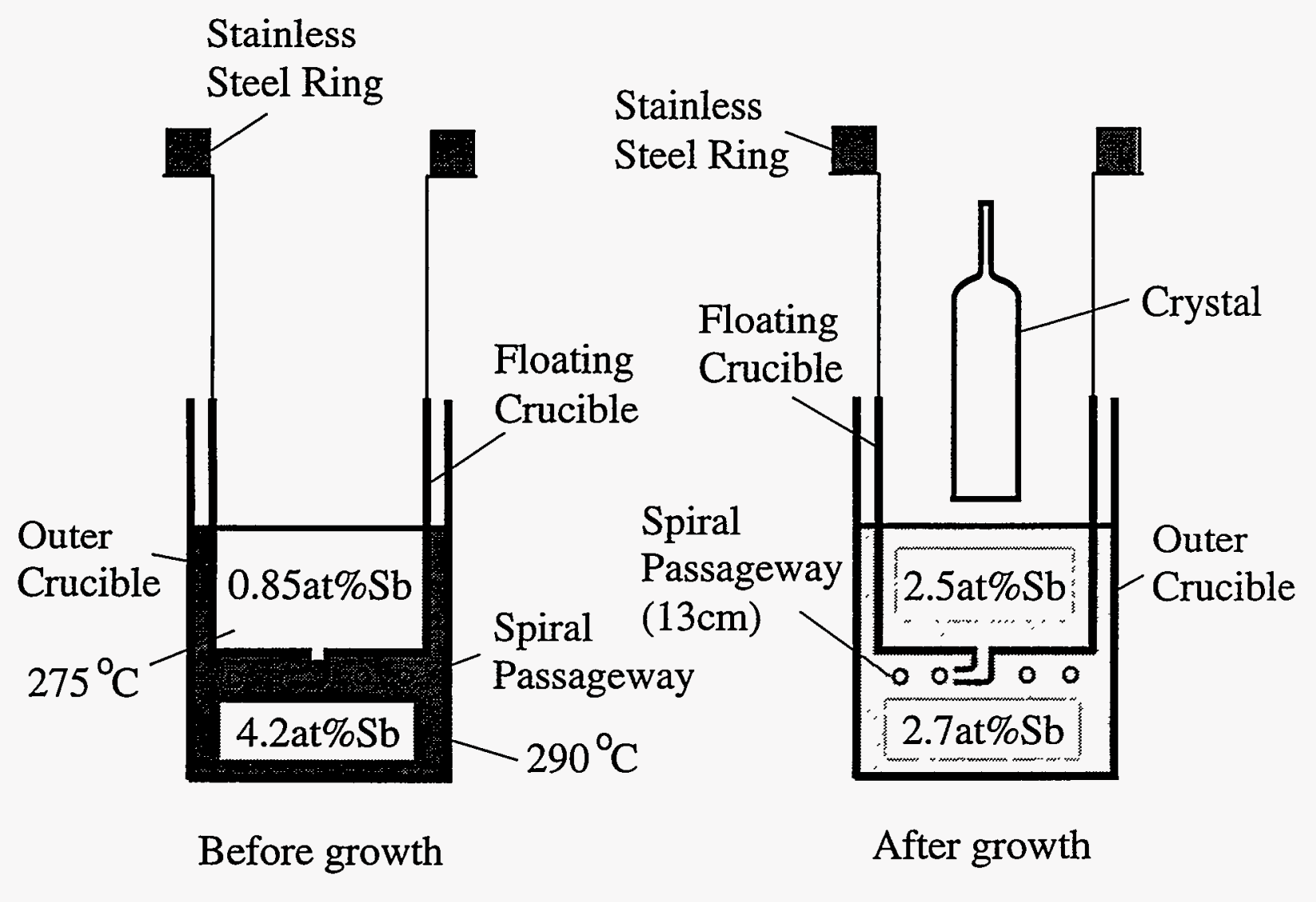

(a)

(b)

Figure 3.6 Composition of Bi-Sb melts: (a) before growth; (b) after growth. 


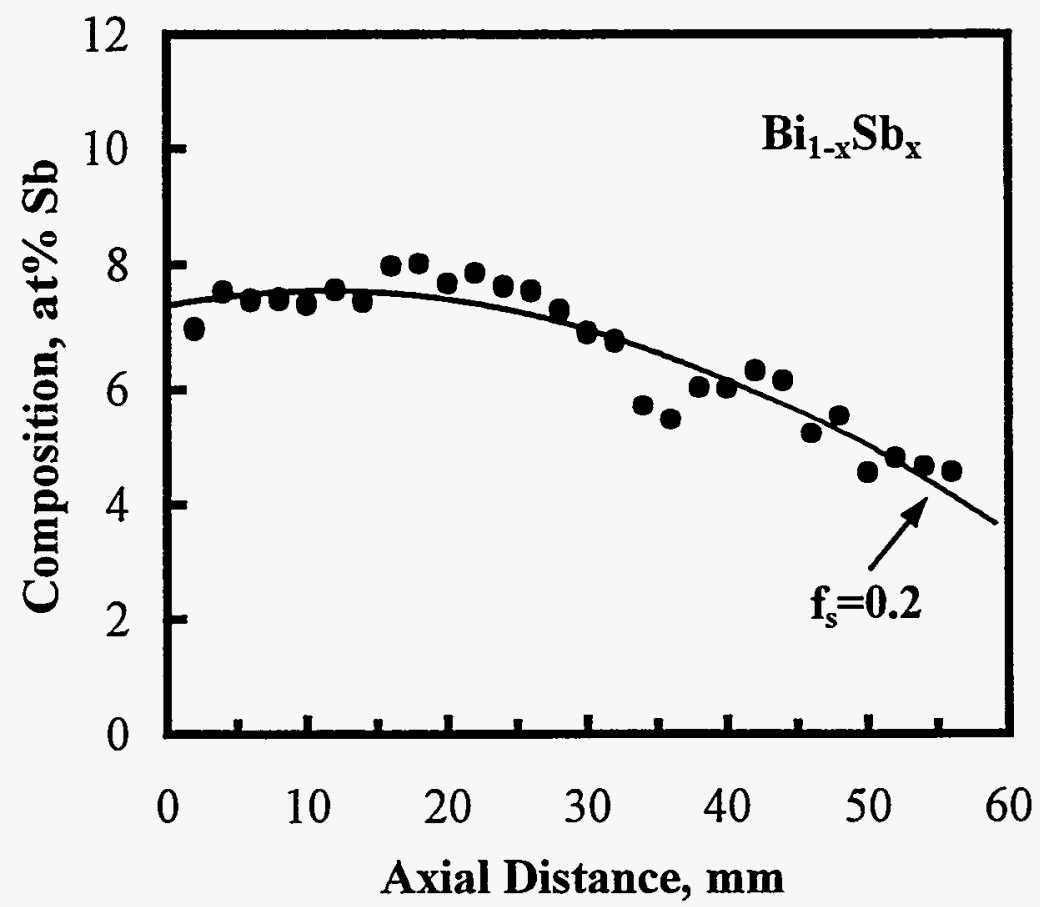

(a)

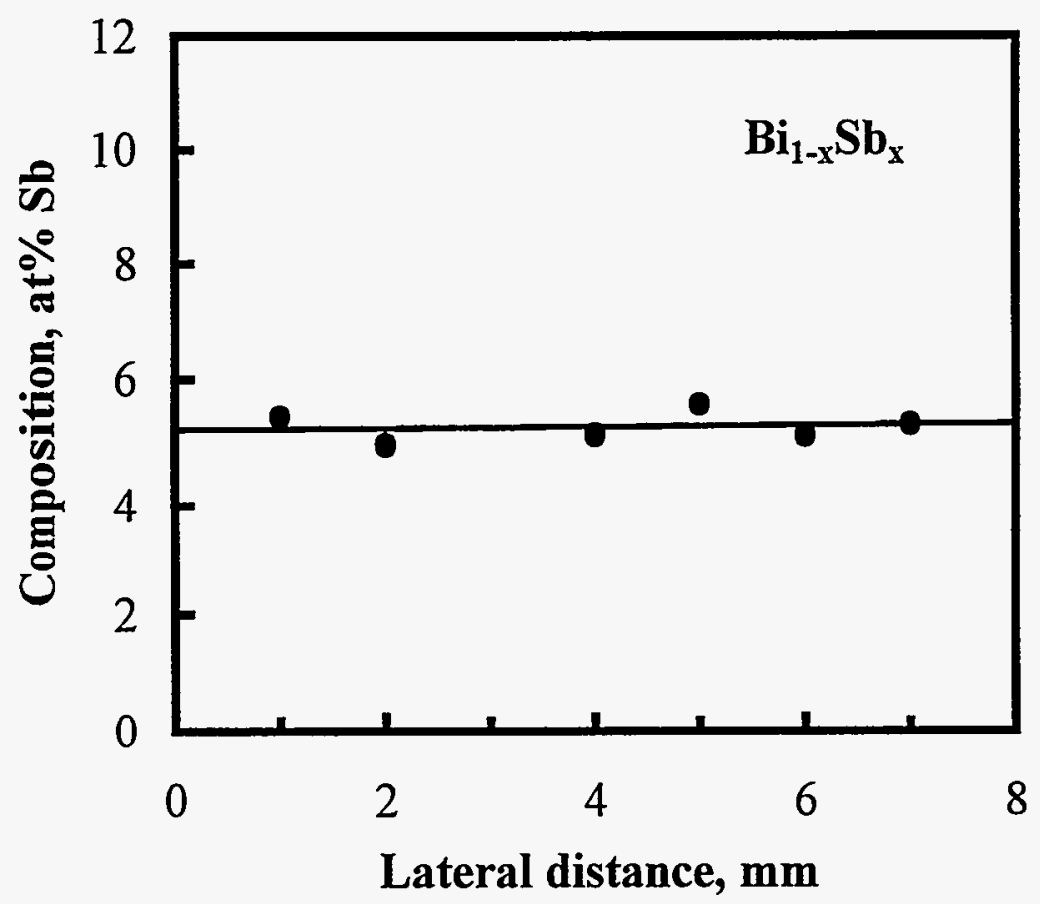

(b)

Figure 3.7 Composition profiles in a $\mathrm{Bi}_{1-x} \mathrm{Sb}_{x}$ crystal : (a) axial; (b) lateral. 


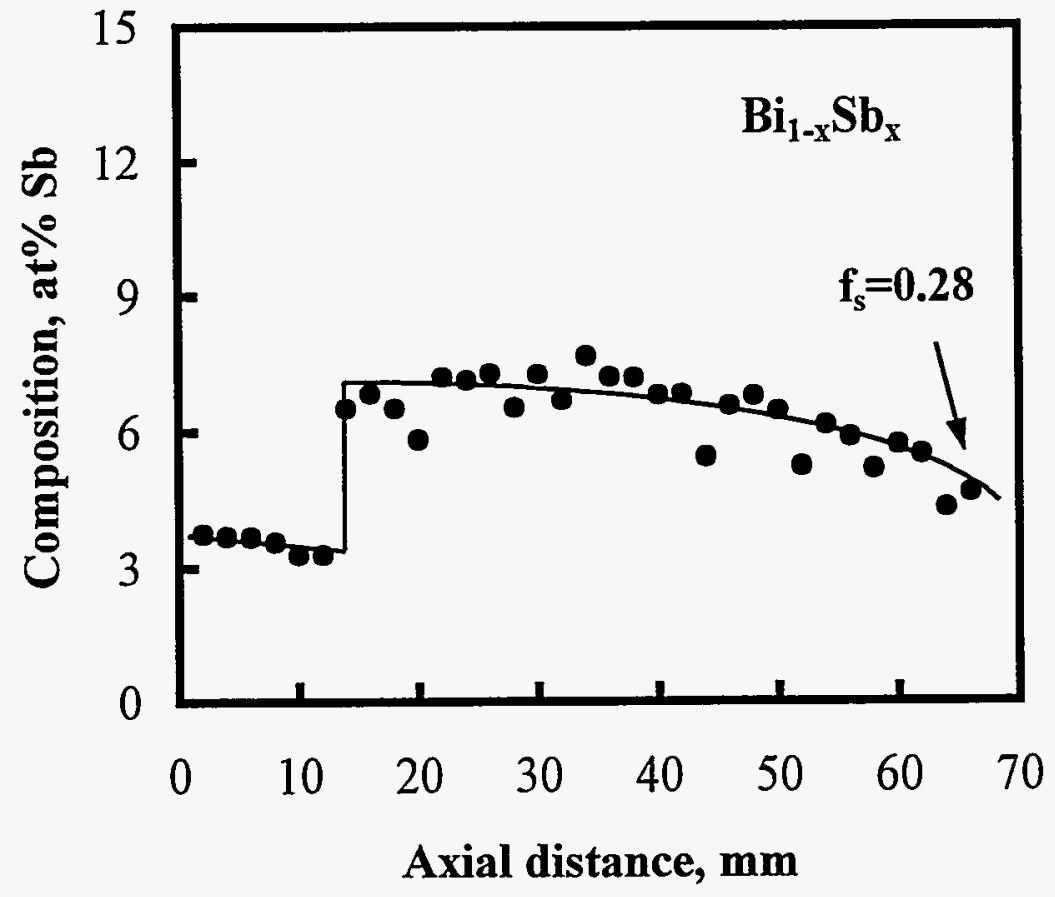

(a)

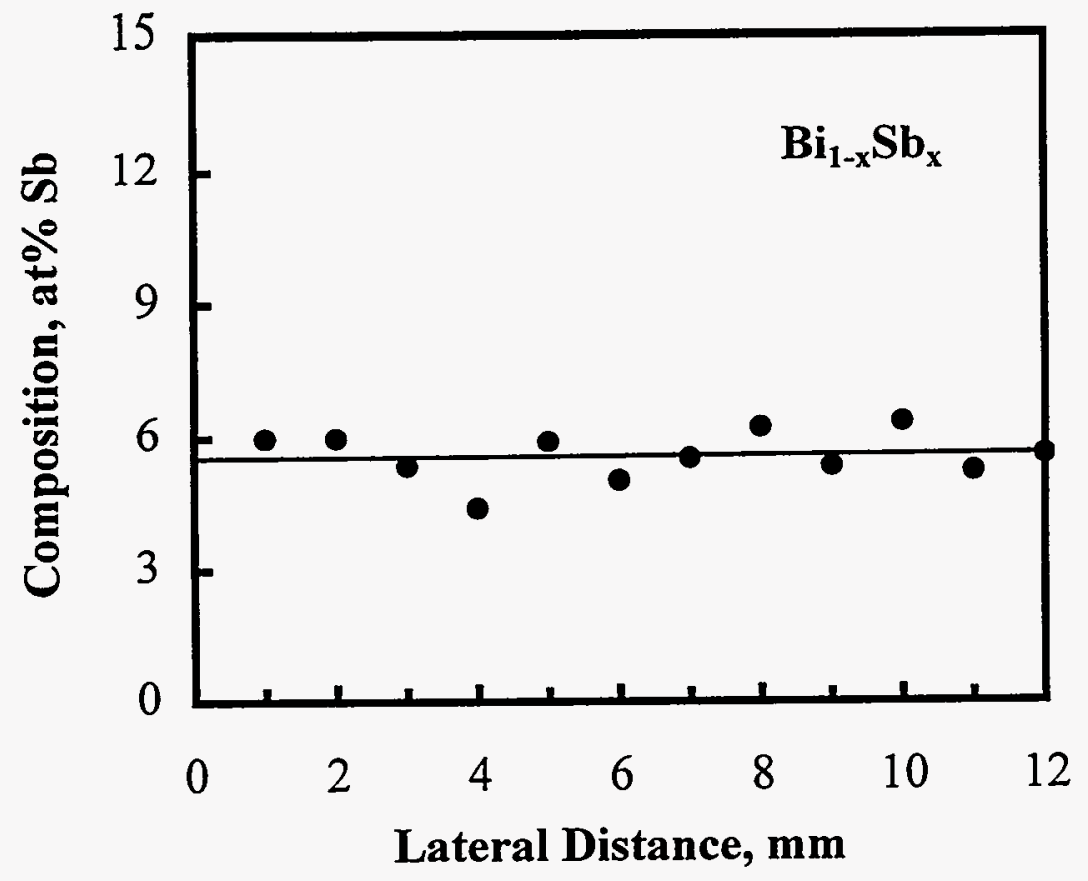

(b)

Figure 3.8 Composition profiles in another $\mathrm{Bi}_{1-x} \mathrm{Sb}_{\mathrm{x}}$ crystal : (a) axial; (b) lateral. 


\section{Czochralski Growth of Ga $a_{1-x}$ In $_{x}$ Sb UNDER a Pressure Differential}

\subsection{Introduction}

Alloy semiconductors are attractive for many applications since the lattice parameter and the band gap can be adjusted by varying the composition. However, alloy semiconductors are often difficult to grow with a uniform composition. Their phase diagrams often exhibit a large gap between the solidus line and the liquidus line, thus resulting in a segregation coefficient significantly different from unity. Furthermore, the liquidus temperature and density of the melt can vary significantly with its composition, thus promoting the chance of thermosolutal convection.

In a recent study on crystal growth of $\mathrm{Ga}_{1-x} \mathrm{In}_{x} \mathrm{Sb}$ by floating-crucible Czochralski (1), two problems were observed. First, mixing occurred between the growth melt in the floating crucible and the replenishing melt in the outer crucible by thermosolutal convection. This caused the compositions of the melts and hence the resultant crystal unpredictable. Reducing the diameter of the spiral tube connecting the melts helped suppress such mixing, but made it difficult for the replenishing melt to pass through. Second, the floating crucible stuck to the outer crucible because the replenishing melt can had a significantly higher liquidus temperature than the growth melt; hence, froze during crystal growth.

Tanaka et al. ${ }^{(2)}$ used a double-crucible technique to grow $\mathrm{Ga}_{1-x} \mathrm{I} \mathrm{n}_{\mathrm{x}} \mathrm{Sb}$ single crystals up to about $5 \mathrm{~mole} \% \mathrm{InSb}$. A three-piece, precision-machined graphite assembly was used. A solution in contact with a solid GaSb source was injected by a graphite piston 
into a graphite crucible through a hole at its bottom. The resultant crystals were about $1 \mathrm{~cm}$ in diameter and $1.5 \mathrm{~cm}$ long.

Koh et al. ${ }^{(3)}$ grew $\mathrm{Bi}_{1-x} \mathrm{Sb}_{x}$ single crystals about 5 and 10 at\% $\mathrm{Sb}$ also using a threepiece, precision-machined graphite assembly. The replenishing melt was injected into a very small $(1 \mathrm{~cm}$ diameter by $0.3 \mathrm{~cm}$ height $)$ graphite crucible through a small $(0.1$ $\mathrm{cm}$ diameter by $2 \mathrm{~cm}$ length) hole at its bottom.

\subsection{Experimental procedure}

A transparent furnace was used for crystal growth, as shown schematically in Figure 4.1. It consisted of, from the inside out, a quartz tube as the chamber, a Kanthal wire wound around a quartz tube as the heater, and a gold-coated quartz tube as the radiation heat shield. The chamber was divided into two chambers, an upper chamber for crystal growth and a lower chamber for replenishing. The bottom of the upper chamber, which served as the crucible for the crystal growth, had a capillary tube going into a crucible in the lower chamber for replenishing.

Initially, the growth and replenishing crucibles were $3.5 \mathrm{~cm}$ and $2.7 \mathrm{~cm} \mathrm{ID,}$ respectively. The charge in either crucible was from 50 to $60 \mathrm{~g}$. To increase the fraction of the melts (growth plus replenishment) that solidified into the crystal without increasing the growth time significantly, they were later reduced to $2.7 \mathrm{~cm}$ and 1.4 or $1.3 \mathrm{~cm} \mathrm{ID,} \mathrm{respectively.} \mathrm{The} \mathrm{charge} \mathrm{in} \mathrm{either} \mathrm{crucible} \mathrm{was} 20$ to $30 \mathrm{~g}$. The capillary tube, either 2.35 or $2 \mathrm{~mm}$ ID, initially about $60 \mathrm{~cm}$ long, was later reduced to about $30 \mathrm{~cm}$ long. To reduce the length of the capillary tube without changing its 
height, the middle portion of the tube was shaped into the form of a coil (not shown in Fig.4.1). Two heaters were used, an upper heater for the growth melt and a lower heater for the replenishing melt.

A conical reflector prepared from a $0.013 \mathrm{~cm}$ thick molybdenum foil was placed about $5 \mathrm{~mm}$ above the melt and coaxially around the growing crystal. The diameter of the reflector was about $1.8 \mathrm{~cm}$ at the bottom. It was supported by three small depressions made into the quartz tube (not shown). In a recent study on growth of $\mathrm{Ga}_{1-x} \mathrm{In}_{x} \mathrm{Sb}$ crystals by the conventional Czochralski process ${ }^{(4)}$ it was found that such a conical reflector helped the crystal growth remain monocrystalline.

The charges for the growth and replenishing crucibles were in the form of alloy ingots close to the crucibles in diameter. They were prepared from $₫ \mathrm{~N} \mathrm{Ga}$ and $\mathrm{Sb}$ and $5 \mathrm{~N} \mathrm{InSb}$, with 1 to 5 at\% extra $\mathrm{Sb}^{(5)}$, in view of the evaporation of $\mathrm{Sb}$ over the relatively long time required for crystal growth. Macroscopic homogeneity was enhanced by melting in a quartz tube chamber, stirring, and water quenching. A small sample was taken from the melt right before quenching with a small spoon. The sample was dissolved in an acid solution of $2 \mathrm{HNO}_{3}: 1 \mathrm{HF}$ and diluted for measuring the In concentration by inductively coupled plasma mass spectrometry (ICP-MS). Before crystal growth the ingots were cleaned first by grinding and then by etching in a 2: $1: 1$ mixture of $\mathrm{HNO}_{3}: \mathrm{HF}: \mathrm{CH}_{3} \mathrm{COOH}^{(6,7)}$.

The whole chamber was pumped down to below $1 \times 10^{-3}$ torr and then purged with $5 \mathrm{~N}$ hydrogen at an overpressure of $2.8 \mathrm{psi}$. After repeating this procedure several 
times, the charge in the replenishing crucible was melted. The pressure in the lower chamber was then raised to an overpressure of 3.3 psi to cause the replenishing melt to enter the capillary tube. The upper heater was then turned on to let the replenishing melt reach and solidify onto the charge in the growth crucible, which later was also melted.

Single crystal seeds of the [111] direction were used. After seeding, and prior to pulling the growth melt was held for three hours to homogenize. The pulling speed was 0.8 to $1.0 \mathrm{~mm} / \mathrm{hr}$ and the rotation speed was 20 to $30 \mathrm{rpm}$. As the crystal was being pulled from the melt, the replenishing crucible was raised to keep the level of the growth melt constant. The speed at which the replenishing crucible was raised $V_{r}$ $=\left(A_{c} / A_{r}\right) V_{c} ;$ where $V_{c}$ is the crystal pulling speed, $A_{c}$ the crystal cross-sectional area, and $\mathrm{A}_{\mathrm{r}}$ the cross-sectional area of the replenishing melt.

After crystal growth the melts were allowed to solidify in their crucibles. The composition of the replenishing melt after crystal growth was measured. Then the ingot in the replenishing crucible was remelted in a quartz tube chamber, stirred, and a small sample was removed with a spoon for ICP-MS analysis. The composition profiles in the resultant crystals were measured by electron probe microanalysis (EPMA, WDS). Composition measurements of the ingots by EPMA, however, were not adequate since they were microscopically inhomogeneous due to segregation induced by dendritic solidification. 
Before growing $\mathrm{Ga}_{1-x} \mathrm{In}_{x} \mathrm{Sb}$ crystals, test experiments were carried out using a model alloy $\mathrm{Bi}_{1-x} \mathrm{Sb}_{x}$. Pyrex glass chambers and crucibles were used. $\mathrm{Bi}_{1-x} \mathrm{Sb}_{\mathrm{x}}$ ingots were prepared from $5 \mathrm{~N} \mathrm{Bi}$ and $6 \mathrm{~N} \mathrm{Sb}$, with rigorous stirring and subsequent quenching to enhance macroscopic homogeneity. The ingots were cleaned by grinding, acid etching, and water rinsing. The pulling speed was about $1.3 \mathrm{~mm} / \mathrm{hr}$ and the rotation speed was $30 \mathrm{rpm}$.

Initially, the growth crucible had a $3.5 \mathrm{~cm}$ ID and the replenishing crucible had either a 2.7 or $3.0 \mathrm{~cm} \mathrm{ID}$. The charge in either crucible was from 50 to $60 \mathrm{~g}$. Later on the growth crucible was reduced to $2.7 \mathrm{~cm} \mathrm{ID}$, and the replenishing crucible reduced to 1.4 or $1.3 \mathrm{~cm}$ ID. The charge in either crucible was from 20 to $30 \mathrm{~g}$. The fraction of the melts (growth plus replenishment) that solidified into the crystal was higher with the smaller charges. The capillary tube, which had either a 2.35 or $2 \mathrm{~mm} \mathrm{ID,} \mathrm{was} \mathrm{initially} \mathrm{about} 60$ $\mathrm{cm}$ long. It was later reduced to about $30 \mathrm{~cm}$ long. In either case the middle portion of the tube was shaped into the form of a coil (not shown in Fig. 4.1) to save space.

\subsection{Results and discussion}

The $\mathrm{Bi}-\mathrm{Sb}{ }^{(8)}$ and InSb-GaSb ${ }^{(9)}$ phase diagrams are shown in Figs. 1.2 and 1.3. Figure 4.2 shows the composition profiles in a test $\mathrm{Bi}_{1-x} \mathrm{Sb}_{\mathrm{x}}$ crystal, which are essentially uniform. The fraction of the melts solidified, $f_{s}$, defined as 1 - (final charges in crucibles)/(initial charges in crucibles), is 0.19 . The capillary tube had a $0.2 \mathrm{~cm}$ ID. The compositions of the charges in the growth and replenishing crucibles 
were 0.85 and 4.2 at $\% \mathrm{Sb}$, respectively.

The grown crystal weighed $55 \mathrm{~g}$ and its diameter was about $12 \mathrm{~mm}$. The weight of the charge in the growth crucible was $100 \mathrm{~g}$ after crystal growth, about the same as that of the charge before crystal growth. The weight of the charge in the replenishing crucible was about $155 \mathrm{~g}$ after crystal growth, much less than that of the charge before crystal growth. Melt level in the growth crucible remained relatively constant, the consumed volume of the melt for grown crystal was about the loss in the supply crucible. The melt composition in the replenishing crucible remained almost unchanged after crystal growth, $\mathrm{Bi}-3.8$ at $\% \mathrm{Sb}$, according to the ICP-MS measurements. Thus our technique was effective in preventing back diffusion and thermosolutal convection.

The composition profiles in a $\mathrm{Bi}_{1-\mathrm{x}} \mathrm{Sb}_{\mathrm{x}}$ crystal grown from a melt of 0.85 at $\% \mathrm{Sb}$ by the conventional Czochralski process are shown in Fig. 4.3 for comparison. Although polycrystalline seed was used, and intentional necking was not performed, a large portion of the grown crystal was single crystalline. The preferential orientation of $\mathrm{Bi}_{1-\mathrm{x}} \mathrm{Sb}_{\mathrm{x}}$ was the direction parallel to the cleaved (111) plane identified by the X-ray Laue back-reflection pattern. The grown crystal was about $70 \mathrm{~g}$ and its diameter was about $12 \mathrm{~mm}$. The Sb concentration dropped from 2 at $\%$ at the seed end of the crystal to 0.5 at $\%$ at the end of crystal. Since there was no melt replenishing and $\mathrm{k}_{\mathrm{eff}}>1$ in this $\mathrm{Bi}_{1-x} \mathrm{Sb}_{\mathrm{x}}$ system, it is reasoned that the $\mathrm{Sb}$ concentration decreases with the increasing crystal length. According to ICP-MS results, the composition of charge 
was $\mathrm{Bi}-0.85$ at $\% \mathrm{Sb}$ before crystal growth, and became $\mathrm{Bi}-0.13 \mathrm{at} \% \mathrm{Sb}$ after crystal growth.

Figure 4.4 shows a $\mathrm{Ga}_{1-x} \mathrm{In}_{x} \mathrm{Sb}$ single crystal with about 2 mole\% InSb. Condensation of $\mathrm{Sb}$ vapor during crystal growth is evident, e.g., on the seed crystal and the starting end of the grown crystal. This is why charges were prepared with extra $\mathrm{Sb}$. In fact, it has been shown that GaSb crystals of good quality can be grown from Sb-rich melts, even as high as 45 at $\%$ Ga: 55 at $\% \mathrm{Sb}^{(5)}$.

Composition profiles in this crystal are shown in Fig.4.5. The replenishing rate was too high initially, where the crystal was still small in diameter; but was slowed down later, as can be seen from the mild composition variations in Fig.4.5a. The fraction of the melts solidified is about 0.2 . The capillary tube was $0.2 \mathrm{~cm} \mathrm{ID}$. Compositions of the charges in the growth and replenishing crucibles were 16.2 and 3.2 mole \% InSb, respectively.

One disadvantage of the present technique as compared to floating-crucible Czochralski is that the replenishing rate is not automatically identical to the growth rate, thus the crystal composition is not as uniform. As mentioned previously, the floating crucible can stick to the outer crucible causing the replenishing rate to decrease and the crystal composition to vary. As shown by the phase diagrams in Figiures 1.2 and 1.3, the wide gap between the liquidus and solidus lines suggests that the liquidus temperature of the replenishing melt can be significantly higher than the growth melt in both $\mathrm{Ga}_{1-x} \mathrm{In}_{x} \mathrm{Sb}$ and $\mathrm{Bi}_{1-x} \mathrm{Sb}_{x}$. Therefore, when the growth melt is cool 
enough for crystal growth, the replenishing melt around the floating crucible solidifies and solders it to the outer crucible, unless enough insulation can be put around the floating crucible. This problem is eliminated in the present technique since the two crucibles are well separated and heated by two separate heaters, as shown in Fig. 4.1.

Figure 4.6 shows a $\mathrm{Ga}_{1-x} \mathrm{In}_{x} \mathrm{Sb}$ crystal with about 4 mole\% InSb. Starting from the left, seed 1 is a seed crystal of about 0.8 mole\% InSb, seed 2 is a seed crystal of about 2 to $3 \mathrm{~mole} \% \mathrm{InSb}$, and then the crystal. The crystal composition is uniform, as shown by the composition profiles in Fig. 4.7. The fraction of the melts solidified, $\mathrm{f}_{\mathrm{s}}$, is about 0.4 . The capillary tube was $0.2 \mathrm{~cm}$ ID. The compositions of the charges in the growth and replenishing crucibles were 38 and 4.4 mole \% InSb, respectively.

The crystal composition vs. the fraction solidified is shown in Fig. 4.8. For comparison, a single crystal grown by the conventional Czochralski process is also included and shows the expected segregation.

Earlier experiments were conducted with $0.235 \mathrm{~cm}$ ID capillary tubes. Figure 4.9 shows the composition profiles in a single crystal of nearly 5 mole\% InSb. The fraction of the melts solidified is about 0.33 . As shown, the crystal composition is uniform. The capillary tube was $0.235 \mathrm{~cm}$ ID. The compositions of the charges in the growth and replenishing crucibles were 36 and $5 \mathrm{~mole} \%$ InSb, respectively.

Figure 4.10 shows another crystal grown with a $0.235 \mathrm{~cm}$ ID capillary tube. The composition profile, however, is not smooth but has an abrupt change, as shown in 
Fig. 4.11a. To find out if mixing between the growth and replenishing melts occurred during crystal growth, the composition of the replenishing melt was checked. It was 5.9 mole\% InSb before experiment, but was $21.5 \mathrm{~mole} \%$ InSb afterward, thus confirming that mixing did occur during crystal growth. No sudden melt level changes were observed during crystal growth, either in the replenishing or growth melt. The line mark on the crystal surface at about $1.5 \mathrm{~cm}$ from the finishing end of the crystal was due to a furnace temperature adjustment.

The compositions of the charges in the growth and replenishing crucibles were 48.0 and 5.9 mole\% InSb, respectively. From the phase diagram in Fig. 1.3, the liquidus temperature of the growth melt is about $50{ }^{\circ} \mathrm{C}$ lower than that of the replenishing melt. The density of the InSb melt of $6.43 \mathrm{~g} / \mathrm{cm}^{3}{ }^{(10)}$ is about $7 \%$ greater than that of the $\mathrm{GaSb}$ melt of $6.03 \mathrm{~g} / \mathrm{cm}^{3}{ }^{(11)}$. As such, the growth melt at the top can be appreciably greater in density than the replenishing melt at the bottom. In other words, this density inversion can cause thermosolutal convection, and hence mixing between the melts.

A capillary tube can be an effective way of suppressing such mixing since the passageway between the melts is long and narrow. The effectiveness, however, decreases with increasing diameter of the tube. As compared to a $0.2 \mathrm{~cm}$ ID tube, a $0.235 \mathrm{~cm}$ tube has a tube cross-sectional area nearly $40 \%$ larger. As such, it is not as effective in preventing mixing. In our floating-crucible Czochralski growth ${ }^{(1)}$, the growth and replenishing melts were connected with a $0.4 \mathrm{~cm}$ ID spiral tube, which is 
$400 \%$ larger in the cross-sectional area. Consequently, mixing between the melts occurred during crystal growth. Significant reduction in the tube diameter is not feasible in floating-crucible Czochralski since no pressure is available to force the replenishing melt through the tube.

Attempts were made to use $0.1 \mathrm{~cm}$ ID capillary tubes to further suppress mixing between the melts. Smooth replenishing, however, became more difficult because of the high resistance to flow through the tube.

\subsection{Conclusions}

A new technique has been developed to grow $\mathrm{Ga}_{1-x} \mathrm{In}_{x} \mathrm{Sb}$ alloy crystals of uniform compositions. Single crystals up to nearly 5 mole $\%$ InSb were grown with a $0.2 \mathrm{~cm}$ ID capillary tube connecting the growth melt at the top and the replenishing melt at the bottom. With the use of a larger tube, e.g., $0.235 \mathrm{~cm} \mathrm{ID,} \mathrm{mixing} \mathrm{between} \mathrm{the} \mathrm{melts}$ occurred during crystal growth and resulted in abrupt changes in the crystal composition. 


\subsection{References}

1. S. C. Tsaur and S. Kou, to be submitted to J. Crystal Growth.

2. A. Tanaka, A. Watanabe, M. Kimura and T. Sukegawa, J. Crystal Growth 135 (1994) 269.

3. H. J. Koh, P. Rudolph and T. Fukuda, J. Crystal Growth 154 (1995) 151.

4. S. C. Tsaur and S. Kou, to be submitted to J. Crystal Growth.

5. Y. Ohmori, K. Sugii, S. Akai and K. Matsumoto, J. Crystal Growth 60 (1982) 79.

6. F. Moravec, J. Crystal Growth 128 (1993) 457.

7. A. Katsui and C. Uemura, J. Applied Physics 19 (1980) L318.

8. J. P. Dismukes and W. M. Yim, J. Crystal Growth 22 (1974) 287.

9. J. P. Garandet, T. Duffar and J. J. Favier, J. Crystal Growth 106 (1990) 426.

10. S. Nakamura and T. Hibiya, Int. J. Thermophys. 13 (1992) 1061.

11. A. S. Jordan, J. Crystal growth 71 (1985) 551. 
Pulling \& rotation

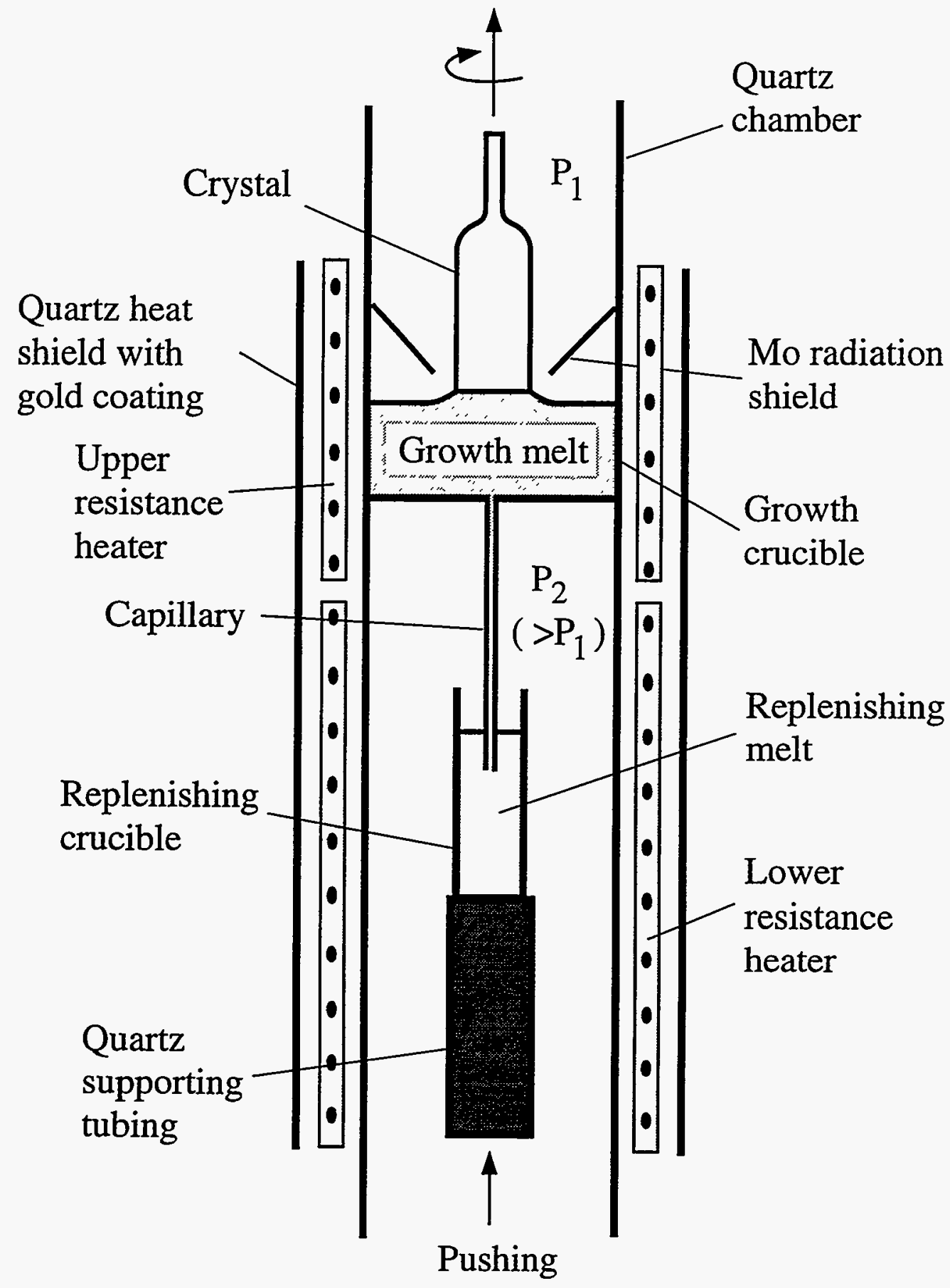

Figure 4.1 Schematic illustration of Czochralski pulling by pressure-differential technique. 


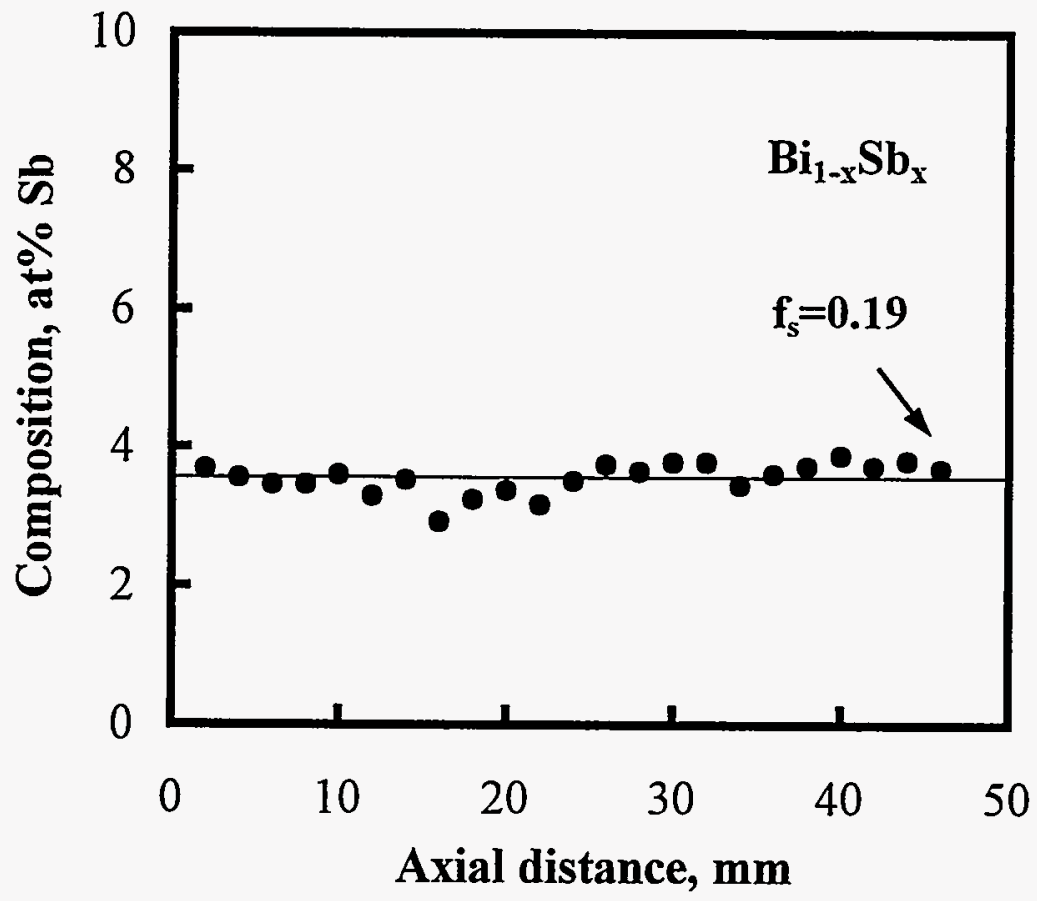

(a)

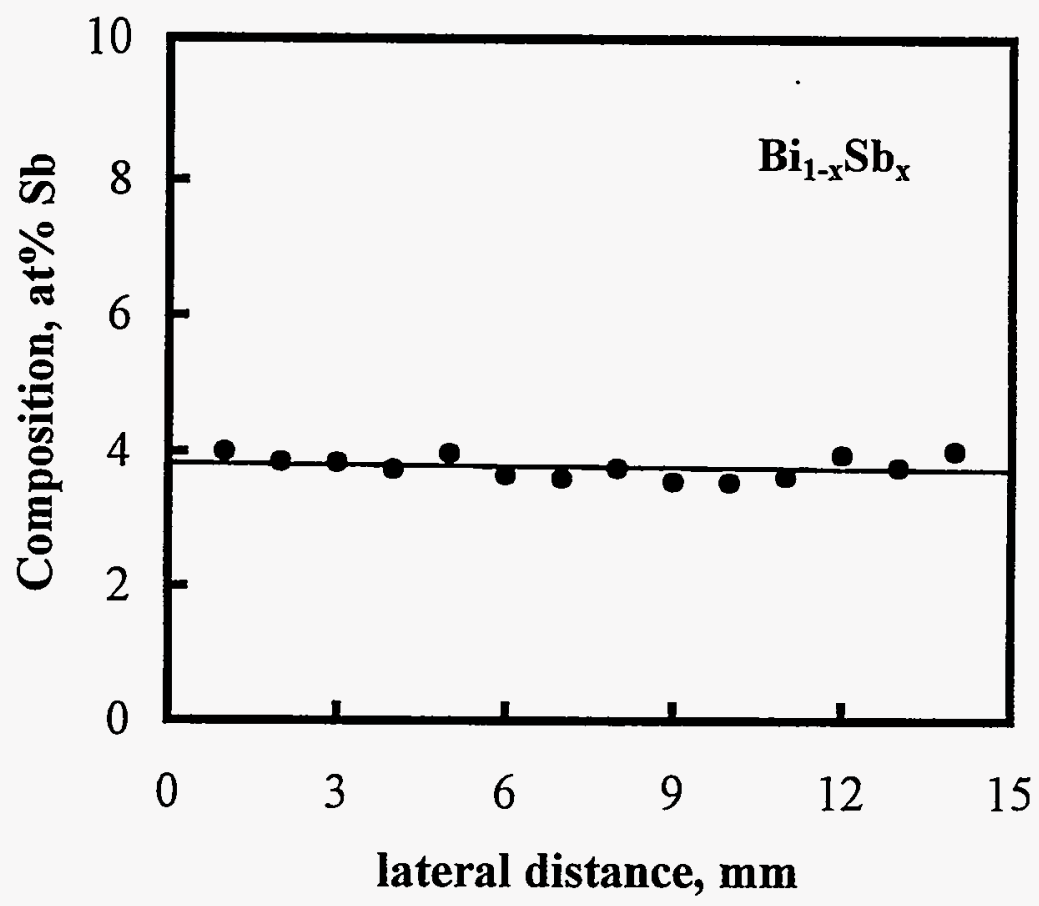

(b)

Figure 4.2 Composition profiles in a $\mathrm{Bi}_{1-\mathrm{S}} \mathrm{Sb}_{\mathrm{x}}$ crystal of around $4 \mathrm{at} \% \mathrm{Sb}$ : (a)axial ; (b) lateral. 


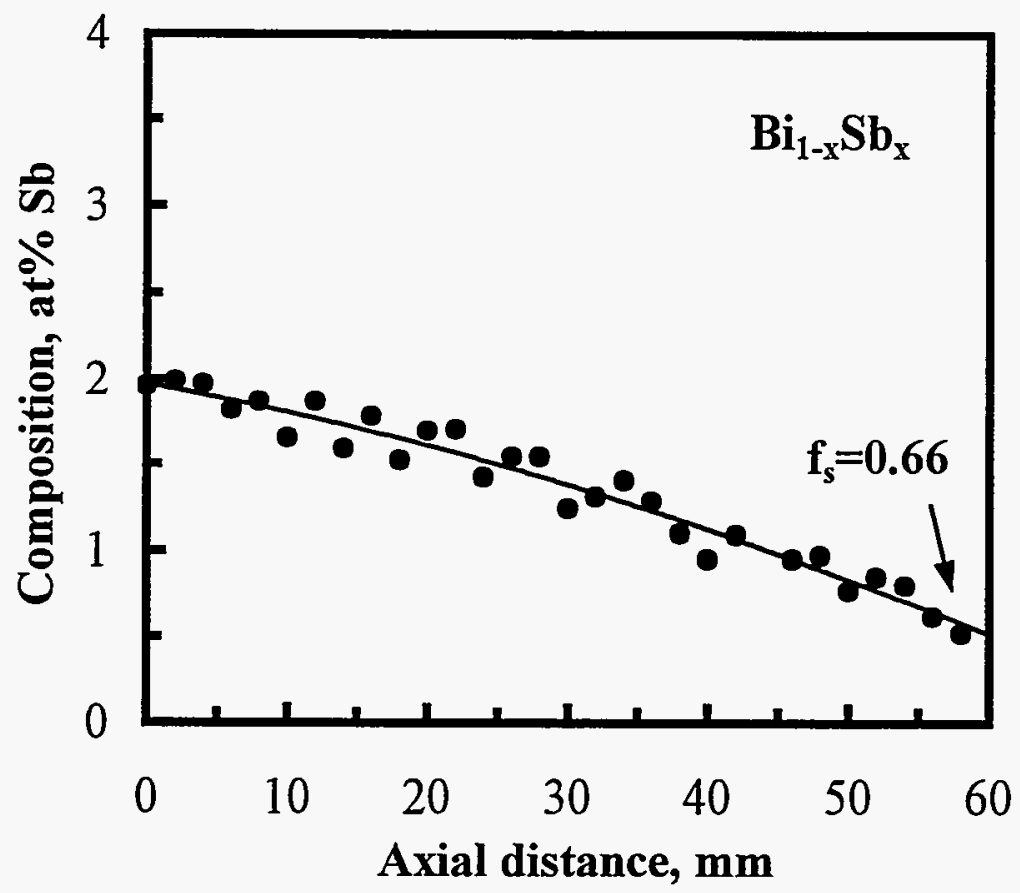

(a)

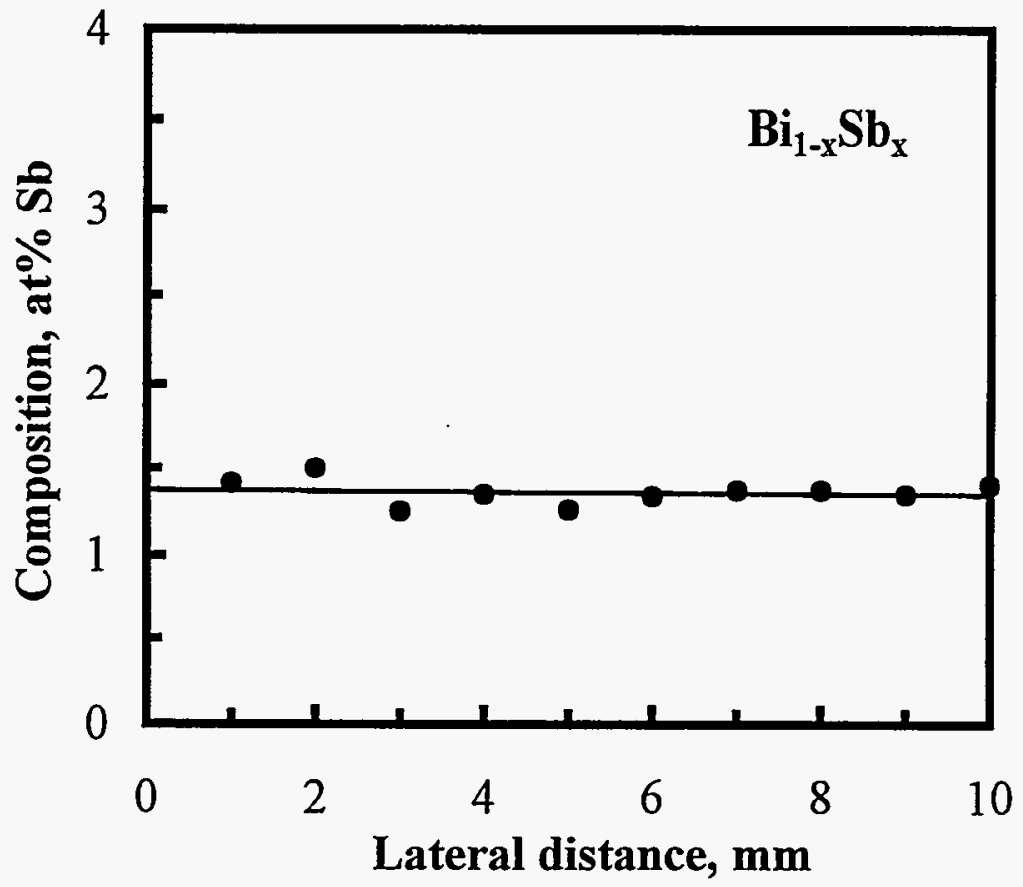

(b)

Figure 4.3 Composition profiles in a $\mathrm{Bi}_{1-x} \mathrm{Sb}_{\mathrm{x}}$ crystal grown by conventional Czochralski : (a)axial ; (b) lateral. 


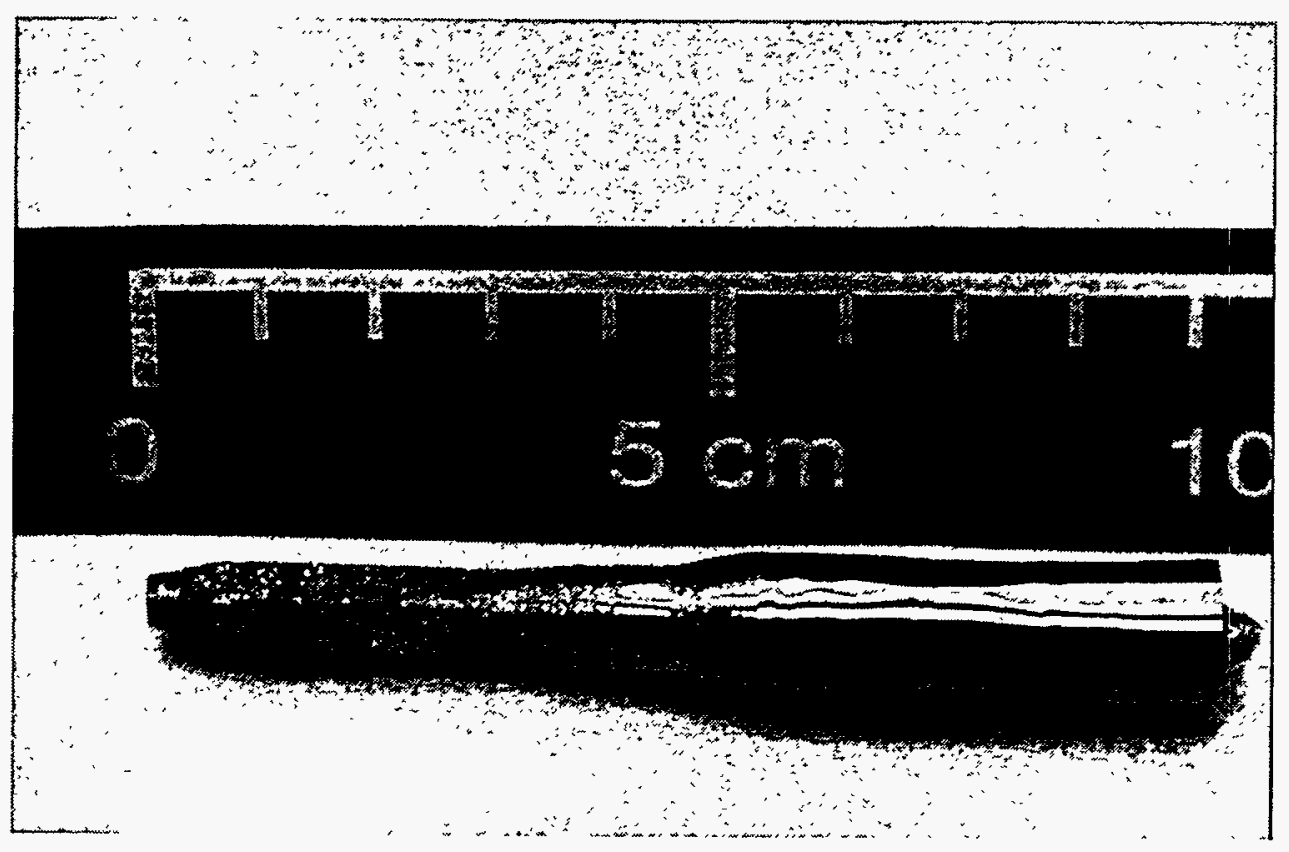

Figure $4.4 \mathrm{~A} \mathrm{Ga}_{1-x} \mathrm{In}_{x} \mathrm{Sb}$ single crystal with about 2 mole\% InSb. 


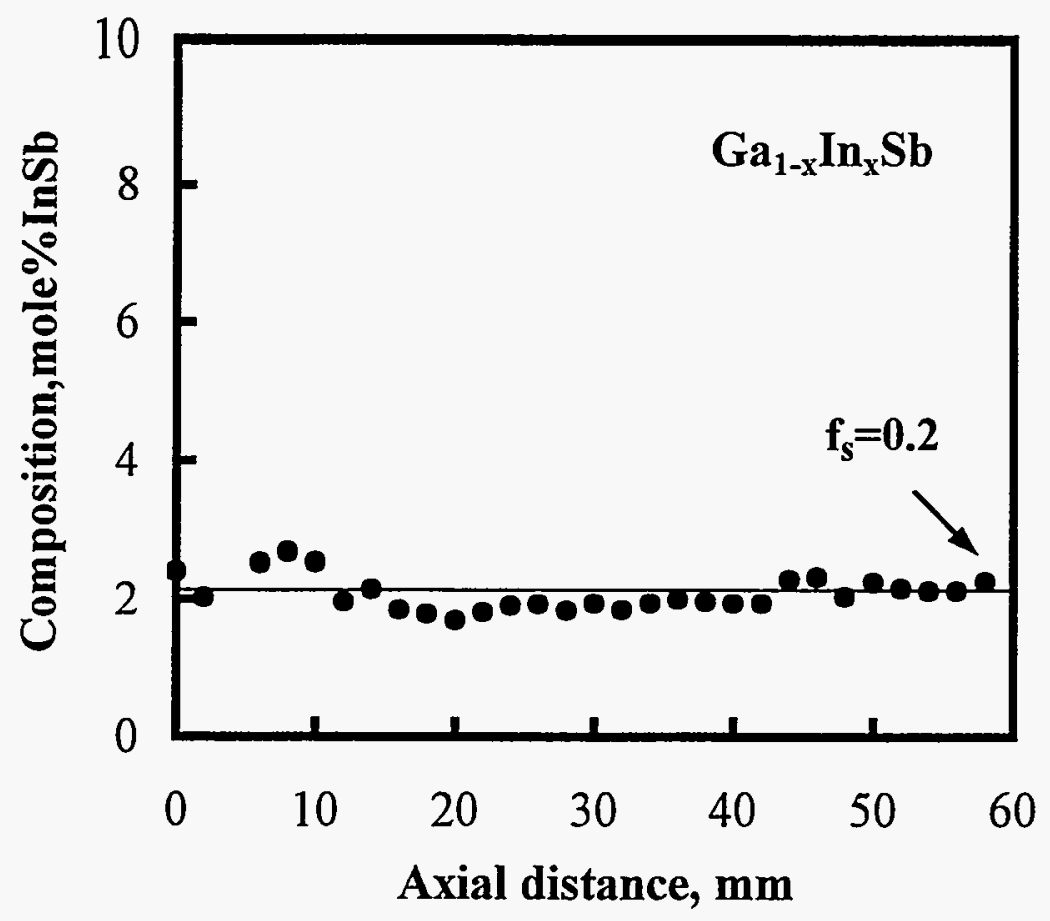

(a)

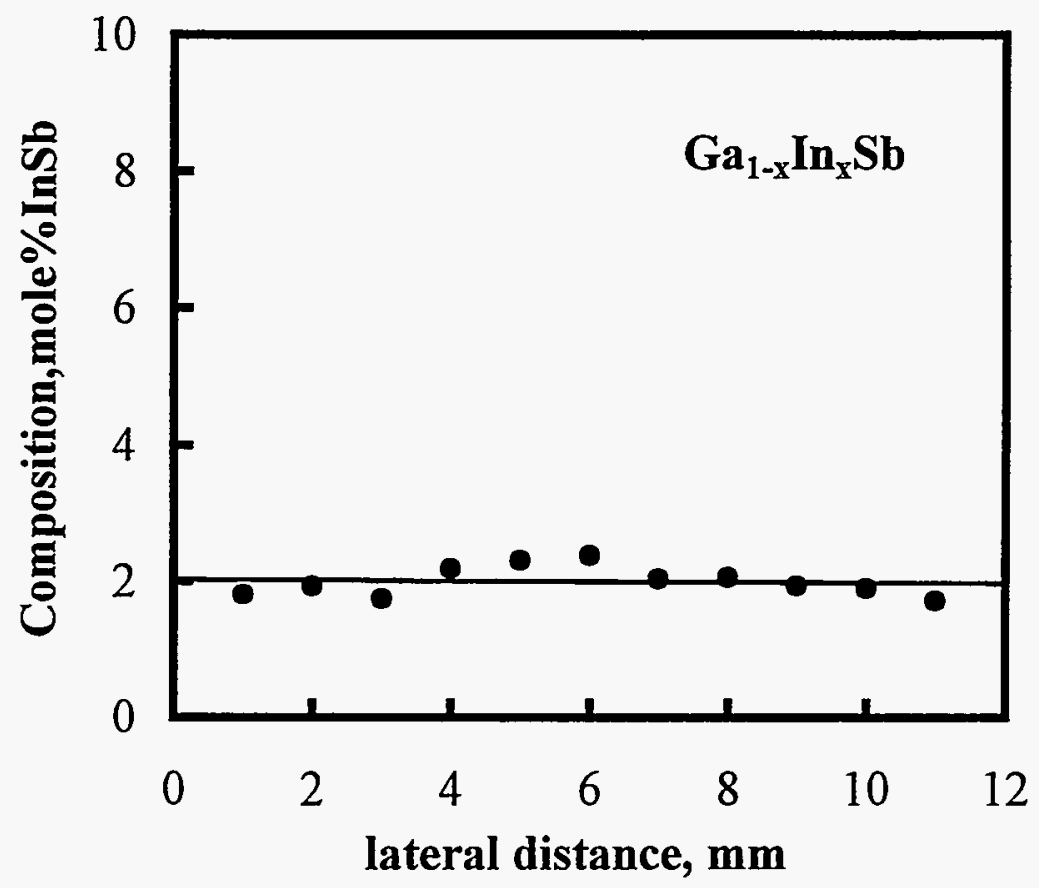

(b)

Figure 4.5 Composition profiles in the crystal in Fig. 4.4 : (a) axial; (b) lateral. 


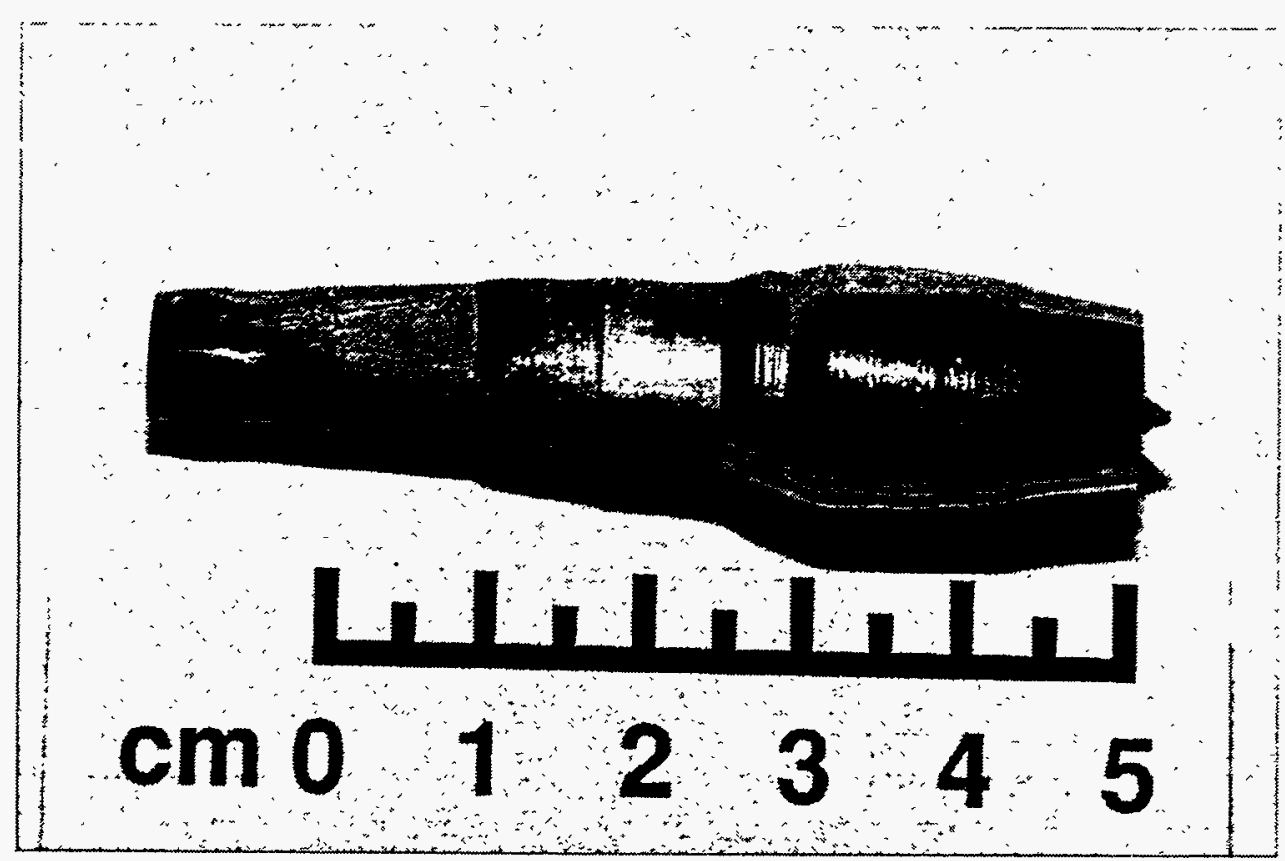

Figure 4.6 $\mathrm{A} \mathrm{Ga}_{1-x} \mathrm{In}_{x} \mathrm{Sb}$ single crystal with about $4 \mathrm{~mole} \% \mathrm{InSb}$. 


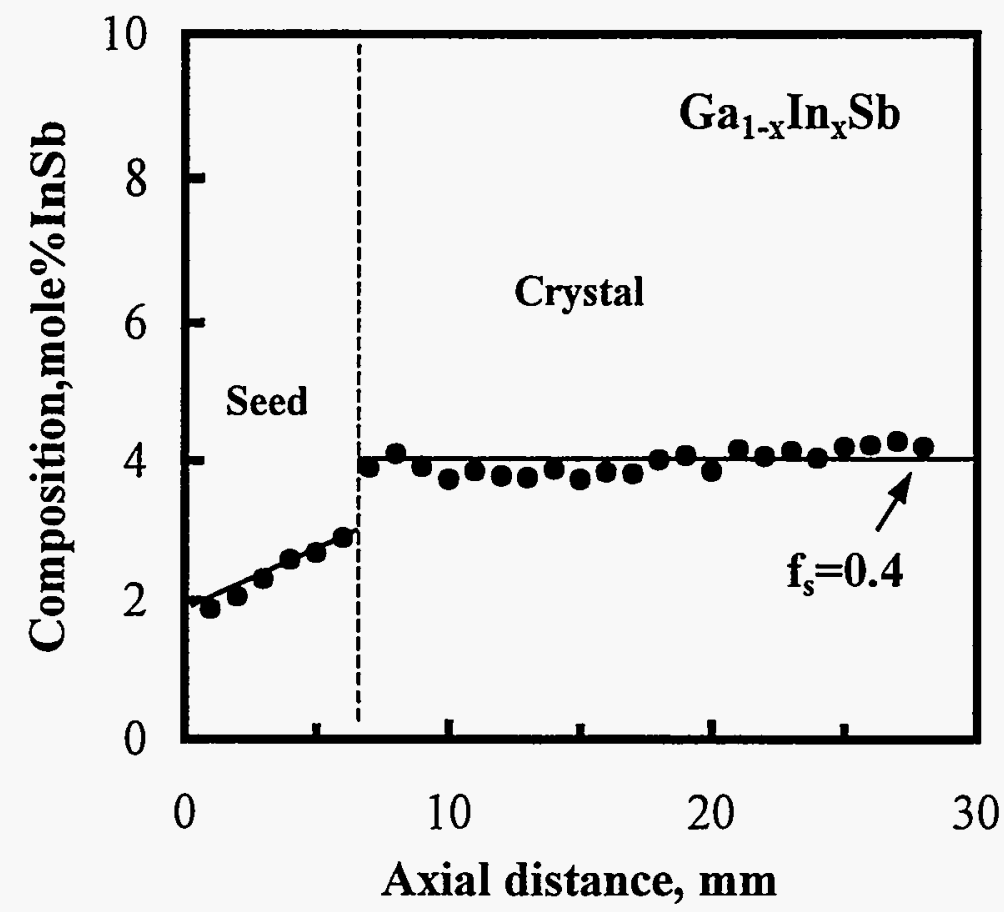

(a)

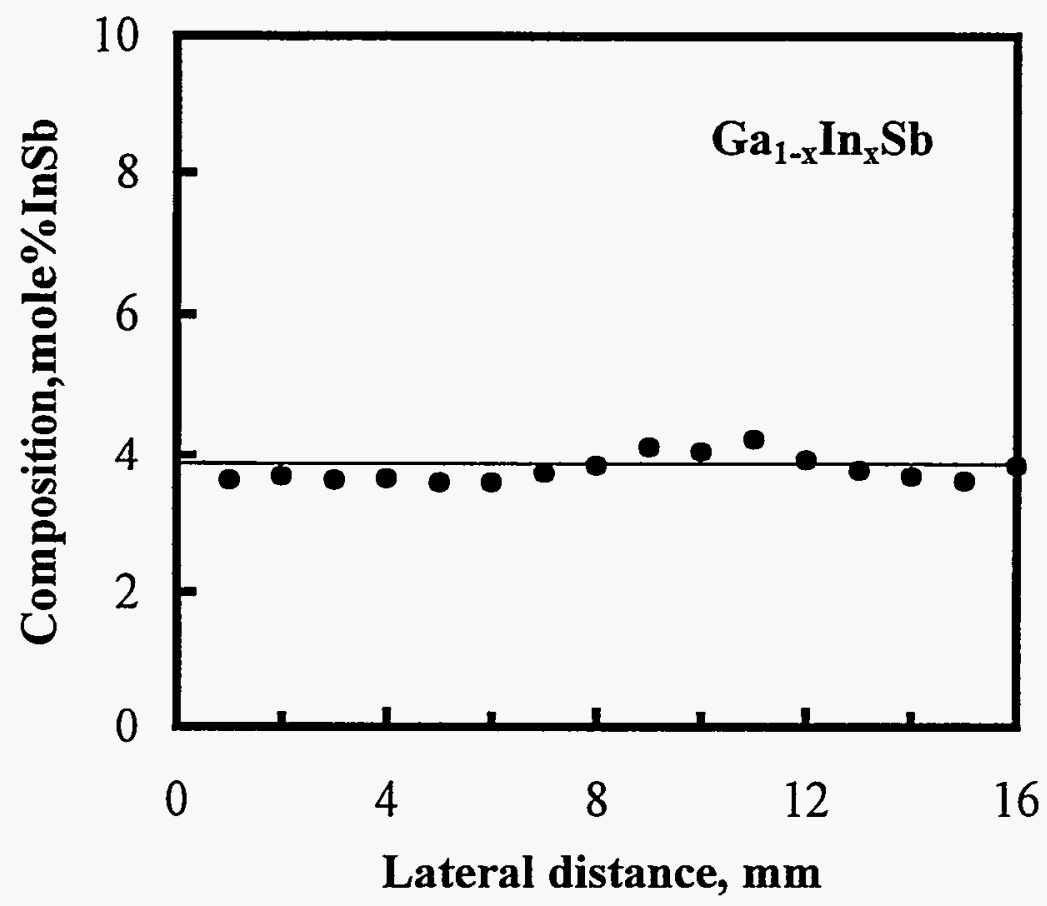

(b)

Figure 4.7 Composition profiles in the crystal in Fig. 4.6 : (a) axial; (b) lateral. 


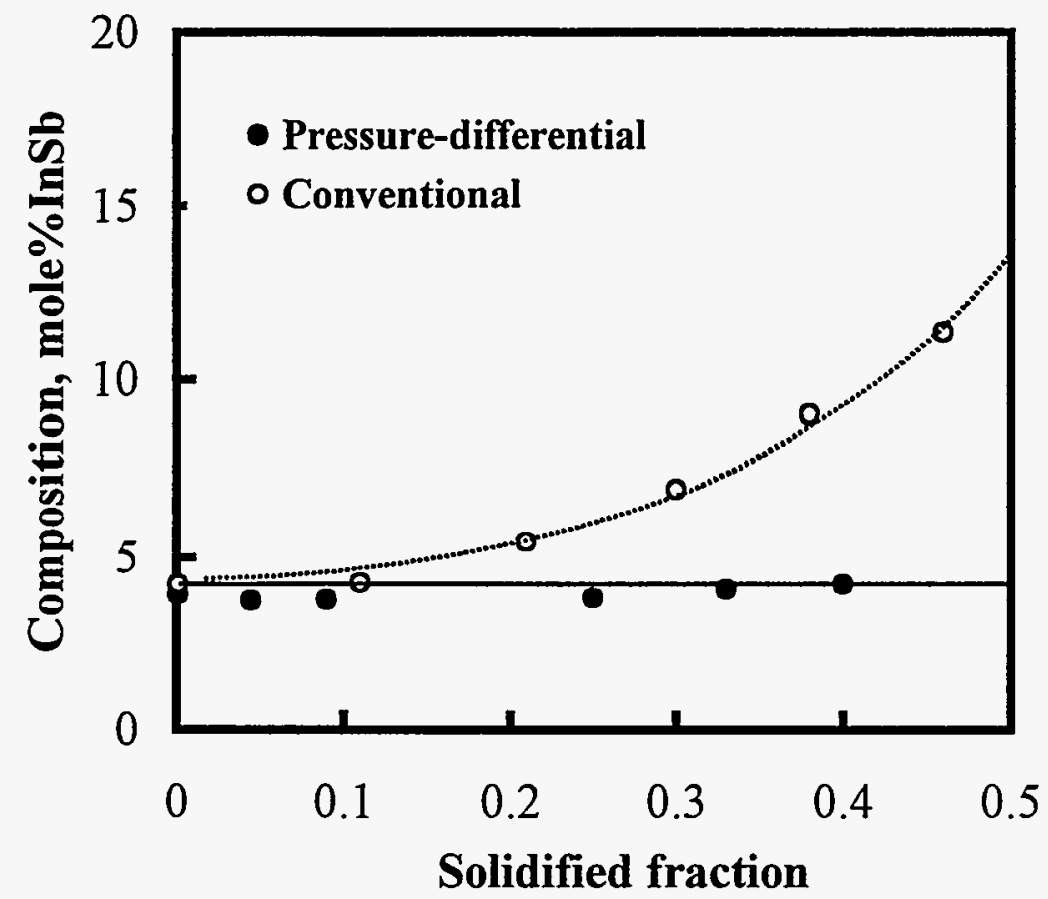

Figure 4.8 Curves of composition vs. fraction solidified in the crystal in Fig. 4.6 and a conventional Czochralski crystal. 


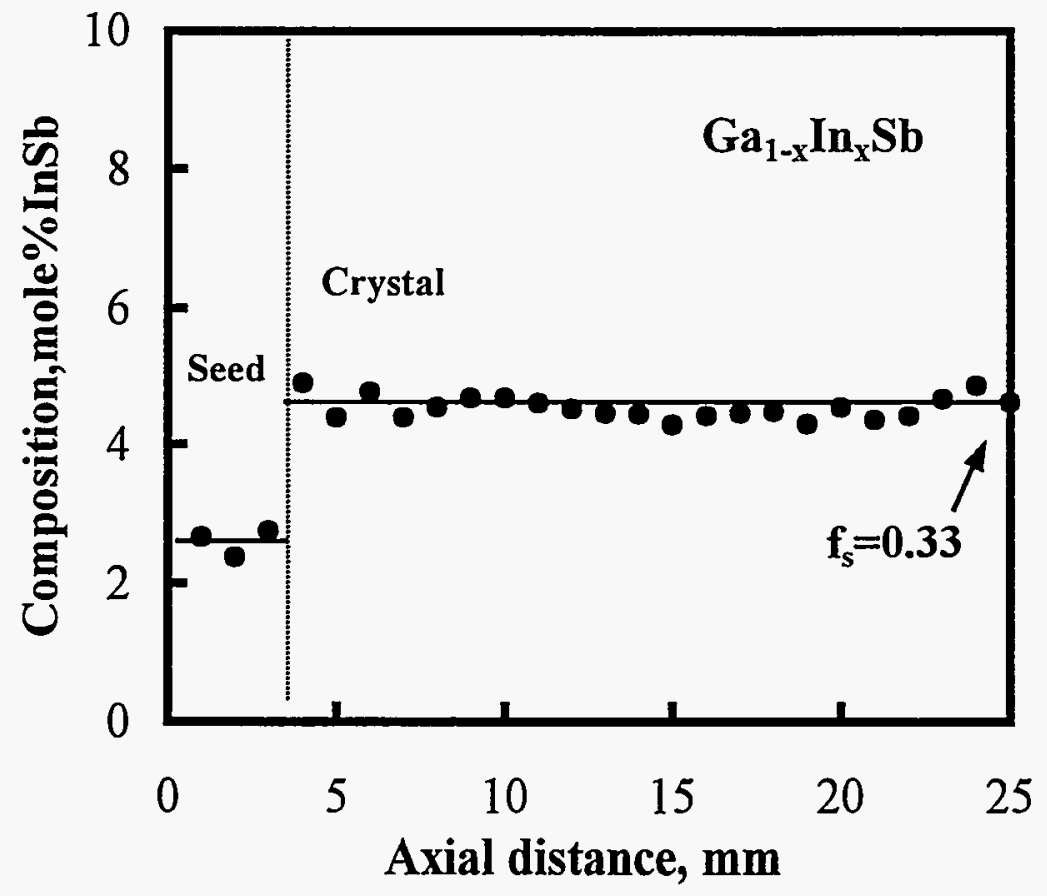

(a)

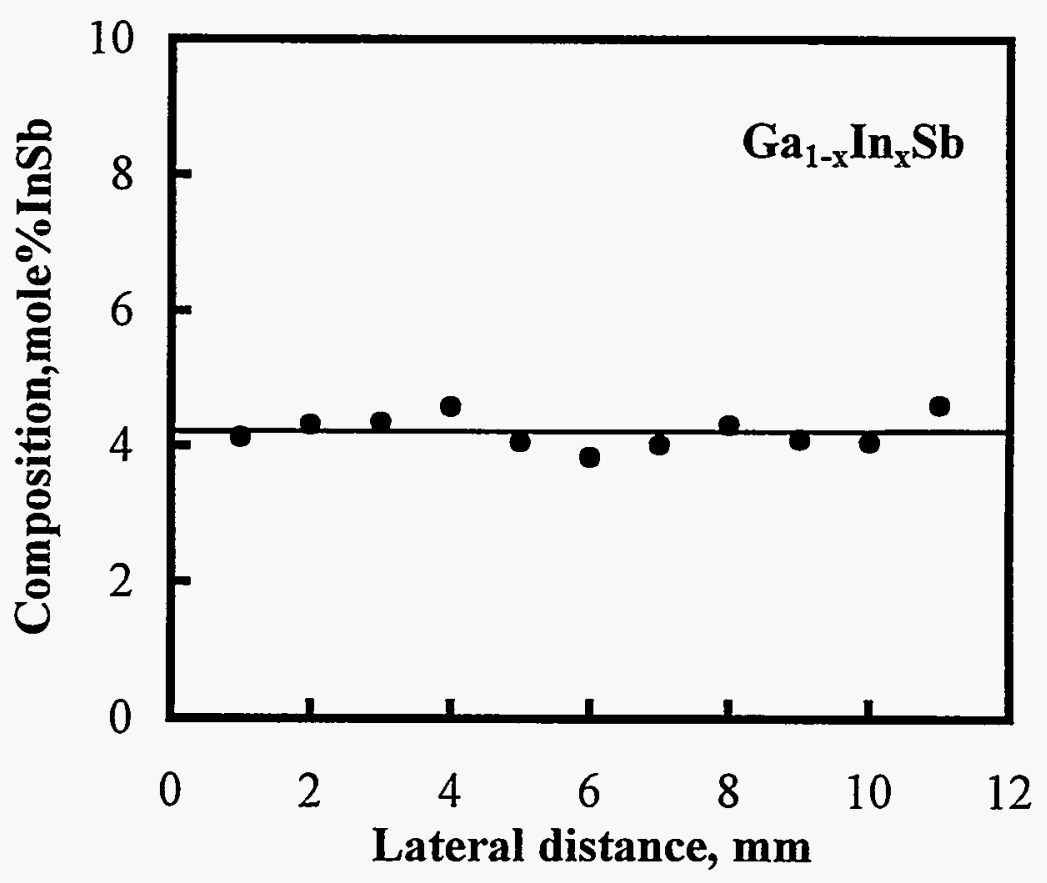

(b)

Figure 4.9 Composition profiles in a $\mathrm{Ga}_{1-\mathrm{x}} \mathrm{In}_{\mathrm{x}} \mathrm{Sb}$ single crystal with nearly 5 mole\% InSb : (a) axial; (b) lateral. 


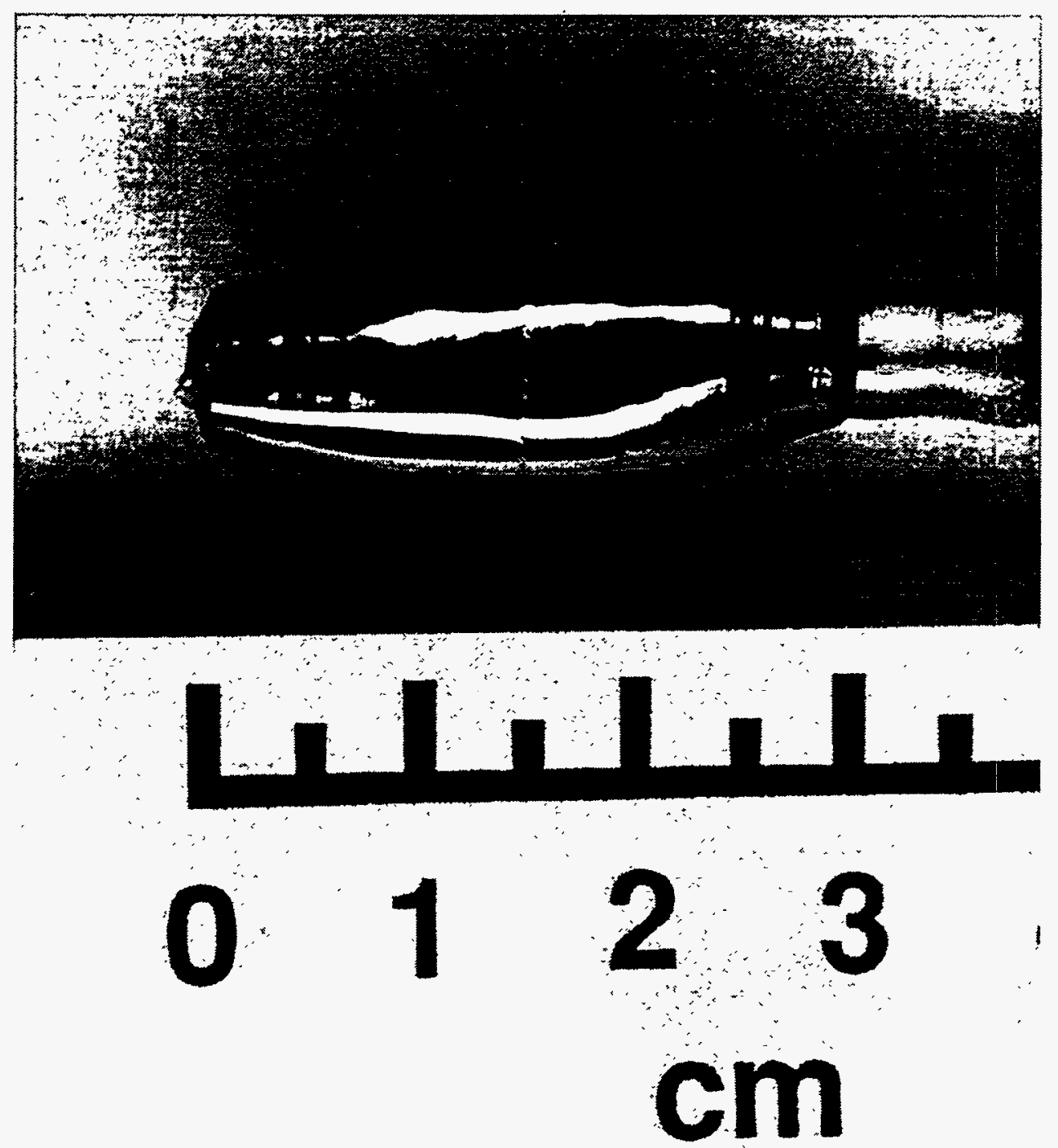

Figure $4.10 \mathrm{~A} \mathrm{Ga}_{1-\mathrm{x}} \mathrm{In}_{\mathrm{x}} \mathrm{Sb}$ single crystal with about $5 \mathrm{~mole} \% \mathrm{InSb}$. 

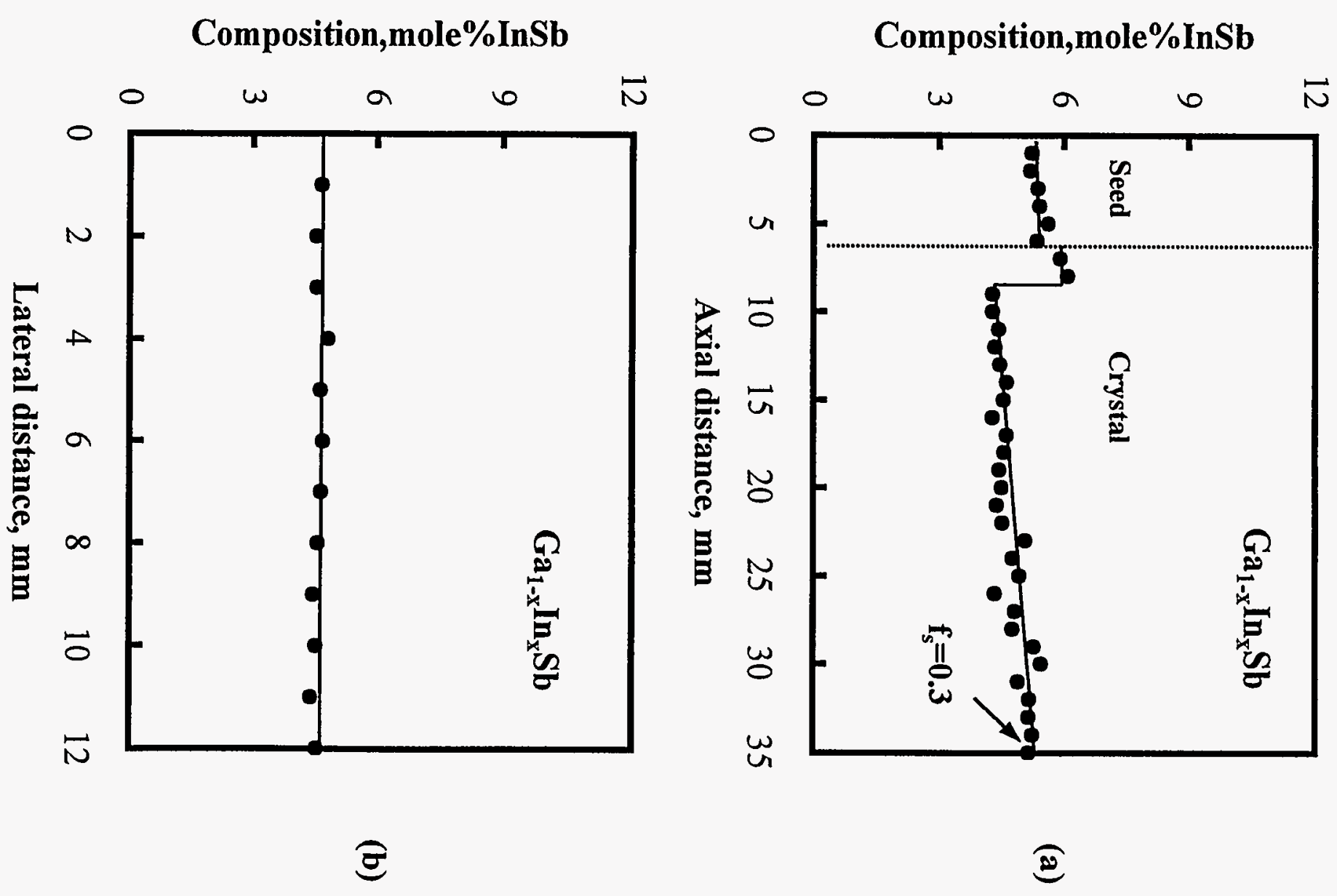


\section{SUMMARY}

Alloy semiconductor substrates, which have a tailored lattice constant for an epitaxial layer, offer the possibility to prepare a variety of epitaxial structures. Especially $\mathrm{Ga}_{1-x} \mathrm{In}_{\mathrm{x}} \mathrm{Sb}$, an important substrate, because it can be used for fabrication of the infrared sensor or laser diode.

Attempts were made to grow alloy crystals of $\mathrm{Ga}_{1-x} \mathrm{In}_{x} \mathrm{Sb}$ by the conventional Czochralski process. A transparent furnace was used, with hydrogen purging through the chamber during crystal growth. The large separation of the solidus and liquidus lines in the phase diagram leads to critical growth rate on the order of $\mathrm{mm} / \mathrm{hr}$, and thus to long growth time. The high oxidizing tendency of the melt makes the growth system technologically difficult to handle. Polycrystalline growth could be suppressed by using a low pulling rate, only if the diameter of the grown crystal remains comparable to that of the seed crystal. Furthermore, the fluctuation of the solid composition becomes more sensitive to temperature fluctuation as the InSb concentration increases in the melt.

Single crystal seeds up to about 2 to $5 \mathrm{~mole} \%$ InSb were grown from seeds up to about 1 to 2 mole\% InSb. These were grown from essentially pure GaSb seeds of the [111] direction. Single crystals were grown with InSb rising from about 2 to $6 \mathrm{~mole} \%$ at the seed ends to about 14 to $23 \mathrm{~mole} \% \mathrm{InSb}$ at the finish ends. A conical reflector was installed above the melt and coaxially around the growing crystal to help the crystal grow monocrystalline. 
Due to the segregation during crystal growth, the crystal showed a non-constant concentration profile. The conventional Czochralski process for crystal growth was modified to allow melt replenishing, and hence reduction of segregation. Both floating-crucible technique and pressure-differential technique were investigated.

A floating-crucible technique that had been effective in reducing segregation in doped crystals was used to reduce segregation in Czochralski growth of alloy crystals of $\mathrm{Ga}_{1-x} \mathrm{In}_{\mathrm{x}} \mathrm{Sb}$. The growth melt in the floating crucible was replenished by a melt of the targeted crystal composition through a spiral tube at the bottom of the floating crucible, which was designed to suppress back diffusion. Crystals close to the targeted composition of $1 \mathrm{~mole} \%$ InSb were grown. However, difficulties were encountered in reaching higher targeted InSb concentrations. Crystals about 2 mole\% were grown when 4 mole $\%$ was targeted. $\mathrm{Bi}_{1-\mathrm{S}} \mathrm{Sb}_{\mathrm{x}}$ was used as a model material to help understand the problem. It was observed that mixing occurred between the melts rendering the compositions of the melts, and hence the resultant crystal unpredictable. The higher density of the growth melt than the replenishing melt triggered thermosolutal convection resulting in mixing. It was also observed that the floating crucible stuck to the outer crucible when the liquidus temperature of the replenishing melt was significantly higher than that of the growth melt.

In the crystal growth using a pressure-differential technique, a quartz tube was separated into an upper chamber for crystal growth and a lower chamber for replenishing. The growth melt in the upper chamber and the replenishing melt in the 
lower chamber were kept at different temperatures by two separate heaters. The melts were connected by a capillary tube to suppress mixing between them. A constant pressure differential was maintained between the chambers to keep the growth melt up in the growth chamber. The diameter of the capillary was very important in feeding control. We experimentally determined that a $2 \mathrm{~mm}$ ID diameter is good for the replenishing melt under the conditions of our experiments. The method was first tested with a low temperature alloy $\mathrm{Bi}_{1-x} \mathrm{Sb}_{x^{*}}$. Single crystals of $\mathrm{Ga}_{1-x} \mathrm{In}_{\mathrm{x}} \mathrm{Sb}$ were grown with uniform compositions up to about $5 \mathrm{~mole} \%$ InSb. 


\section{APPENDIX}

\subsection{Transparent Czochralski puller}

In order to grow low temperature crystals such as $\mathrm{Bi}_{1-x} \mathrm{Sb}_{x}$, and $\mathrm{Ga}_{1-x} \mathrm{In}_{x} \mathrm{Sb}$, we developed a transparent Czochralski (CZ) puller shown schematically in Fig. 6.1. It was very convenient to observe the solid / liquid interface and monitor the diameter change of the crystal during crystal pulling. $\mathrm{Bi}$ and $\mathrm{GaSb}$ single crystals have been grown up to $6 \mathrm{~cm}$ in length and with diameter ranges from 10 to $20 \mathrm{~mm}$.

$\mathrm{A} \mathrm{Bi}$ single crystal was grown by conventional $\mathrm{CZ}$ at a constant pulling rate of 1.25 $\mathrm{mm} / \mathrm{hr}$ and a rotation speed of $30 \mathrm{rpm}$ under $20 \mathrm{~cm}^{3} / \mathrm{min}$ hydrogen purge. The photograph of the crystal is shown in Fig.6.2. The GaSb single crystals were grown on a [111]B GaSb seed by conventional $\mathrm{CZ}$. The pulling rate was $2 \mathrm{~mm} / \mathrm{hr}$, and the seed rotation rate was $20 \mathrm{rpm}$ under $12.4 \mathrm{~cm}^{3} / \mathrm{min}$ hydrogen purge. Dislocations in the grown crystal were examined by chemical etching. Fig. 6.3 shows the typically etched (111)A surface of grown crystal which reveals the etch pits. The composition of this crystal is 2 mole\% InSb. It has been found that the dislocation density of the samples was not uniform, a higher density of dislocations was frequently observed near the edge of the wafer where agglomerations of dislocations were formed.

\subsection{Ingot preparation for $\mathrm{Ga}_{\mathrm{l}-\mathrm{I}} \mathrm{In}_{\mathrm{x}} \mathrm{Sb}$ crystal growth}

The charges for the crystal growth were in the form of alloy ingots close to the crucibles in diameter. They were prepared from $6 \mathrm{~N}$ Ga and $\mathrm{Sb}$ and $5 \mathrm{~N} \mathrm{InSb}$, with 1 5 
at $\%$ extra $\mathrm{Sb}$, in view of the evaporation of $\mathrm{Sb}$ over the relatively long time required for crystal growth. Macroscopic homogeneity was enhanced by melting in a quartz tube chamber, stirring, and water quenching. A small sample was taken from the melt right before quenching with a small spoon. The sample was dissolved in an acid solution of $2 \mathrm{HNO}_{3}$ : $1 \mathrm{HF}$ and diluted for measuring the In concentration by inductively coupled plasma mass spectrometry (ICP-MS).

Fig.6.4 shows the etched structures of furnace-cooled and quenched ingots. The main discrepancy is the second phase distribution, which is more uniform in the quenched ingot than in the furnace-cooled ingot. The second phase has the eutectic composition, since the melt was slightly Sb-rich.

\subsection{Heat radiation shield}

To grow a crystal with low thermal conductivity such as $\mathrm{Ga}_{1-x} \mathrm{In}_{x} \mathrm{Sb}$, it is important to quickly dissipate heat from the grown crystal and heat radiated from heat sources such as the melt and heater. The emission of heat from the melt is a major cause of interface breakdown. Most of the emission of heat is caused by heat radiation, therefore, a radiation shield is required to suppress the heat emission. In particular, when a temperature gradient at and about a solid-liquid interface is large, the alloy single crystals can be grown successfully.

Durpet et al. ${ }^{(4)}$ pointed out how the temperature gradients and the stress field in the crystal could be affected by using a heat shield inside the crucible for the liquid encapsulant Czochralski (LEC) growth of GaAs. Their simulation results reveal that 
use of a downward inclined Mo reflector leads to a decrease of the Von Mises stress level in the crystal.

Bornside et al. ${ }^{(5)}$ showed that, in the silicon growth, an additional bottom heater and heat shield can reduce the Von Mises stress at the melt/crystal interface and the maximum value of stress in the crystal. According to their calculation, the axial temperature gradient is higher in the melt with a heat shield. The existence of a heat shield also flattens the interface significantly. It can be concluded that crystal quality is improved with the addition of a heat shield.

Fig. 6.5 shows the effect of the radiation shield on the crystallinity of grown $\mathrm{Ga}_{\mathrm{l}-\mathrm{I}} \mathrm{In}_{\mathrm{x}} \mathrm{Sb}$ crystals. As shown in Fig. 6.5(a), a single crystal of 19 mole\% InSb can be obtained by the presence of heat shield as described in experiment 6 , chapter 2 . Nevertheless, from Fig. 6.5(b), the onset of polycrstallinity is observed in the crystal grown without a heat shield as described in experiment 7 , chapter 2 . The nominal composition is $16 \mathrm{~mole} \% \mathrm{InSb}$.

\subsection{Effective segregation coefficient}

In order to grow single crystals of a preselected composition reliably, the equilibrium between the liquid and solid phases has been studied. Short crystals were grown from relatively large melts. The compositions of crystals and melts were determined by ICP-MS technique as mentioned above. Yonenaga et al. ${ }^{(1)}$ have shown that $\mathrm{k}_{\text {eff }}$ values are far from $\mathrm{K}_{0}$ in their $\mathrm{Si}_{\mathrm{x}} \mathrm{Ge}_{1-\mathrm{x}}$ growth. Kurten et al. ${ }^{(2)}$ concluded that there is no difference within the error limits between $k$ and $k_{\text {eff }}$, showing complete 
mixing of the melt because of induction heating. However, in our case, we found a significant discrepancy between $\mathrm{k}$ and $\mathrm{k}_{\text {eff }}$.

The effective segregation coefficient of $\mathrm{Sb}$ in the $\mathrm{Bi}_{1-x} \mathrm{Sb}_{\mathrm{x}}$ system was found to increase gradually from 2.2 to 2.6 with $\mathrm{Sb}$ content increasing up to 3.6 at\% $\mathrm{Sb}$ in the melt, as shown in Fig. 6.6. The effective segregation coefficient of $\mathrm{InSb}$ in the $\mathrm{Ga}_{1}$. ${ }_{x} \mathrm{I} \mathrm{n}_{\mathrm{x}} \mathrm{Sb}$ system was found to increase gradually from 0.12 to 0.18 with InSb content increasing up to $56 \mathrm{~mole} \% \mathrm{InSb}$ in the melt, as shown in Fig. 6.7.

\subsection{Structural defects}

There are several mechanisms, which have been identified that induce defect structures in the grown alloy crystal. Oxide film on the melt surface often triggers twinning during crystal pulling. Furthermore, it was found that twins start to develop if the crystal diameter exceeds a critical size. A similar effect was observed when the diameter undergoes excessive changes. Thus it is necessary to maintain the diameter of the growing crystal, and especially avoid the usual necking procedure. A high density of structural defects such as twin boundaries, low angle grain boundaries, and dislocations are the typical problems of the melt growth of $\mathrm{Ga}_{1-x} \mathrm{In}_{x} \mathrm{Sb}$. As shown in Fig. 6.8, a grown crystal with a $10 \mathrm{~mole} \%$ InSb has a thin lamella structure of twins, comparatively wide twin bands, and grain boundaries that are easily recognized by the difference of light reflection on the wafer sliced perpendicular to the growth axis.

In the alloy crystal growth, the formation of dislocations is expected due to the lattice mismatch, and provides the initial dislocation sources for further stress-induced 
multiplication mechanism during solidification. Fig. 6.9 shows the defects of $\mathrm{Ga}_{1-x} \mathrm{In}_{\mathrm{x}} \mathrm{Sb}$ crystal of $10 \mathrm{~mole} \% \mathrm{InSb}$ grown from a seed of $2.5 \mathrm{~mole} \% \mathrm{InSb}$. Only the first part of the grown crystal is single crystal, further parts consist of small grains and twins. In another case, shown in Fig. 6.10, because the InSb concentration difference is up to 3 mole\% and seed thermal shock damage from rapid seed lowering, the grown crystal is polycrystalline from the seed-crystal interface. It is also found that the interface is not flat, showing that temperature fluctuation is significant.

To grow $\mathrm{Ga}_{1-x} \mathrm{In}_{\mathrm{x}} \mathrm{Sb}$ single crystals, one has to pay special attention to the pulling rate. If the axial temperature gradient of the puller is $\nabla T \approx 100^{\circ} \mathrm{C} / \mathrm{cm}$, according to Tiller's constitutional supercooling criteria, a very slow pulling rate of less than 1 $\mathrm{mm} / \mathrm{hr}$ is required. As shown in Fig. 6.11, a single crystal can be grown up to 17 mole $\%$ InSb when the pulling rate is as slow as $0.85 \mathrm{~mm} / \mathrm{hr}$. The growth interface breaks down when the pulling rate is much faster than the planar growth rate, causing the formation of a second phase. According to the schematic phase diagram proposed by Plaskett et al. ${ }^{(3)}$, shown in Fig. 6.12, the second phase has the eutectic composition because the melt was slightly Sb-rich.

\subsection{Back diffusion in Czochralski growth with melt replenishing}

Back diffusion is the phenomenon of concern in doped crystal growth with melt replenishing. This was the perceived explanation when an unexpected composition profile of alloy crystal grown by the floating-crucible technique was obtained. Nevertheless, according to the following calculation, back diffusion was not the 
dominant mechanism. Kou ${ }^{(6)}$ described the required length of passageway to suppress back diffusion during crystal pulling by:

$$
\begin{aligned}
& \frac{\mathrm{v}_{f} \mathrm{~L}}{\mathrm{D}_{\ell}}=5+\ln \left|\frac{1}{\mathrm{k}_{\mathrm{eff}}}-1\right| \quad \text { and } \\
& \frac{\mathrm{v}_{\mathrm{f}}}{\mathrm{v}_{\mathrm{p}}}=\frac{\rho_{\mathrm{s}} \mathrm{r}^{2} \mathrm{R}^{2}}{\mathrm{r}_{\mathrm{c}}{ }^{2}\left(\rho_{\ell} \mathrm{R}^{2}-\rho_{\mathrm{s}} \mathrm{r}^{2}\right)}
\end{aligned}
$$

For GaSb - 28 mole $\%$ InSb melt: $\mathrm{k}_{\mathrm{eff}}=0.14, \mathrm{v}_{\mathrm{p}}=0.1 \mathrm{~cm} / \mathrm{hr}, \mathrm{r}=0.5 \mathrm{~cm}, \mathrm{R}=1.75 \mathrm{~cm}$, and $r_{c}=0.4 \mathrm{~cm}, D_{\ell}=2.8 \times 10^{-5} \mathrm{~cm}^{2} / \mathrm{s}, V_{f}=4.37 \times 10^{-5} \mathrm{~cm} / \mathrm{s}$, and $\mathrm{L}=4.4 \mathrm{~cm}$. However, the required time for seeding and melt homogenization is not considered in this calculation. Another way to estimate the required length of passageway is ${ }^{(6)}$ :

$$
\mathrm{z}=4 \sqrt{\mathrm{D}_{\ell} \mathrm{t}} \approx 4.02 \mathrm{~cm}
$$

where $\mathrm{t}$ is about $10 \mathrm{hr}$. The distance of $4.4 \mathrm{~cm}$ or $4.02 \mathrm{~cm}$ is shorter than that of the $10-13 \mathrm{~cm}$ passageway at the bottom of the floating crucible, or the $26-76 \mathrm{~cm}$ in the pressure-differential technique. Therefore, back diffusion is not the cause that the In concentrations became averaged out as discussed in chapter 3 previously.

\subsection{Melt replenishing in Czochralski growth under a pressure differential}

In order to reduce the segregation in grown crystal, melt replenishing was attempted under a pressure differential, as mentioned in chapter 4 . The replenishing melt was supplied from a lower chamber of pressure $p_{2}$ through a capillary of inner diameter $r_{c}$ to an upper chamber of pressure $p_{l}$. The barometric formula was good enough to estimate the relationship between the pressure differential and the height of 
growth melt. Assuming that the height difference between the upper melt and the lower melt level is $\Delta \mathrm{h}$, from Bernoulli's equation ${ }^{(6)}$ we have:

$$
\left(0-\frac{1}{2} \rho_{\ell} v_{f}^{2}\right)+\rho_{\ell} g \Delta h+\left(p_{1}-p_{2}\right)=0
$$

Therefore, the mass flow rate is:

$$
\dot{\mathrm{m}}=\pi \mathrm{r}_{\mathrm{c}}^{2} \rho_{\ell} \mathrm{v}_{\mathrm{f}}=\pi \mathrm{r}_{\mathrm{c}}^{2} \rho_{\ell} \sqrt{2 \mathrm{~g} \Delta \mathrm{h}+\frac{2\left(\mathrm{p}_{1}-\mathrm{p}_{2}\right)}{\rho_{\ell}}}
$$

Letting the melt in the growth crucible be the control volume $\Omega$, the overall mass balance is:

$$
\frac{d}{d t}\left(\rho_{\ell} \Omega\right)=\rho_{\ell} v_{r} A_{r}-\rho_{s} v_{p} A_{s}
$$

where $v_{r}$ and $A_{r}$ are the lifting speed of the replenishing crucible and the inner crosssectional area of the replenishing crucible, respectively. If the composition of the growth melt is to be uniform at $C_{s} / k_{e f f}$, the species overall mass balance must be:

$$
\frac{\mathrm{d}}{\mathrm{dt}}\left(\frac{\mathrm{C}_{\mathrm{s}}}{\mathrm{k}_{\mathrm{eff}}} \rho, \Omega\right)=\mathrm{C}_{\mathrm{r}} \rho_{\ell} \mathrm{v}_{\mathrm{r}} \mathrm{A}_{\mathrm{r}}-\mathrm{C}_{\mathrm{s}} \rho_{\mathrm{s}} \mathrm{v}_{\mathrm{p}} \mathrm{A}_{\mathrm{s}}
$$

Substituting Equation (33) into Equation (34):

$$
C_{s}=\frac{k_{e f f} \rho_{\ell} v_{r} A_{r}}{\rho_{\ell} v_{r} A_{r}+\left(k_{e f f}-1\right) \rho_{s} v_{p} A_{s}} C_{r}
$$

To grow a uniform $\mathrm{Ga}_{1-x} \mathrm{In}_{\mathrm{x}} \mathrm{Sb}$ crystal of $1 \mathrm{~cm}$ diameter:

$$
C_{s}=\frac{0.53 v_{r}}{v_{r}-0.035}
$$

where $\mathrm{k}_{\mathrm{eff}}$ is 0.133 , the inner diameter of the replenishing crucible is $1.4 \mathrm{~cm}, \mathrm{v}_{\mathrm{p}}$ is 
$0.085 \mathrm{~cm} / \mathrm{hr}$, and $\mathrm{C}_{\mathrm{r}}$ is $4 \mathrm{~mole} \%$ InSb. Practically, the crystal diameter is not ideally uniform, therefore the lifting speed must be adjusted simultaneously to grow a crystal with uniform axial composition. 


\subsection{References}

1. I. Yonenaga, A. Matsui, S. Tozawa, K. Sumino and T. Fukuda, J. Crystal Growth 154 (1995) 275.

2. M. Kurten and J. Schilz, J. Crystal Growth 139 (1994) 1.

3. T. S. Plaskett and J. F. Woods, J. Crystal Growth 11 (1971) 341.

4. F. Dupret, P. Nicodeme and Y. Ryckmans, J. Crystal Growth 97 (1989) 162.

5. D. E. Bornside, T. A. Kinney and R. A. Brown, J. Crystal Growth 108 (1991) 779.

6. S. Kou, Transport Phenomena and Materials processing (John Wiley \& Son, New York, 1996) 556. 


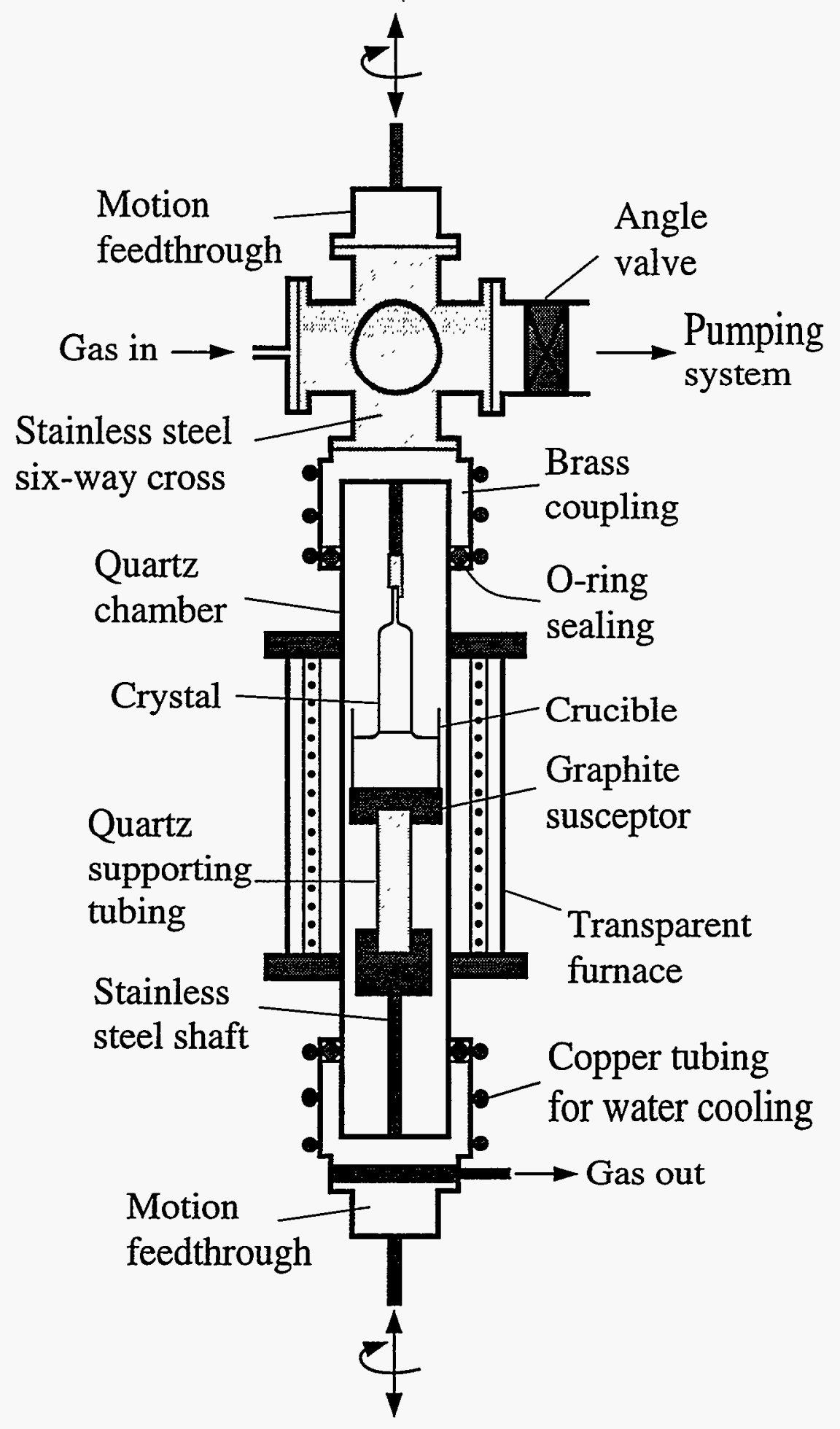

Figure 6.1 Apparatus of transparent Czochralski puller. 


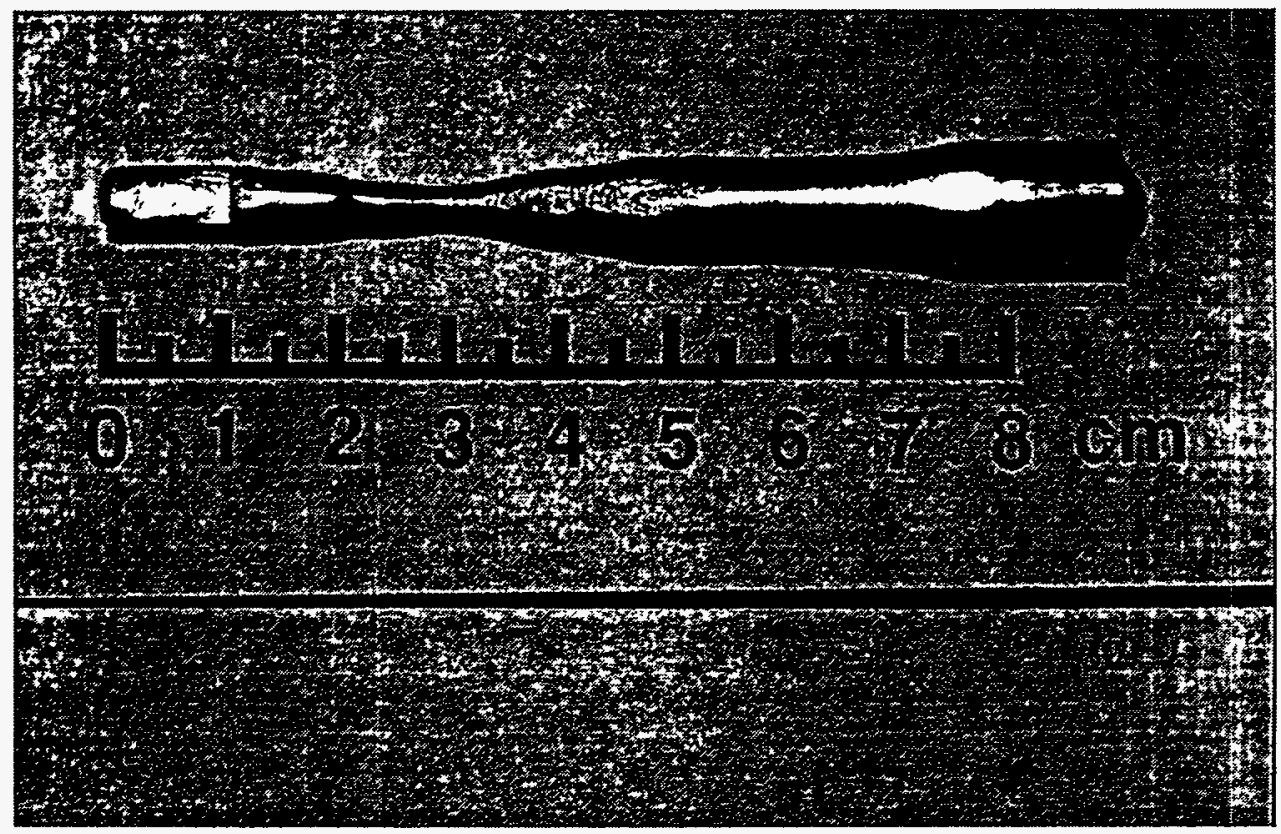

Figure $6.2 \mathrm{Bi}$ single crystal. 


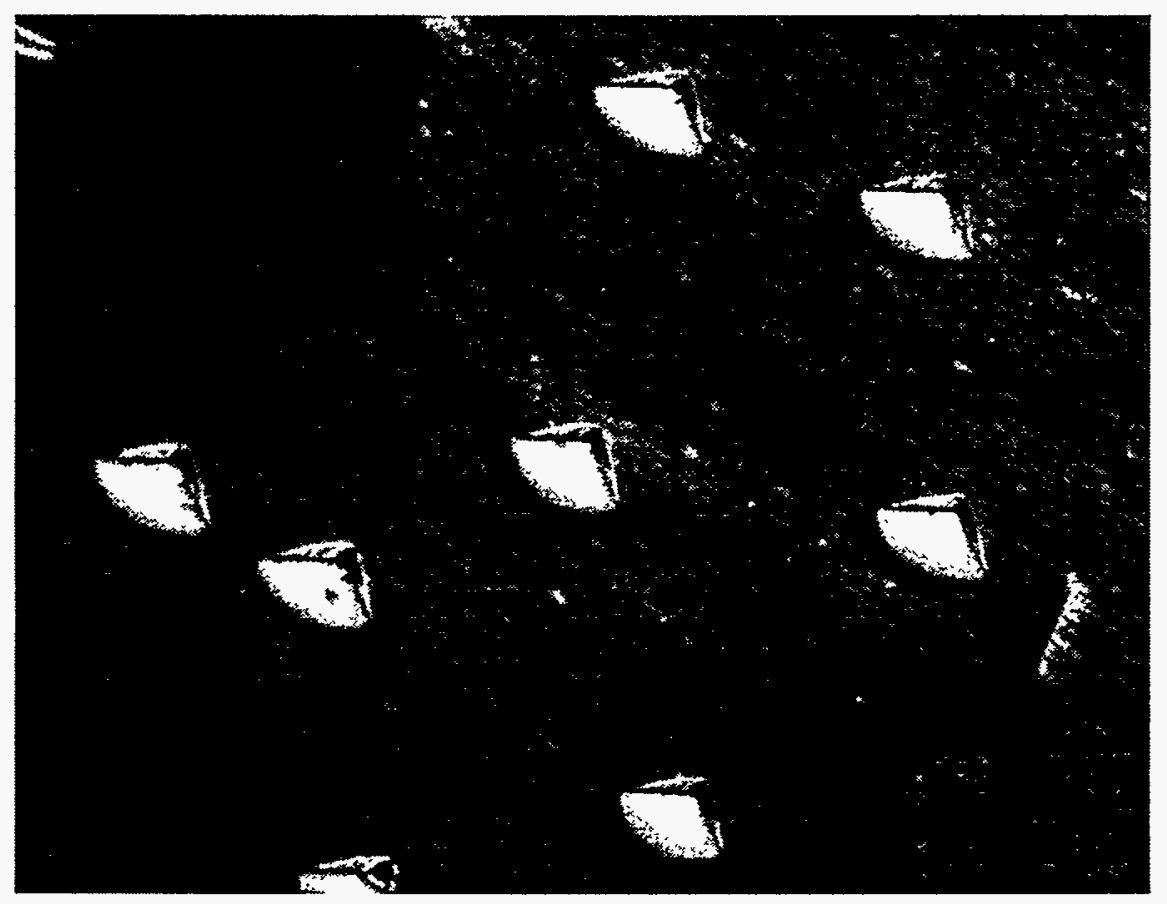

Figure 6.3 Etched (111)A surface of GaSb - 2 mole\% InSb single crystal. The surface was etched with a solution of $1 \mathrm{HF}+9 \mathrm{HNO}_{3}+20 \mathrm{CH}_{3} \mathrm{COOH}$ and then etched with $2 \%$ Br-methonal solution. 


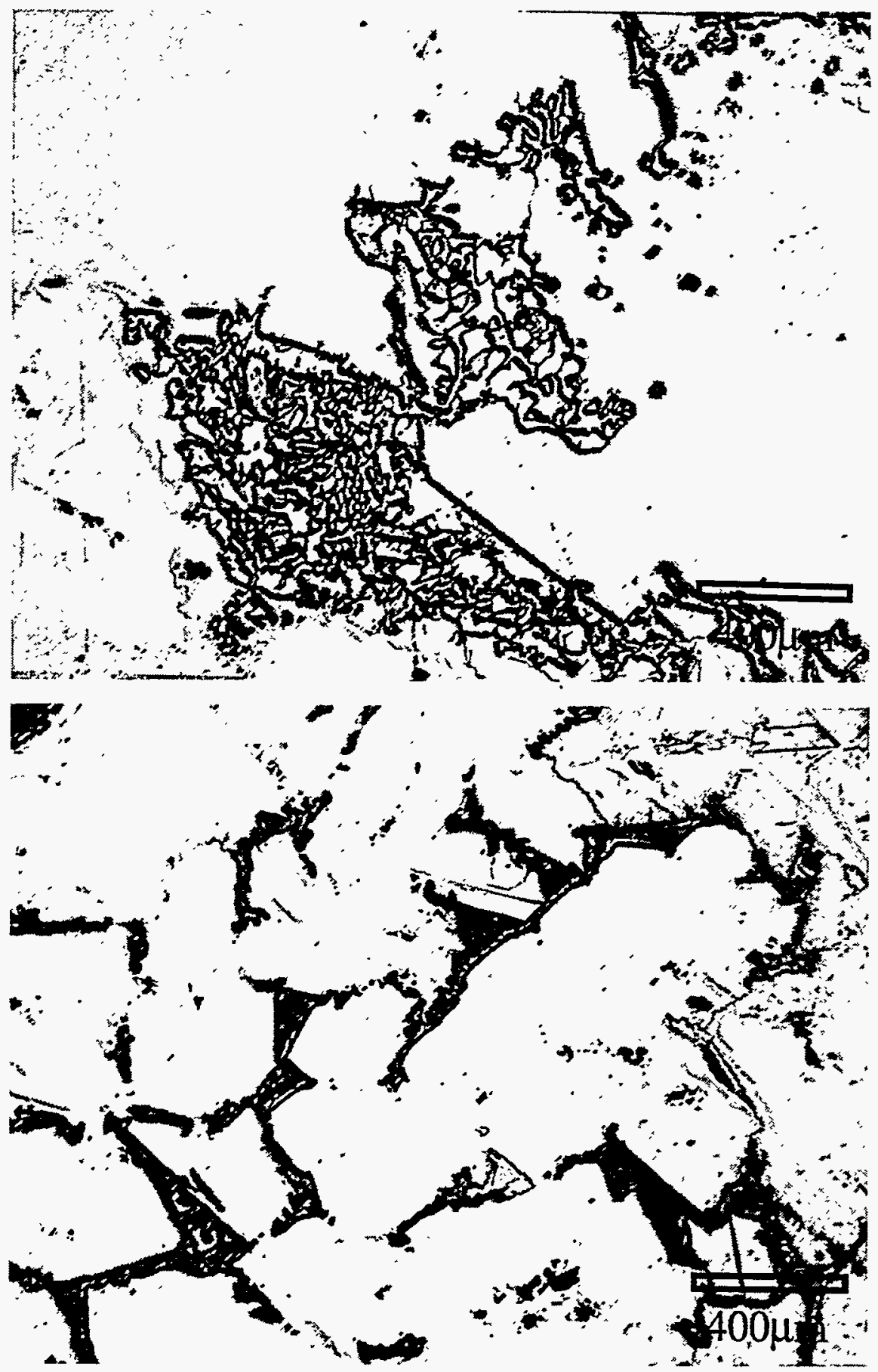

(a)

Figure 6.4 Etched GaSb - 50 mole\% InSb Ingots (a) furnace-cooled (b) quenched. 


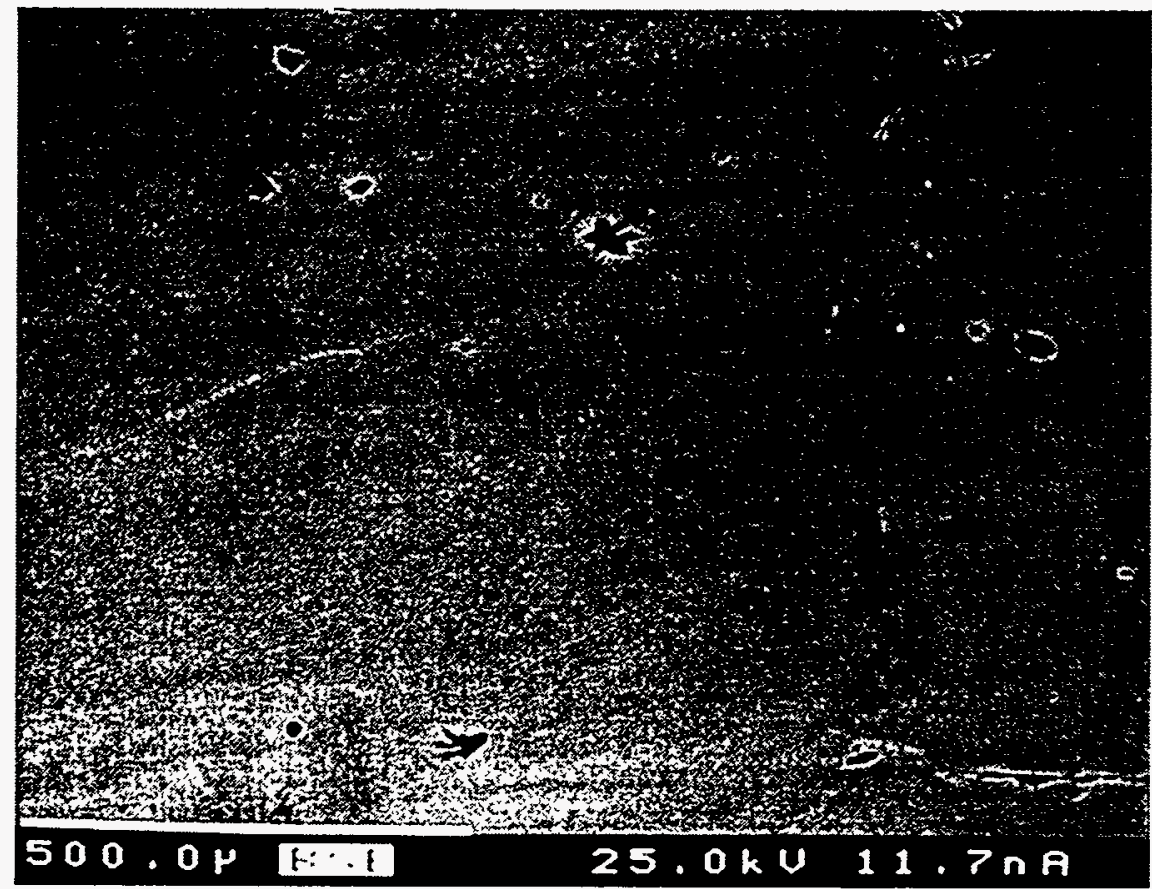

(a)

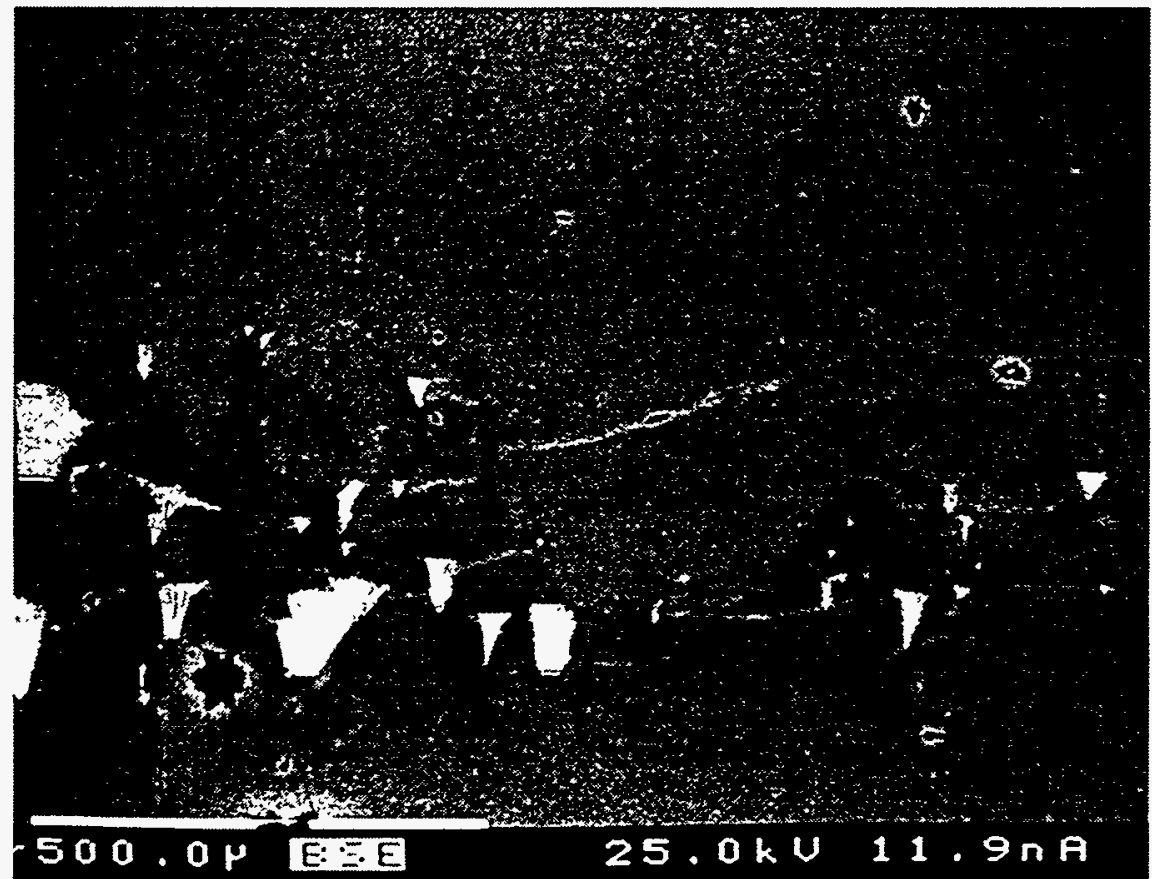

(b)

Figure 6.5 Crystals sliced along the growth direction $\langle 111\rangle$ (a) nominal composition 19 mole\% InSb; (b) nominal composition 16 mole\% InSb. 


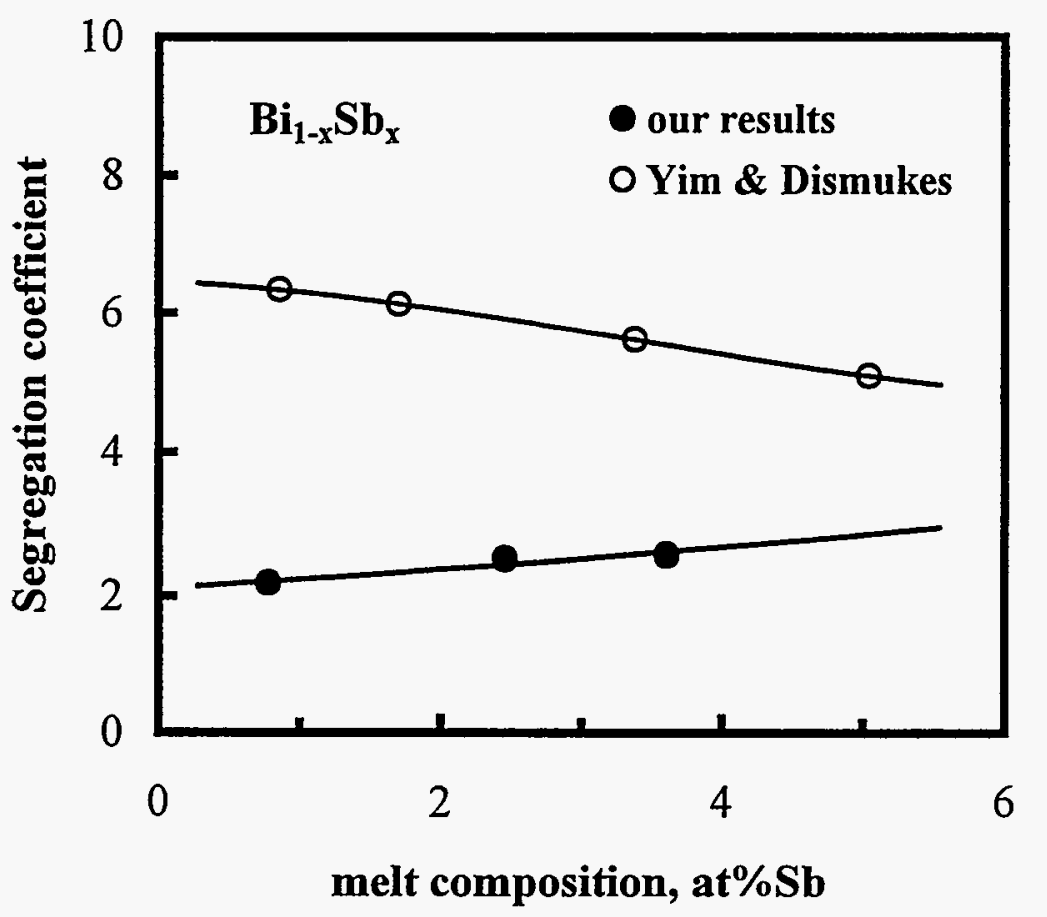

Figure 6.6 Segregation coefficient of $\mathrm{Bi}_{1-x} \mathrm{Sb}_{x}$. 


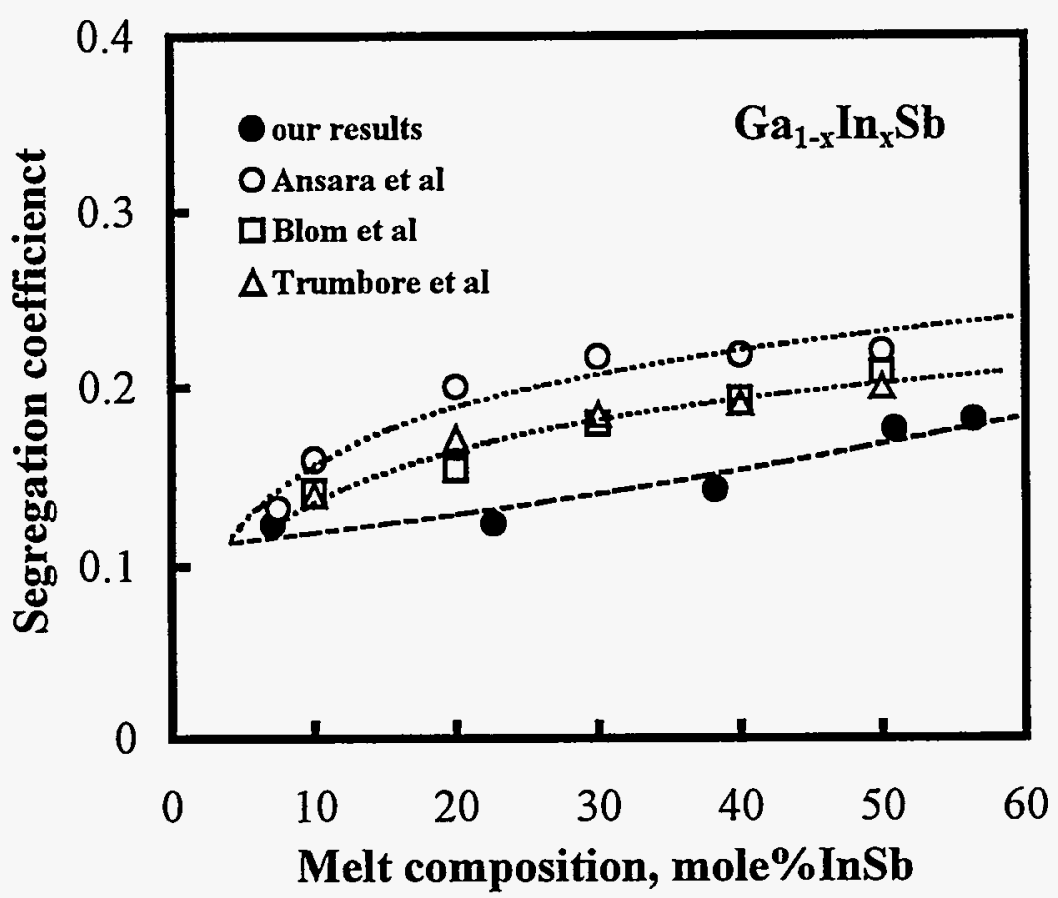

Figure 6.7 Segregation coefficient of $\mathrm{Ga}_{1-x} \mathrm{In}_{\mathrm{x}} \mathrm{Sb}$. 


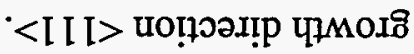

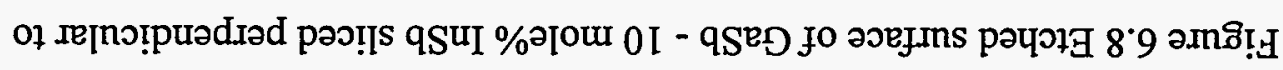

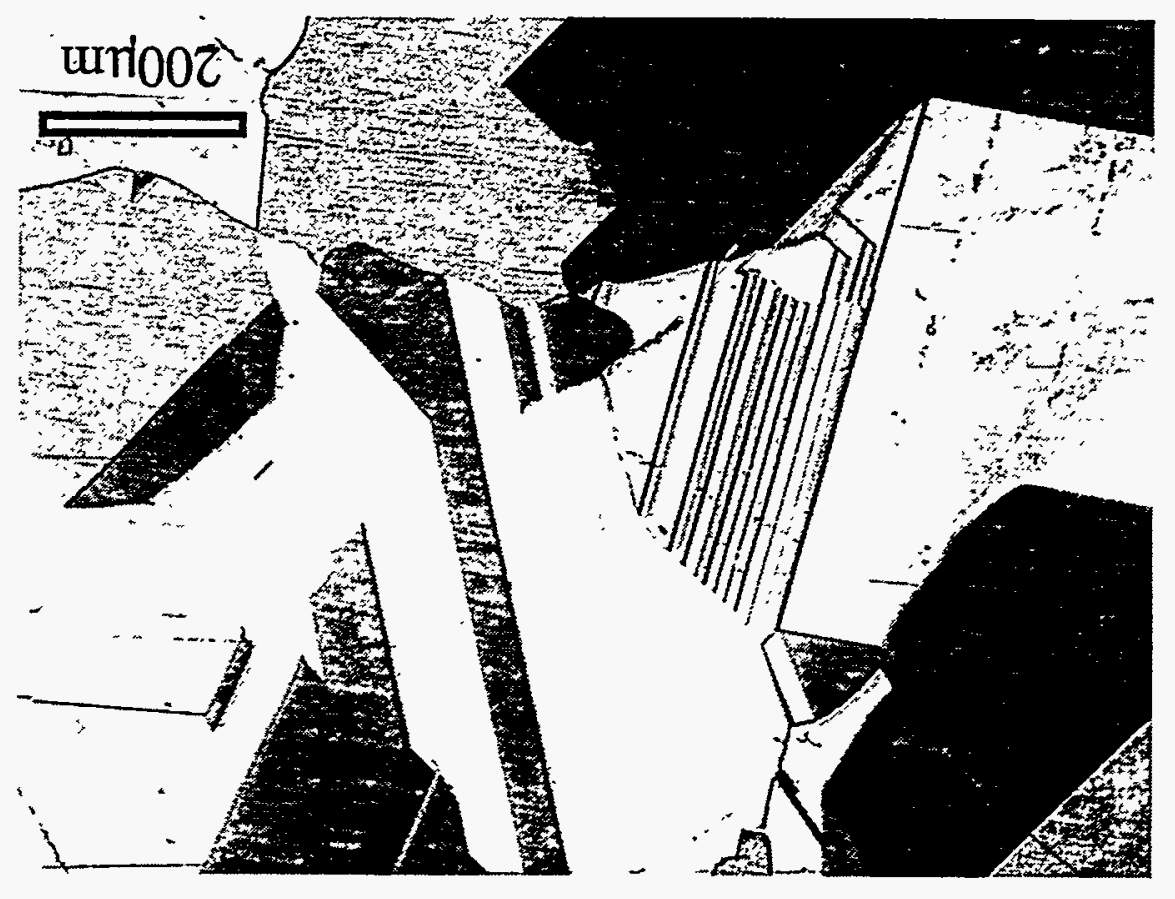




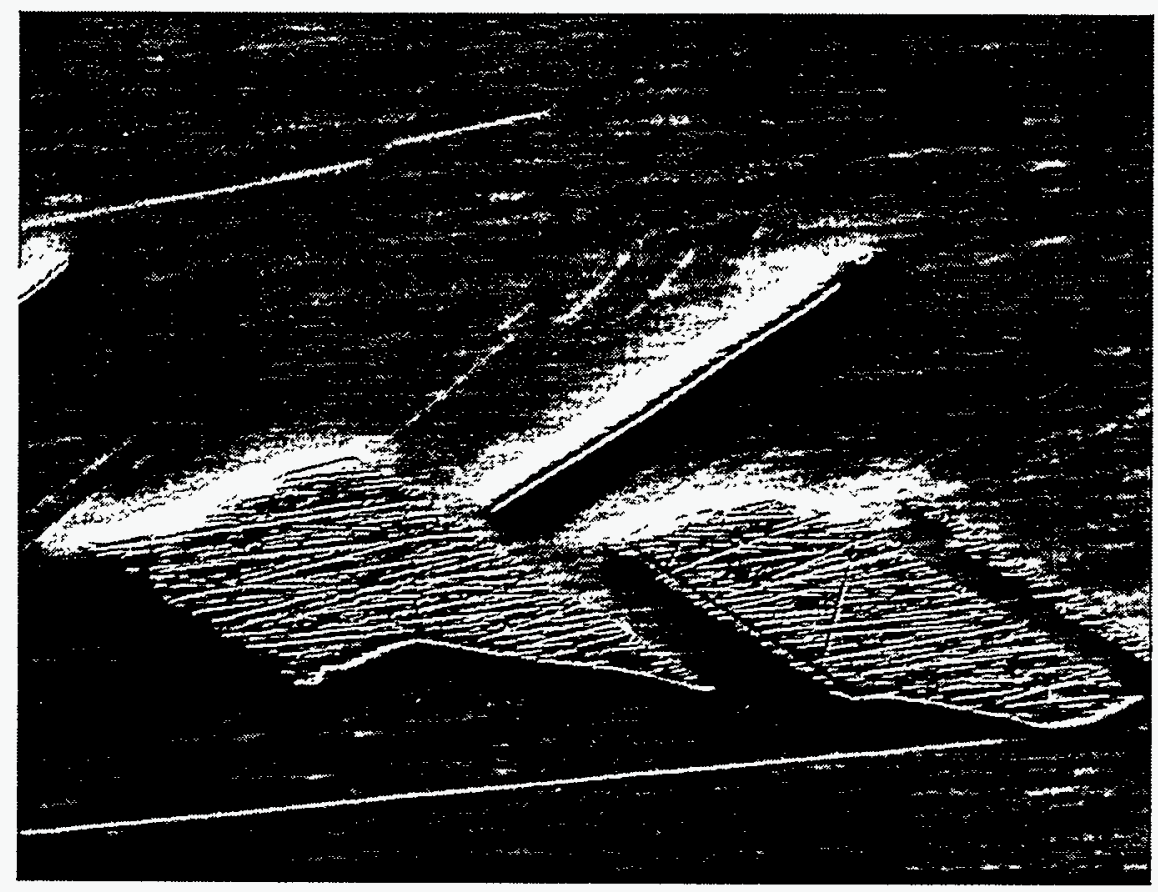

Figure 6.9 Etched surface of $\mathrm{GaSb}$ - 10 mole\% InSb sliced parallel to growth direction $<111>$. 


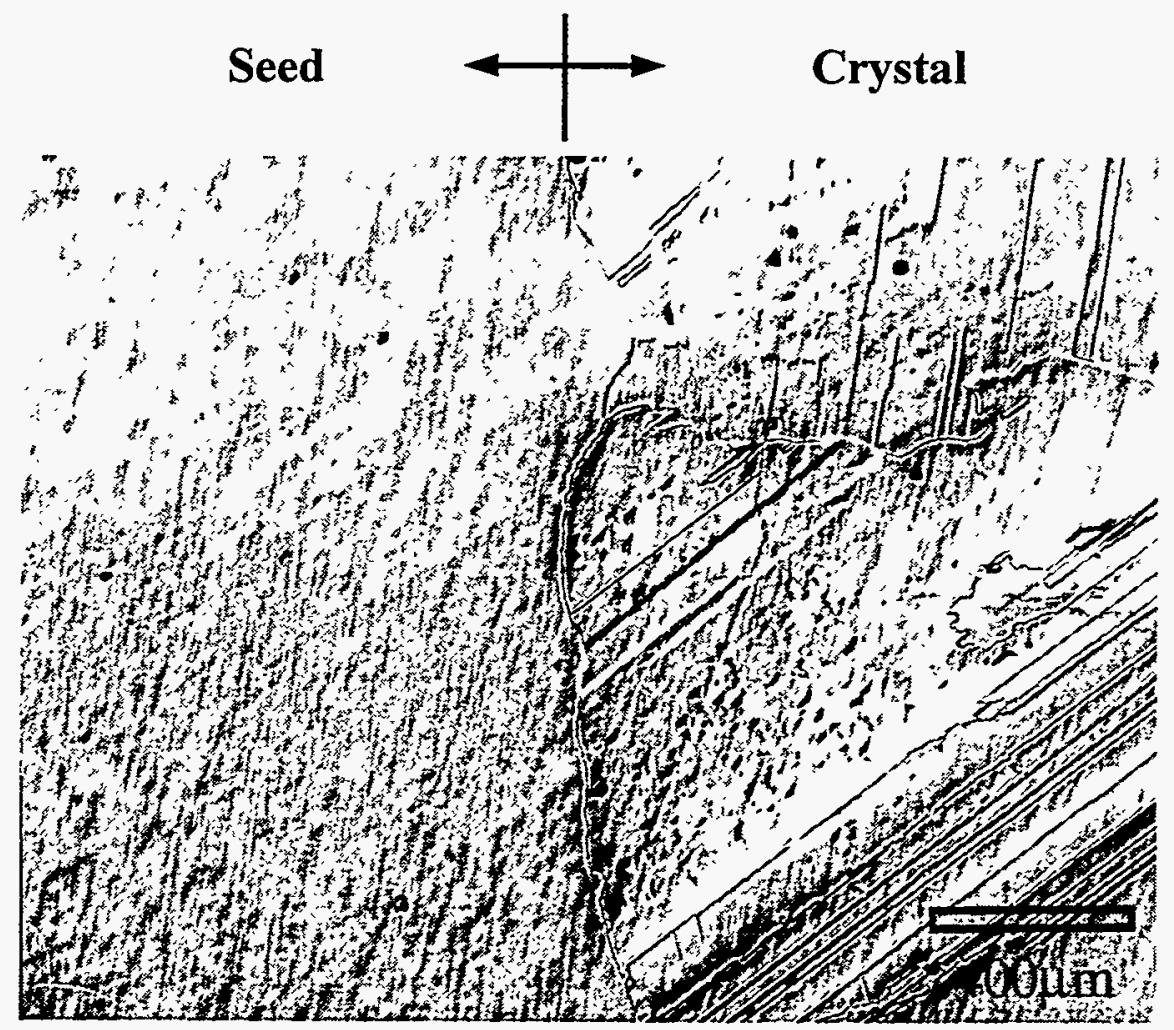

Figure 6.10 Etched surface of grown crystal sliced parallel to growth direction $<111>$. Seed : 7.4 mole\% InSb; Crystal : 4.6 mole\% InSb. 

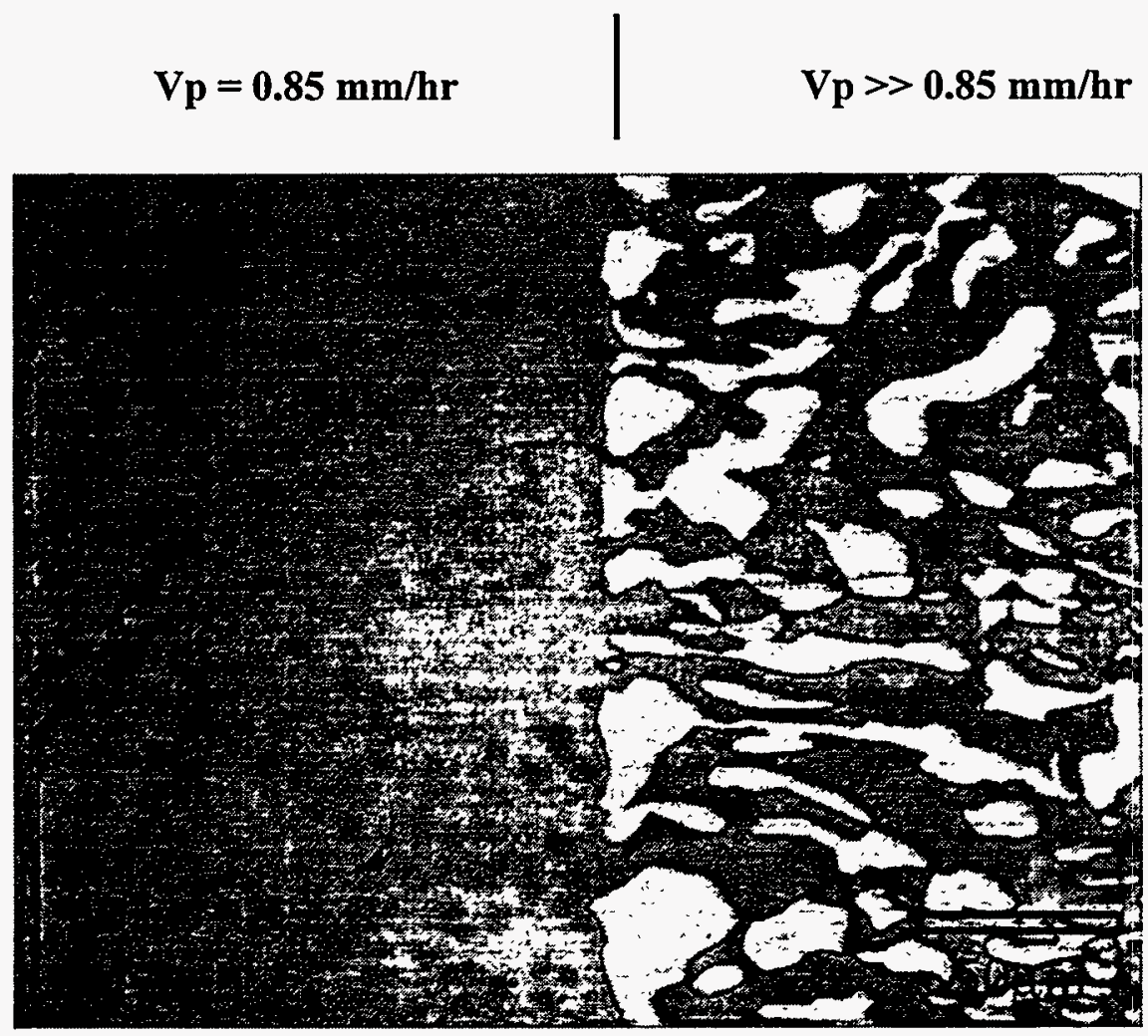

Figure 6.11 Etched surface of grown crystal sliced parallel to growth direction $<111>$. 


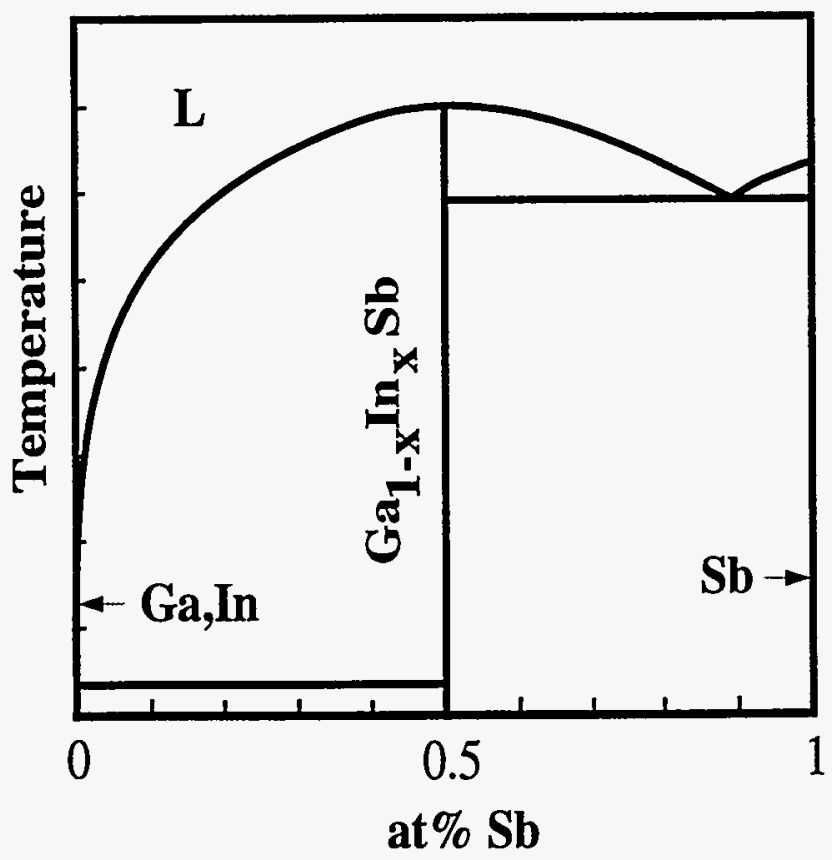

Figure 6.12 Schematic pseudo binary phase diagram of $\mathrm{Ga}_{1-x} \mathrm{In}_{x} \mathrm{Sb}$. 